Pecvnia, 10 (2010), pp. 133-201

\title{
Análisis de un fragmento del libro Manual de un "cambio de feria" de Medina del Campo no identificado, correspondiente a la feria de Octubre de $1564^{*}$
}

Recibido: Mayo 2010

Aceptado: Agosto 2010
José $M^{a}$ González Ferrando

Madrid (España)
El hallazgo casual de dos pliegos del Manual de un cambio, referidos a la feria de Octubre de 1564 de Medina del Campo, nos ha permitido disponer por primera vez de una muestra del Diario de la contabilidad por partida doble que empleaban los banqueros en Castilla a mediados del siglo XVI. Pese a la brevedad del texto contable, la información que nos facilita es grande, tanto por lo que atañe al formato de los asientos como a las operaciones registradas y al elenco de personas citadas.

Respecto de los asientos, el fragmento muestra lo que debieron de ser los incipientes intentos de contabilizar las operaciones complejas de negociación de cambios mediante asientos de
The accidental finding of two loose folders of the Manual of a banker, referred to the fair of October 1564 of Medina del Campo, has allowed having us for the first time a sample of the Journal of the accounts by double entry that used the bankers in Castile in the middle of $16^{\text {th }}$ Century. In spite of the shortness of the accounting text, the information it facilitates to us is large, as much with regard to the format of the entries such as the registered operations and the lot of mentioned people.

As far as the entries are concerned, the fragment shows what type were being the incipient attempts to enter the complex operations of negotiation of bills of exchange

Una versión previa y abreviada de este trabajo se presentó al VI Encuentro de Trabajo sobre Historia de la Contabilidad: Cuentas, Mercaderes e Instituciones, celebrado en la Universidad de Valladolid del 5 al 7 de Noviembre de 2008. 
estructura compuesta, aunque ello diera lugar a una partida doble un tanto heterodoxa. En cuanto a las operaciones, encontramos un repertorio de las típicas que se realizaban en las ferias castellanas, de entre las cuales destaca la negociación de letras "con tanto al millar". En tercer lugar, la nómina de personas que aparecen citadas en los asientos abarca desde mercaderes castellanos, andaluces y catalanes hasta banqueros italianos residentes no solo en Castilla y Andalucía sino en el Franco Condado, Génova, Venecia, Nápoles y Sicilia.

Palabras clave: asiento complejo o compuesto; cambio o banco; feria; letra con tanto al millar; partida doble. by means of entries of composed structure, although it gave rise to a somewhat heterodox double entry. As for the operations we found a sample of the typical ones that were made in the Castilian fairs, among them the negotiation of bills of exchange con tanto al millar must be highlighted. Thirdly, the list of people who appear mentioned in the entries includes Castilian, Andalusian and Catalan merchants and bankers and Italian resident bankers not only in Castile and Andalusia but in the FrancheCompté, Genoa, Venice, Naples and Sicily.

Key words: compound entry; banker; fair; bill of exchange con tanto al millar; double entry.

\section{INTRODUCCIÓN}

\section{El "oficio" de banquero en la Castilla del siglo XVI}

A diferencia del Reino de Aragón, en el que desde antiguo coexistieron la banca pública y la privada, en los Reinos de Castilla desde finales del siglo XIII o comienzos del XIV el "oficio" de banquero fue considerado libre y franco, por lo que no hubo más que un solo tipo de banca: los bancos privados, que en la Castilla del siglo XVI se ajustaban a una de estas dos modalidades:

\section{- cambios o bancos particulares y}

- cambios o bancos públicos ${ }^{1}$

Al ser libre la profesión de banquero, tal como se ha indicado, para actuar como cambio o banco particular no se necesitaba cumplir ningún requisito previo. Por contra, el desempeño del "oficio" de

1 Aunque empleamos indistintamente el término de cambio o banco para designar al banquero, parece ser que en el tercio norte de la Castilla del siglo XVI-Burgos, Santander, Valladolid, Medina del Campo, etc.- la denominación más usual era la de cambio, en tanto que en el tercio sur -Sevilla, Cádiz, Córdoba, etc.- era la de banco, y en el centro -Segovia, Toledo y en particular Madrid- era indiferente su utilización, aunque quizá con una ligera preferencia hacia la de banco. 
cambio o banco público -que sólo podían ejercer los naturales del Reino y no los extranjeros, aunque tuvieran carta de naturaleza- requería para operar en la Corte que la designación fuera hecha por el Rey, y para las otras plazas, que lo fuera por el Concejo local, además de estar en todo caso integrado al menos por dos varones de buena fama y obligados solidariamente, haber constituido fianza suficiente ante el correspondiente Concejo para evitar quiebras y fraudes, y jurado usar fielmente su "oficio"2, sin arte, engaño ni colusión alguna.

Los cambios o bancos públicos no podían dedicarse a ninguna otra actividad comercial, ya fuera directa o indirectamente, ni a ningún otro "oficio público", y se establecían normalmente en lugares de mucha contratación. Debían disponer de monedas de oro, plata y vellón para llevar a cabo los cambios de "moneda presente" que se les pidieran -a cuyo efecto habían de tener un peso con guindaleta-, así como realizar las negociaciones de cambios para cualquier otro lugar del Reino o fuera de él mediante letras de cambio, con "moneda ausente" ${ }^{3}$.

Siguiendo a Ruiz Martín (1970a: 22-41) y de acuerdo con la función y ámbito de aplicación de los banqueros privados, se podía establecer entre ellos la siguiente diferenciación:

- cambios o bancos locales

- cambios o bancos de feria

- cambios o bancos de Corte

según que, respectivamente, operasen en las ciudades y villas de Castilla intermediando entre los mercaderes y depositantes particulares, que lo hicieran en las distintas plazas feriales castellanas para dar servicio de cuenta corriente y financiero a los mercaderes y demás tratantes y contratantes, o que -nombrados y escogidos por el Rey- se centrasen en atender las necesidades económicas de una Corte largo tiempo itinerante,

\footnotetext{
2 Como el nombramiento de los cambios o bancos públicos se hacía por pública Autoridad del Reino, se convertían en "oficio público", y por requerir que los que lo desempeñaran fuesen personas llanas, abonadas y de buena fama, tampoco era "oficio vil". no podían ejercerlo.

Por otra parte, al tratarse de "oficio público", las mujeres -al igual que los siervos-

Según indica Cantos Benítez (1763: cap. 17, n 7, pp. 126-127 y cap. $18, \mathrm{n}^{\circ} 1$, p. 133), en las postrimerías del siglo XVI y primeros años del XVII, con la concesión de licencias para la creación de bancos públicos a naturalizados y extranjeros, la institución fue decayendo hasta prácticamente desaparecer, superada por los cambios y bancos privados, en gran parte en manos de extranjeros y mercaderes, sin fianzas, seguridad ni restricción alguna.
} 
así como de los señores, cortesanos y personas de muy distinta calidad relacionados con ella.

Pero de hecho, entre los dos primeros no existía una clara delimitación de su actividad, ya que los cambios o bancos de feria solían ser en gran parte una delegación o sucursal de los cambios o bancos públicos de plazas importantes -Burgos, Valladolid, Segovia, Toledo y aun Madridmás o menos próximas al lugar de celebración de dichas ferias: Medina del Campo (Mayo y Octubre), Medina de Rioseco (Mayo y Pasqüilla) y Villalón (Cuaresma).

\section{La "cuenta y razón" de los cambios o bancos privados}

Todos los cambios o bancos, ya fueran particulares o públicos, de conformidad con las Pragmáticas de 4 de Diciembre de 1549 y de 11 de Marzo de 1552, habían de llevar la "cuenta y razón" por "Debe y Ha de Haber" -partida doble-, mediante "Manual" -Diario- y libro de "Caxa" -Mayor-, con día, mes y año, en lengua castellana, sin dejar hojas en blanco entre las que estuviesen escritas en sus libros ${ }^{4}$, asentando en dichos libros la moneda que recibían y en la que pagaban, sin que hubiera fraude en ello, y a qué personas lo daban y de dónde eran vecinos, y haciéndoselo firmar en sus Manuales.

Una somera idea de la forma en que se aplicaban estos preceptos por los cambios o bancos nos la facilita Bartolomé Salvador de Solórzano en el apéndice de Advertencias que figura incorporado al final de su tratado ${ }^{5}$, en el que señala que resulta más fácil llevar la "cuenta y razón" de un banquero que la de un mercader, porque los asientos con que se contabilizan sus transacciones son más sencillos que los de un negocio comercial, aunque ciertamente el número de operaciones y la cantidad de cuentas a utilizar eran mucho mayores, lo que requería más trabajo para su registro y daba lugar a que la mayor parte de los cambios o bancos empleasen dos Manuales en los que las diferentes negociaciones se asentaban por dos manos.

$4 \quad$ Refiriéndose sin duda al Mayor, señala además Albornoz (1573: f. 123, col. 3) que ha de ir "el debito en frente del credito"; es decir, con secciones contrapuestas.

5 Salvador de Solórzano (1590 [1990]) Advertencias para las Personas que estos dos libros Manual, y de Caxa tuvieren: para que del todo entiendan lo tocante a dichos libros, como adelante parece. Capítulo octavo: Donde se deduce lo que se contiene en las cuentas de libros de bancos, y de algunas advertencias para ello; ff. 12 vuelto-15 vuelto. 
Destaca igualmente las ventajas para mercaderes y demás tratantes de disponer de cuenta abierta en el cambio o banco para efectuar sus pagos y cobros por medio de la misma, frente al trabajo de contar y guardar ellos el dinero, así como por lo que supone de tranquilidad al evitar el riesgo de que se lo hurtasen o de que los mataran ladrones por robárselo, como podría ocurrir si lo guardasen en su casa ${ }^{6}$.

6 Acerca de la operativa cotidiana de estos bancos nos da una vívida descripción Juan López Ossorio en su manuscrito sobre la historia de Medina del Campo redactado entre 1614 y 1616, cuyo texto reproducimos siguiendo la transcripción de Ildefonso Rodríguez y Fernández (1903-4: 332-4):

... En la rúa Nueva sacaba cada uno su banco con un tablón de nogal grande y ancho, y junto a él un banco de respaldar adonde se asentaba el cambio y el que había de escribir en el Manual, y fué tiempo que hubo 16 cambios, porque había uno de Valladolid, uno de Medina de Rioseco, dos de Burgos, dos de la corte, uno de Toledo y otro de Segovia, y los demás eran de esta villa, pues el modo como se hacían estos pagos era en esta manera y forma:

Tenían los cambios armadas sus cuentas con cada uno que les enviaba el dinero entre pagos y se los hacían buenos en su cuenta y deudor á su libro; luego, en sacando los libros a la rúa, escribían desde las diez hasta las doce, y en dándolas, luego se cerraban los libros, y por la tarde escribían otras dos horas, y era tanta la gente que acudía a librar en cada cambio, que no se daban manos a escribir, ...

...El que había de pagar á quien debía, llegábase al banco con quien tenía armada su cuenta, y decía:

-Debe Pedro, por Juan tantos mil maravedises, que le da por obligación.

Y si era por cédula de cambio, decían lo mismo, y si la persona que cobraba esta partida tenía su cuenta en el mismo banco, quedábase allí, y cuando pasaban las partidas del Manual al Mayor de caja, hacía el banco acreedor al que cobraba y deudor al que pagaba, á cada uno en la cuenta que les tenía armada, y si el que cobraba tenía cuenta en otro cambio, acabada de asentar la partida en el Manual, decía:

-Pasa a Fulano.-

que era el cambio donde tenía su cuenta, y ponía al pie de la partida el nombre del cambio del que cobraba, y los cambios tenían armadas sus cuentas unos con otros de estas partidas que se pasaban, y cada dos días referían los cambios unos con otros estas cuentas para ver quién debía a quién, y al fin de los pagos pagábale un cambio a otro lo que se alcanzaba.

Acabado un mercader de pagar todo lo que debía, y que tenía compradas sus mercaderías para irse a su casa, iba á referir con su cambio, y si le debía el cambio, no le podía pedir ningún resto hasta que pasasen veinte días después de fenecidos los pagamentos y de haber referido los cambios unos con otros; pero si éste tal había menester sacar su dinero, pagando al cambio cinco al millar por el contado, porque esto manda la Ordenanza de los cambios, se lo habían de contar luego, y si el cambio alcanzaba algún resto al mercader, acomodábanse muy bien con ellos, y en breve término se lo enviaban, y hartas veces con mayor suma para que los tuviere en su poder hasta los otros pagos, ...

Alguna precisión más al respecto nos aporta el autor desconocido de la Relación de la antigüedad y sitio de Medina del Campo y sus ferias... hasta... 1606 (1850: 549-50), cuando nos dice de los cambios que:

...el estilo de las ferias ha sido concurrir á ellas de todas las ciudades, villas y lugares principales del reino, y de los reinos y provincias de Europa, unos con mercaderías y otros con débitos contraidos a pagar en el término de los pagos de cada una de las dichas ferias, que eran los veinte dias últimos de ellas, y que en ellos la Córte y las úniversidades de Búrgos y Sevilla, y las principales ciudades de contratacion como Toledo, Granada, Córdoba, Cuenca, Segovia, Palencia y otras que se agregaban á estas, ponian su crédito 
Otra ventaja complementaria de tener cuenta corriente en un banco o cambio público, añade nuestro autor, es la de que tanto para el mercader o tratante interesado como para aquellos que le transfirieron dinero a su cuenta bancaria o lo recibieron con cargo a la misma, la referida cuenta servía de escritura pública, pues lo eran los bancos, a los que se les daba $\mathrm{fe}^{7}$.

Indica también que como la mayor parte de las cuentas abiertas por el cambio o banco corresponden a clientes, los asientos a realizar en su Manual son muy sencillos, del formato de asientos simples, semejantes al empleado por los mercaderes castellanos, y a tal efecto detalla en cuatro ejemplos los que a su juicio pueden presentarse ${ }^{8}$, que por nuestra parte resumimos en los tres tipos siguientes:

a) Ingreso por parte de un cliente de "dinero de contado"

Caxa

deve por

Fulano

b) Libranza de un cliente a favor de otro

Fulano (librado) deve por Fulano (librador)

c) Retirada por parte de un cliente de "dinero de contado"

Fulano deve por Caxa

en las personas que de conformidad cada ciudad ó villa de por sí ó en compañia de otras nombraron por cambio. Y que el oficio de este tal era tener libro de caja de el crédito y débito de las personas que le elegian, y que estos cambios cuando venian á la feria de Medina presentaban en el Ayuntamiento sus fianzas, y ella nombraba Regidores Comisarios que juntasen los principales de la contratacion, para ver si eran bastantes, ó en cuanta mas cantidad convenia que se afianzasen; y con esta aprobacion se comenzaban los pagos, habiendo en ellos seis ú ocho cambios, que cada mañana a cierta hora salian á la rua, y asentaban en los manuales las partidas de débito, sin tener obligacion á contarlas hasta el último dia de los pagos que se cerraban los libros, y esta manera de pago se llamaba de contado; y si el cambio queria pagarla en reales ántes del último dia de los pagos, llevaba cinco al millar por el contado, pero no podia ser compelido á contar ántes de pasar el último dia, y todos los aprovechamientos del cambio se resumian en este, y en dos ducados que llevaba de cada cuenta de los que la armaban en el oficio, y en tener á la mano el dinero que en él ponian las personas que le nombraron como en depósito, de que tácitamente les era permitido aprovecharse para goce de los cinco á el millar por el contado; y asentadas las partidas en la forma dicha, por la mañana luego recogian los manuales en su casa, y pasábanlas á el libro de caja, en la cuenta que con cada uno tenía armada, para volver a salir á la tarde á su hora á asentar de nuevo partidas de pago, yendo mas enterados del crédito que [á] cada uno le quedaba en el libro de el cambio.

7 En efecto, como manifiesta Hevia y Bolaños (1619: libro II, cap. 8, $\mathrm{n}^{\text {os }}$ 9-11 y 26 , pp. $337-8$ y 344), los libros de los cambios o bancos públicos hacían plena fe por tener el carácter de prueba plena.

8 Una exposición más amplia de la contabilidad bancaria en la Castilla del siglo XVI puede verse en González Ferrando (1991: 720-44). 
Que ésta era la fórmula corrientemente empleada por los banqueros de Medina del Campo para asentar las partidas en sus Diarios parece corroborarlo la copia de un asiento relativo a la feria de Octubre de 1542, tomada del Manual del cambio de dicha villa Enrique Bul y recogida por Ramón Carande en las Autoridades del tomo primero de su obra clásica (Carande Thovar 1965: 529-30), que -con alguna mínima corrección- resulta ser del tenor siguiente:

Viernes a 29 de Diciembre de 1542 años

Alonso de Baeza deve por Alberto Kuehn y Antonio Martin j quento D mill. maravedis que se los da por Hugo Angelo, por lo de la artilleria de Alemania

1.5000000

Indirectamente parece también confirmar el empleo de esta clase de asientos la redacción de las partidas del Mayor (1498-1500) del banquero de Corte Ochoa Pérez de Salinas, primer libro de cuentas -llevado en partida doble- que se ha conocido de un cambio o banco, cuya reproducción, con un estudio preliminar de Felipe Ruiz Martín, publicara en 1980 Armando Represa, y cuyo contenido ha sido minuciosamente analizado por Fernando Martín Lamouroux (1988) ${ }^{9}$.

Dados los antecedentes expuestos, y como no se sabía de la existencia en ningún Archivo español de al menos un Manual de cambio o banco para contrastarla, parece que hubiera de aceptarse como lógica la conclusión de que los asientos de los Diarios de los banqueros de la época debían de ser básicamente similares a los de los Manuales de los mercaderes castellanos coetáneos, tanto más cuanto que incluso el teólogo valenciano Miguel Salón, al tratar -en un latín salpicado de tecnicismos en castellanode los "Libros de ferias" llevados por los cambios y de los asientos que en tales libros se transcribían (Salón 1598: cols. 1.662-3) ${ }^{10}$, viene también a coincidir en líneas generales con lo que hasta ahora se conocía.

Así, respecto de los "libros de Ferias" señala que están integrados por dos: uno menor, llamado Manual, y otro mayor.

9 Del examen de las partidas de este Mayor se desprende por cierto que no todas proceden de su previo registro en el Diario, ya que en el texto de varias de ellas se indica que se hacen "sin manual", lo que supone una aplicación un tanto laxa de la partida doble.

10 Este autor se ocupa de los "libros de Ferias" en las columnas 1.662 y 1.663 de la Controversia XII, desarrollada en la amplia Sección que dedica a la Disputatio de Cambiis (cols. 1.475-1.820) en el tomo segundo de sus Comentarios a la segunda segunda de la Suma Teológica de Santo Tomás. 
Y en cuanto a los asientos, el formato que detalla para registrar las operaciones en el libro Manual es básicamente el siguiente:

Deve Pedro de Valencia mil escudos, que me ha sacado a pagar loan de Valencia en esta feria de Agosto en mí mismo, cambiados consigo mismo

que complementa, según proceda en cada caso, con alguna de las siguientes precisiones: "y remite por cuenta corriente", "y remite por cuenta corriente de loan de Valencia" o "y remite por cuenta corriente de N", cuyo asiento se trasladaría al libro que él denomina simplemente "mayor" -es decir, más grande- en el folio correspondiente a la cuenta de cada una de las dos personas intervinientes en la operación -deudor y acreedor-, en la siguiente forma:

Deve Pedro [de Valencia] su cuenta corriente sobre de loan de Valencia mil escudos, que me ha sacado dicho loan de Valencia a mí mismo

y

Ha de haver loan de Valencia su cuenta corriente mil escudos, [que] me ha remitido de mi mismo, cambiados consigo mismo

Cuál no sería mi asombro, pues, cuando hace algunos años tropecé en la Biblioteca Nacional de Madrid con un fragmento integrado por dos pliegos del libro Manual de un cambio no identificado, en el que no sólo se empleaban asientos simples, sino que en algunos casos también se hacía uso de los asientos complejos o compuestos, y para colmo, por añadidura, no sólo todos eran de factura verdaderamente original sino que incluso algunos de ellos resultaban un tanto heterodoxos ${ }^{11}$.

\section{El fragmento del Manual}

El referido fragmento se había empleado como material para hacer las guardas de la encuadernación realizada en pergamino de un tratado sobre Garantías, Cauciones y Seguros ${ }^{12}$-infolio editado en Lyón, escrito en latín y obra de varios autores- pues el encuadernador castellano

11 El hallazgo de este fragmento del Manual de un cambio de Medina del Campo lo anticipé ya en breve noticia -con alguna información no del todo correcta- en un artículo sobre Salvador de Solórzano publicado hace algún tiempo (González Ferrando 1991: 737-40).

${ }^{12}$ Se trata de la obra colectiva en lengua latina denominada Tractatus Assecurationis et Cautionis editada en Lyón en 1572, a cuya redacción han contribuido no menos de veinte autores, catalogada en la Biblioteca Nacional con la signatura 3/20.079. 
del libro había cosido en sentido inverso al texto de la obra, conservando una solapa o pestaña de unos dos centímetros, sendos pliegos del libro Manual de un cambio de Medina del Campo referidos a negociaciones celebradas en la feria de Octubre de 1564 de dicha villa; pero por desgracia el expresado cambio no resultaba directamente identificable ${ }^{13}$ y a ambos pliegos se les habían reducido los márgenes e incluso uno de ellos tenía una hoja desgarrada e incompleta.

En efecto, por ser inferior el tamaño de las hojas del tratado $-340 \times 220$ mm.- a la medida de los pliegos del libro Manual utilizados como guardas -que debían de ser de unos $365 \times 260 \mathrm{~mm}$.- al guillotinarlos para igualarlos con aquéllas, se ha eliminado una parte de los márgenes del registro del cambio, lo que si bien en cuanto a los bordes superior e inferior casi no ha llegado a afectar al texto, en lo que respecta al margen lateral exterior ha dado lugar a la pérdida de una parte del mismo: la relativa a los importes de la columna exterior de los asientos en las hojas impares y a la numeración de los folios del Mayor y título de las cuentas en las pares; y por lo que se refiere al margen interior, el texto de dos de las páginas de cada pliego quedaba oculto por la solapa cerrada correspondiente al doblez de cada uno de los pliegos.

Por fortuna, por lo que hace al margen exterior, parte de esta información puede recuperarse indirectamente cuando se trata de los importes de los asientos -columna exterior-, aunque ya no es tan fácil hacerlo cuando afecta al número del folio de las cuentas y/o de su título si éstos no se repiten en hojas más completas. $Y$ en cuanto al margen interior, la información contenida en la parte oculta de las solapas se ha podido rescatar seccionándolas con un bisturí, si bien la costura de los pliegos dificulta en más de un caso la lectura de los datos.

Estas cuatro hojas que integran el fragmento de dicho Manual, y de las que como ya se ha señalado una está desgarrada e incompleta, nos proporcionan las ocho páginas que en reproducción fotográfica se presentan en las páginas pares del Anexo $\mathrm{I}^{14}$, reproducción que no ha podido

13 La mención en uno de los asientos a Simón Ruiz, el conocido mercaderbanquero de Medina del Campo, dejaba abierta la puerta, empero, a su identificación indirecta dado que en el "Archivo de Simón Ruiz" del Archivo Histórico Provincial de Valladolid, y entre los libros de cuentas de este mercader, se conservan los de Ferias correspondientes a la feria de Octubre de 1564 de Medina del Campo.

14 Para la ordenación de las páginas de este Anexo se ha tomado como referencia el número del folio de la "seudocuenta" de Partimentos, que en uno de los pliegos es en todos los casos el 44 , en tanto que hacia la mitad del otro pasa a ser el 45 , sin duda por haberse completado ya el folio 44. 
recoger el texto incluido en las solapas, pues por razones técnicas la fotografía ha tenido que limitarse al tamaño del infolio. Pero en las páginas impares de dicho Anexo se elimina este inconveniente puesto que frente a cada una de las reproducciones fotográficas se ha incluido su transcripción, y en ella se ha recogido ya el complemento de información proporcionado por las solapas.

Al propio tiempo, para facilitar su identificación, en la transcripción se han numerado los sesenta y dos asientos que en total contiene el fragmento del Manual, de los cuales hay cuarenta y nueve (1$30 ; 37-38$ y 46-62) que están suficientemente completos y otros tres (31, 32 y 39) son al menos inteligibles; de los restantes diez, sólo figura algún dato suelto en seis de ellos (33-36 y 40-41), y de los otros cuatro (42-45) no se aprecia prácticamente nada más que indicios ${ }^{15}$.

Por lo que respecta a la transcripción, como ya ha quedado reiterado, se ha completado el texto fotografiado con la parte reconocible de palabras, cantidades y números de folio del Mayor que ocultaban las dos pestañas o solapas. Para diferenciarlas del texto existente, las letras, cifras, palabras y cantidades suplidas figuran entre corchetes, y en cuanto a las cifras y palabras que no han podido ser identificadas, se han sustituido por uno o más puntos entre los corchetes.

Asimismo se ha respetado tanto la singular denominación atribuida a algunas ciudades como la ortografía del texto del libro Manual, aunque se ha puntuado y acentuado con criterio ortográfico actual, criterio que se ha seguido igualmente en el empleo de mayúsculas y minúsculas; con relación a las cantidades expresadas en "cuenta guarisma" se ha respetado también el uso del "cuento" y del "calderón numeral", y al propio tiempo se han resuelto cuando era preciso las abundantes abreviaturas de todo orden que aparecen en los asientos.

Por otra parte, y con objeto de no recargar más el ya abundante número de Notas al texto con la explicación de los frecuentes tecnicismos que no sólo aparecen en él sino también en el Anexo I, referidos sobre todo a la práctica cambiaria y comercial de la Castilla del siglo XVI, así como de algunos contratos bancarios un tanto particulares propios de aquel tiempo, se agrega al final del trabajo un Glosario en el que todos ellos se desarrollan de manera sistemática y con la adecuada

15 Con objeto de destacarlos de los asientos completos, los trece incompletos -31-36 y 39-45- se han numerado en negrita. 
amplitud, señalando en su caso las correspondientes interrelaciones. Dicho Glosario se completa, además, con la lista de las Abreviaturas que aparecen en el fragmento del Manual.

\section{LOS ASIENTOS}

La escritura empleada en la redacción de los asientos del Manual no deja de ser parecida a la en general reposada y legible que utilizaban en sus libros de cuentas los mercaderes castellanos, pero se nota que es de factura más rápida y ligera, lo que la hace en cierto modo asemejarse a la letra procesal, si bien resulta mucho más clara y legible que esta última, por faltarle el típico encadenamiento de palabras.

Como moneda de cuenta se utiliza el maravedí, siempre redondeado a unidades enteras, al igual que en el caso de los mercaderes castellanos.

El método de numeración que se sigue es el denominado en aquel tiempo "cuenta guarisma", y ello tanto para las cantidades incluidas en el cuerpo de los asientos como para las sumas anotadas en el margen derecho del asiento -columna exterior de cantidades-, pero ya sin recurrir en dicha columna exterior, e incluso en alguna ocasión en el propio cuerpo de los asientos, al símbolo del "cuento" - $q^{\circ}$ - para denotar los millones, sin ni siquiera sustituirlo por un punto.

Pero con relación a las prácticas usuales seguidas en los Manuales por los mercaderes castellanos, en este fragmento de Manual tanto los asientos simples como los compuestos muestran dos particularidades.

En primer lugar, en vez de emplear en los asientos simples el típico quebrado simbólico para indicar el folio del Mayor que, respectivamente, corresponde a la cuenta de cargo -numerador- y a la de abono -denominador-, dicho número se sitúa aisladamente, frente a la correlativa cuenta cargada o abonada. Como era de suponer, esta misma forma es la que se utiliza para identificar los folios del Mayor de cada una de las diversas cuentas que aparecen en los asientos compuestos o complejos.

$Y$ en segundo lugar, para indicar que se ha llevado a cabo el traslado de las partidas del Manual al Mayor, en vez de colocar un punto detrás de cada uno de los pertinentes números de los folios del Mayor, se recurre al inusual procedimiento descrito por Salvador de Solórzano (1590 [1990]: ff. $51 \mathrm{v}-52 \mathrm{r}$ ), ya que vemos en las páginas originales del Anexo I 
que se ha trazado una raya ligeramente curvada sobre cada una de las cantidades que figuran en la columna exterior.

Por otra parte, la corrección de errores se hace de forma un tanto dispar en los distintos casos. Así, en el asiento núm. 27 se ha empleado el clásico término de "digo" para anular la mención errónea de Andrea Ynperial y Hijos y escribir la correcta de David Ynperial; en los asientos núms. 20, 25 y 27 se ha utilizado la expresión "Vuena por" -con la que se designa la cuenta de abono-, para lograr el mismo efecto:

(20) Domingo nuestro, aparte, D.L. "Vuena por" el libro del nuestro Domingo,

(25) Negroli, de Milán. "Vuena por" Juan Celesia, aparte, H.L.,

(27) el nuestro Domingo, D.L. "Va por" el libro del nuestro Domingo;

en el asiento núm. 4, primero se ha tachado pura y simplemente la cuenta equivocada de Anrriq Bul y conp ${ }^{a}$ para sobreescribir entre líneas la adecuada de Cuenta de Tratas fechas en Pontarli feria de Apparición y luego se ha incluido, también entre líneas, el texto omitido relativo a los "Lercaros"; y en algún que otro asiento aparecen también pequeños tachones y números sobreimpresos, soluciones estas últimas que resultan un tanto sorprendentes por tratarse de un cambio cuyos libros hacían fe plena en juicio.

Pero todavía ha de señalarse con relación al asiento número 32, que parece ser la corrección -mediante un apunte complementariode otro asiento complejo anterior en el que se omitieron las dos cuentas de abono -crédito- que en éste se incluyen, pero sin que se haga mención en el texto de que se trata del final de una transacción previa cuyo registro había quedado incompleto.

\section{Formato de los asientos}

Tal como ha quedado apuntado anteriormente, el formato de los asientos que nos muestra el fragmento de Manual difiere apreciablemente del típico que aparece en los numerosos libros de cuentas que conocemos de los mercaderes castellanos de aquel tiempo e igualmente "declara" Bartolomé Salvador de Solórzano en su tratado (1590 [1990]: ff. $26 \mathrm{v}^{\circ}-27 \mathrm{r}^{\circ}$, en particular), no sólo porque en ciertos casos utiliza asientos compuestos o complejos -una cuenta deudora y varias acreedoras o viceversa-, sino porque la fórmula general que emplea en su 
redacción tampoco se corresponde con el estilo de los asientos que hasta ahora conocíamos.

Así, en los asientos simples, frente a la usual forma de: cuenta de cargo deve por cuenta de abono utiliza la de:

cuenta de cargo deve por $x x x$ mrs. Vuena por ${ }^{16}$ cuenta de abono

como puede comprobarse, por ejemplo, en las dos primeras páginas -original y transcripción- del fragmento del Manual, asientos números 1 al 18.

Para los asientos compuestos hace uso de lo que podríamos denominar una "seudocuenta" auxiliar que denomina "Partimentos" -complementada con la expresión de "pertenecen a"- para representar, según los casos, tanto a las diversas cuentas de cargo como a las de abono, lo que le permite detallar las partidas de cargo o de abono en que en cada caso se desglosa dicha "seudocuenta" de Partimentos, la cual si bien en cierto modo podría parecer equivalente a nuestro viejo término de "Varios" para señalar la existencia de "varias" cuentas de cargo o de abono en un mismo asiento, introduce de hecho un elemento de heterodoxia contable al romper en estos casos la igualdad de cargos y abonos propia de la partida doble puesto que se emplea como si de una cuenta real más se tratase.

Según que las cuentas de igual signo que intervengan en el asiento complejo sean acreedoras o deudoras, la fórmula que respectivamente para cada variedad se utiliza en el Manual de nuestro cambio es la de:

cuenta de cargo deve por xxx mrs. Vuena por Partimentos
pertenecen a
(detalle interior de cuentas de abono, cuyo importe individual se
reitera igualmente en la columna exterior o de cantidades)

o bien de:

Partimentos deven por $x x x$ mrs. Vuena por cuenta de abono pertenecen a

(detalle interior de cuentas de cargo, cuyo importe individual se repite también en la columna exterior o de cantidades)

16 Esta expresión de "Vuena por" es la que claramente se deduce de la abreviatura "Va por" que se reitera en todos los asientos del Manual. Sin embargo, Salvador de Solórzano en las Advertencias a su tratado de 1590 (cap. octavo, fol. $13 \mathrm{v}^{\circ}$ ) parece señalar como fórmula típica de cambios y bancos para indicar el abono de una partida en cuenta la de "Valen por". 
Como ejemplo del primero de estos dos tipos de asiento -simple- pueden verse en las páginas primera y segunda del fragmento del Manual los ya indicados asientos números 1 al 18; y del segundo tipo de ellos -complejo-, en páginas posteriores, los números 19 al 22 y los 31 y 39 , respectivamente, para cada una de sus dos variedades ${ }^{17}$.

Hay que señalar, empero, que los asientos compuestos redactados en el fragmento de Manual no cubren más que una parte de los que podrían haberse elaborado sobre la base de las transacciones contabilizadas en él, puesto que sólo están referidos bien a las operaciones en que una sola letra de cambio es compartida por varios dadores a cambio, de los que cada uno hubiera aportado una parte alicuanta del importe de la misma para disponer de saldo en plaza extranjera u otra finalidad deseada -asiento núm. 19-, bien a la situación simétrica en la que se repartiera entre varios tomadores a cambio el importe total de una letra -asiento núm. $31^{18}$.

En efecto, los "caxeros" del cambio no se han dado cuenta de la posibilidad de generalizar el uso de los asientos compuestos a las restantes operaciones susceptibles de ser registradas de tal forma: las series de asientos en los que se ha sustituido el título de la cuenta del apunte inicial por la mención de "el dicho" o "los dichos", pues por ejemplo, como se aprecia en los asientos núms. 4 al 8 , con los que se contabiliza la remesa de 10.000 escudos de marco de Pontarlier a Medina del Campo mediante cinco letras de otros tantos libradores, la operación se ha resuelto recurriendo a cinco apuntes -uno por cada trata- en lugar de a un solo asiento complejo; lo mismo ocurre en los asientos núms. 10 al 12, en que se registra la obtención de 4.000 escudos girando tres tratas en sendos asientos simples, entre otros $\operatorname{casos}^{19}$.

17 Conviene recalcar que el importe de la cuenta única de cargo o de abono sacado al margen -columna exterior- en esta última clase de asientos sirve a la vez para identificar la cantidad que, por un lado, se ha de cargar en ella en el folio del Mayor y, por otro, abonar en la cuenta de Partimentos de dicho Mayor o, recíprocamente, la que se ha de cargar en el folio de Partimentos y abonar en el de la correspondiente cuenta única.

18 Ejemplos de estas operaciones con "letras compartidas" se ven con cierta frecuencia en los libros de cuentas de los mercaderes castellanos, que en tales casos especifican que se trata de "letra" o "cambio de más suma" que la reconocida en libros por ellos, cuyo importe sólo corresponde a su alicuanta del valor total de la letra y no a este último.

19 De las 20 operaciones de cambio en Pontarlier de escudos de marco por maravedíes que aparecen en el fragmento -en un año como el de 1564 en que hubo gran "largueza" en las ferias de Besanzón-, una (5\%) lo ha sido a 416; dos (10\%), a 4161/2, y 17 (85\%), a 417 mrs. por $\nabla$. 


\section{La "seudocuenta" de Partimentos}

La mayor originalidad que presentan los asientos compuestos del fragmento de este libro Manual hay que destacar que radica en que para reflejar la existencia de varias cuentas de cargo o de abono se emplea precisamente -y con todas sus consecuencias- una "seudocuenta": la rúbrica auxiliar de Partimentos, con la que se opera como si de una verdadera cuenta se tratase, ya que se abre en el Mayor y se carga o abona por el total de las partidas que resume o representa, dado que éste es el importe que se registra en la columna exterior, no sólo para la cuenta única de cargo o de abono -según los casos- sino también para la citada cuenta de Partimentos.

No cabe la menor duda de que funciona como una auténtica cuenta, pues dispone de su correspondiente folio abierto en el Mayor, tal como lo acredita el número del mismo que figura frente a Partimentos en cada uno de los asientos en que esta rúbrica interviene, y como su uso es bastante frecuente acumula numerosas partidas deudoras y acreedoras, lo que hace que cambie del folio 44 al 45 a partir del asiento número 47 .

Pese a que está muy claro que con tal proceder se rompe -en principio- la igualdad entre cargos y abonos en que se basa la partida doble, y esto nos pudiera hacer dudar de que esta contabilidad estuviera realmente llevada por este procedimiento, dicho equilibrio quedaría sin embargo virtualmente restablecido si al elaborar el balance se prescindiera de dicha "seudocuenta" de Partimentos -ignorándola- o, en otro caso, su saldo se sacase aparte de la suma de los restantes saldos.

\section{El premio del dinero de banco}

Tal como se puede apreciar en el Anexo I, las letras libradas en maravedíes se dice que vienen "con 5" si proceden de Barcelona (asiento núm. 2) y "con 6" si lo hacen de Sevilla (asientos núms. 19-28 y 46-62), que es la fórmula abreviada de indicar que dichas letras sobre ferias castellanas vienen "con tanto al millar"; esto es, tienen un valor efectivo -presentado en la columna exterior- igual al resultado de agregar a su valor nominal -recogido en el cuerpo del asiento- lo que hoy calificaríamos de "premio del dinero de banco", cuyo resultado sería equivalente a multiplicar dicho valor nominal por 1,005 ó 1,006, respectivamente.

Quiere esto decir que en los correspondientes libros de cuentas de los emisores de las letras, desde el mismo momento en que 
son libradas, no se valoran por su nominal sino por el efectivo, por lo que su libranza o emisión no da lugar a beneficio alguno para el librador, en cuyas cuentas a todos los efectos se cifran por el indicado valor efectivo, al igual que ocurre en la cadena siguiente de personas que intervengan a lo largo del proceso de la letra hasta su pago al vencimiento mediante abono -dinero escritural o de banco- en la cuenta del cambio que intermedie en la operación.

Sólo si el pago se realizara en metálico en reales o "dinero de contado" o "fuera de banco", como entonces se decía, éste se haría exclusivamente por el nominal, y el premio "del tanto al millar" que correspondiera en su $\operatorname{caso}^{20}$, quedaría a favor del cambio o banco como compensación a su entrega de "dinero de contado", con lo que de esta forma contribuiría a la remuneración de su actividad ${ }^{21}$.

En las propias letras de cambio se especificaba con toda claridad el premio a aplicar con la mención, a continuación del importe o valor de la letra, de alguna de las expresiones "con más seis al millar", "con seis al millar" o incluso "en banco con seis al millar", en el caso de que el premio vigente fuera del $6 \%$. Cuando no procedía tal premio por pagarse la letra al contado en reales, el texto que se agregaba después del importe podía ser "fuera de banco", "fuera de cambio", "en reales de contado" o "en reales fuera de banco" como más usuales.

20 A este respecto, Cristóbal de Villalón (1546 [1945]: folio 22 recto y vuelto) especifica que por pagar las letras al contado los cambios recibían 5 al millar si venían de Flandes, 6 al millar si procedían de Sevilla y 7 al millar si eran de Valencia o de Lyón.

21 Aparte de este "premio" y de los dos ducados -750 mrs.- que llevaban por cada cuenta abierta (Relación 1850: 549) por "la pena de llevar la cuenta" en sus libros durante la feria, estos cambios y bancos tenían también como ingreso normal el "5 al millar" establecido en la Ordenanza de cambios por anticipar el pago al contado de los saldos a favor de los mercaderes -"reducir el dinero de banco" según entonces se decía- antes del último día de los pagos, si bien este "tanto al millar" llegó a alcanzar en ocasiones el "6 al millar", el "10 al millar" e incluso -según indica Saravia de la Calle (1544 [1999]: 181)- cifras superiores como "25 y 30 al millar".

Mas, dado que los cambios y bancos de feria no eran entidades de depósito, podían dedicar una cierta fracción del dinero recibido de sus clientes a una actividad especulativa en provecho propio como forma de mejorar su rendimiento, aplicando dichos fondos a la negociación de "cambios por letras" y a la concertación de las típicas operaciones castellanas de "contados" y "depósitos", siempre que ponderasen adecuadamente el riesgo de tal política, pues si los deudores por dichas contrataciones resultasen insolventes por falta de patrimonio o de liquidez, podían dejarlos en situación de quiebra, circunstancia que se repitió más de una vez en la segunda mitad del siglo XVI.

Conviene señalar que estas transacciones sólo eran toleradas por los moralistas en cuanto se refiere a la negociación de cambios reales, pues los secos y los ficticios, así como los "contados" y los "depósitos", se consideraban usurarios, y que incluso por Pragmática de 1552 se prohibieron los cambios interiores a precio distinto de la par, todo lo cual no impidió que se continuaran practicando normalmente todas estas operaciones como nos muestran los libros de cuentas de los mercaderes castellanos de la época. 
Conocido generalmente por la denominación de "6 al millar", que era el tipo más utilizado -solía fluctuar entre el 5 y el 7\%o, aunque en alguna ocasión su valor máximo llegara a superar en mucho esta última cifra-, dicho premio o sobreprecio en Castilla del valor del "dinero de contado" sobre el de banco fue reprobado en mayor o menor grado por todos los moralistas que se ocuparon de cambios y bancos a lo largo del siglo $\mathrm{XVI}^{22}$, muy posiblemente porque no llegaron a entender que su razón de ser radicaba en el hecho de que la moneda metálica era un bien escaso en aquel tiempo y por lo tanto era más apreciada que la escritural.

\section{Las ferias de Pontarlier}

Reiteradamente aparece mencionada la plaza de "Pontarli" en el fragmento de Manual, localidad que no es otra que la para nosotros no muy conocida de Pontarlier, e incluso se menciona repetidamente la feria de "Apparición" (Aparición) de la citada población -asientos núms. 4-8, 10 13, 17-18, 29-31 y 37-39-, feria que se iniciaba en el mes de Febrero y era por lo tanto correlativa de la de Octubre de Medina del Campo. Esta feria, que tenía lugar en el Franco Condado -una de las etapas del "camino español" a Flandes-, fue continuación de las más conocidas celebradas en su capital, Besanzón, y herederas a su vez de las de Lyón.

Las ferias de Besanzón fueron consecuencia de que al prohibir Francisco I a finales de 1534 la actividad comercial de los genoveses en Saboya -Lyón y, más adelante, Montluel y Chambery- éstos solicitaron y obtuvieron en 1535 del emperador Carlos V autorización para celebrar sus ferias en el Franco Condado, por aquel tiempo patrimonio de los Habsburgo.

La primera feria de 1535 -de Reyes o Aparición- se celebró en Lons-le-Saunier, pero las siguientes -de Pascua, de Agosto, de Santos y sucesivas-, ya tuvieron lugar en Besanzón -y de ahí su nombre-, plaza en la que se continuaron por espacio de cerca de treinta y cinco años, aunque también lo hicieran fuera de la capital del Franco Condado, en otras localidades próximas, y especialmente en Pontarlier.

22 Incluso Tomás de Mercado (1571 [1977]: 481) llegó a considerarlo como "el negocio mas oscuro de entender y dificil de averiguar" que había visto en sus días. 
Hacia 1571 se reunieron en Poligny y luego en plazas del norte de Italia y de Suiza: 1573, Trento; 1576, Coire; 1577, Rivoli; 1578, Ivrée ${ }^{23}$. En 1579 se trasladaron a la República de Génova y de 1580 a 1621 se reunieron en Piacenza y otras varias plazas, hasta consolidarse su celebración en Novi a partir de este último año.

\section{LAS CUENTAS}

Para ofrecer una más clara imagen de las cuentas que aparecen en los asientos del fragmento del Manual y del volumen de las operaciones registradas en las cuatro hojas que lo integran, se ha elaborado -sobre la base de los cuarenta y nueve asientos completos- el balance de movimiento y saldos que se presenta en las páginas siguientes, con las cuentas ordenadas alfabéticamente e indicando el respectivo folio de Mayor cuando ha sido posible.

Se ha obviado en el referido balance la dificultad que introduce la peculiar utilización que se hace de la "seudocuenta" de Particiones como si fuera una auténtica cuenta, mediante el recurso de separar su movimiento y saldo de la Suma de Balance que corresponde a las setenta y dos cuentas que realmente intervienen en los indicados asientos completos.

A las citadas setenta y dos cuentas auténticas del balance pueden agregarse todavía las otras siete plenamente identificables que sólo aparecen en los asientos incompletos, lo que eleva a setenta y nueve el número total de cuentas reconocibles que se deducen del fragmento del Manual.

Ordenadas a su vez alfabéticamente y con indicación del folio de Mayor, se detallan a continuación estas últimas siete cuentas:

23 Según Henri Lapeyre (1956: 295), las ferias de Besanzón cambiaban continuamente su localización, tras la condena en 1571 del "depósito" en toda la cristiandad por el Papa Pío V, para eludir la crítica de los moralistas ya que de esta forma se respetaba nominalmente la condición de la existencia de la distantia loci, requisito esencial del contrato de cambio para los teólogos. 


\begin{tabular}{|l|r|}
\hline \multicolumn{1}{|c|}{ Título de la cuenta } & Folio \\
\hline Benyto Centurión, de Génova & 114 \\
\hline Nicolao Gentil, de Mesina, [quenta] aparte A. & 138 \\
\hline Batista Lercaro sobre de .... & 99 \\
\hline Nicolao de Negrón, Andrea e Ludovico Centuryoni, de Venecia & 68 \\
\hline Bartolomé e Nicolao Palavesinis & 139 \\
\hline Tomás Salugo sobre de Andrea Centuryoni & 134 \\
\hline Spínola e Centuryoni, de Pontarli & 92 \\
\hline
\end{tabular}

\section{El balance de movimiento y saldos}

Como se aprecia en el referido balance -que se incluye en las páginas siguientes-, dado el corto número de transacciones registradas sólo figuran tres cuentas con contrapartida: las correspondientes a Pero, Jusepe, Justinián e Francisco Coquella; a Nicolao Gentil, de Mesina, cuenta aparte, R.M.; y a David Ynperial -cuyo saldo precisamente es nulo-, de forma que los restantes saldos coinciden exactamente con el movimiento deudor o acreedor.

Al margen de la "seudocuenta" auxiliar de Partimentos ya tratada, de la diferencial de Responsiones ${ }^{24}$, de la de Tratas fechas en Pontarlier, feria de Aparición, que recoge lo que hoy llamaríamos activos financieros, y de las tres de Libros de Corte, las restantes setenta y cuatro cuentas identificadas son todas ellas de carácter personal, de las que una misma persona puede incluso llegar a tener hasta tres más o menos diferenciadas, como es el caso de "Franco Lercaro": Franco Lercaro; Franco Lercaro nuestro, cuenta corrente; y Franco Lercaro nuestro, cuenta aparte D.J.; y el de "Simón nuestro": Simón nuestro, cuenta corrente; Simón nuestro, cuenta aparte D; y Simón nuestro, cuenta aparte G.S.

24 El maravedí que nuestro cambio carga en el asiento núm. 9 a Agustín Gentil por cada escudo de marco cambiado $-10.000 \nabla^{\text {os }}$ en junto- y abona a la cuenta de Responsiones parece tener todo el carácter de un corretaje del 2,4\% (1/417) por garantizar el buen fin de las letras, tal y como lo define Villalón (1542 [1945]: folio $23 \mathrm{r}^{\circ} \mathrm{y} \mathrm{v}^{\circ}$ ) -"estar del creer" o, como decían los mercaderes, "estar por las ditas"-, operación que por cierto este autor considera reprobable. 


\section{BALANCE}

\begin{tabular}{|c|c|c|c|c|c|}
\hline \multicolumn{2}{|l|}{ Cuenta } & \multicolumn{2}{|c|}{ Movimiento } & \multicolumn{2}{|c|}{ Saldo } \\
\hline Título & Folio & Debe & Haber & Deudor & Acreedor \\
\hline Pedro de Angulo & $\ldots$ & 190.511 & - & 190.511 & - \\
\hline Ypólito, Gaetán e Jácome de Bardi & $\ldots$ & 174.754 & - & 174.754 & - \\
\hline Anrriq Bul y conp ${ }^{\mathrm{a}}$, canbio & 3 & 4.860 .080 & - & 4.860 .080 & - \\
\hline $\begin{array}{l}\text { Gabriel Bury y en su ausencia Simón } \\
\text { Ruiz }\end{array}$ & $\ldots$ & 767.130 & - & 767.130 & - \\
\hline $\begin{array}{l}\text { Diego de Bustamante, de Sevilla, } \\
\text { sobre del nuestro Simón }\end{array}$ & $\ldots$ & 155.050 & - & 155.050 & - \\
\hline Alonso de Carrión & $\ldots$ & 299.255 & - & 299.255 & - \\
\hline Alonso de Castro & 21 & 381.965 & - & 381.965 & - \\
\hline $\begin{array}{l}\text { Lope de Castro e Francisco Martínez, } \\
\text { de Lerma }\end{array}$ & .. & 155.531 & - & 155.531 & - \\
\hline Juan Celesia, [quenta] corrente & $\ldots$ & - & 8.310 & - & 8.310 \\
\hline Juan Celesia, [quenta] aparte H.L. & $\ldots$ & - & 35.013 & - & 35.013 \\
\hline Juan Centuryón & $1[.]$. & 4.266 .693 & - & 4.266 .693 & - \\
\hline Alonso e Christóval Cerezo & $\ldots$ & 380.080 & - & 380.080 & - \\
\hline $\begin{array}{l}\text { Cibo e Spínola, de Cáliz, [quenta] } \\
\text { corrente }\end{array}$ & 99 & - & 1.314 .079 & - & 1.314 .079 \\
\hline $\begin{array}{l}\text { Pero, Jusepe, Justinián e Francisco } \\
\text { Coquella }\end{array}$ & 124 & 9.524 & 133.997 & - & 124.473 \\
\hline $\begin{array}{l}\text { Juan Paolo, Guido e Camilo Cusani, } \\
\text { de Milán }\end{array}$ & $\ldots$ & - & 9.524 & - & 9.524 \\
\hline Gonçalo Díez & $\ldots$ & - & 155.050 & - & 155.050 \\
\hline Domingo nuestro & 53 & - & 8.160 & - & 8.160 \\
\hline Domingo y Simón, [quenta] aparte F. & 127 & - & 27.612 & - & 27.612 \\
\hline $\begin{array}{l}\text { Baltasar Doria, de Granada, [quenta] } \\
\text { corrente }\end{array}$ & $\ldots$ & - & 91.607 & - & 91.607 \\
\hline Baltasar Doria, [quenta] aparte B.D. & $\ldots$ & - & 175.206 & - & 175.206 \\
\hline $\begin{array}{l}\text { Juan, Francisco y Antonio de Fornari, } \\
\text { de Nápoles }\end{array}$ & 85 & - & 1.065 .207 & - & 1.065 .207 \\
\hline Agustín Gentil & 6 & 436.571 & - & 436.571 & - \\
\hline $\begin{array}{l}\text { Nicolao Gentil, de Mesina, [quenta] } \\
\text { aparte R.M. }\end{array}$ & 97 & 8.160 & 4.909 .184 & - & 4.901 .024 \\
\hline Alexandre Grasso, de Murcia & $\ldots$ & 188.754 & - & 188.754 & - \\
\hline Jácome de Grimaldo & $\ldots$ & - & 49.120 & - & 49.120 \\
\hline Nicolao de Grimaldo y conpa & 19 & 300.968 & - & 300.968 & - \\
\hline $\begin{array}{l}\text { Ortuño de Ybacax, de Herrera [de } \\
\text { Duero] }\end{array}$ & 28 & 304.818 & - & 304.818 & - \\
\hline \multicolumn{2}{|c|}{ Suma y sigue ............ } & 12.879 .844 & 7.982 .069 & 12.862 .160 & 7.964 .385 \\
\hline
\end{tabular}




\begin{tabular}{|c|c|c|c|c|c|}
\hline \multicolumn{2}{|c|}{ Suma anterior ............ } & 12.879 .844 & 7.982 .069 & 12.862 .160 & 7.964.385 \\
\hline Andrea Ynperial y Hijos & 86 & 158.306 & - & 158.306 & - \\
\hline David Ynperial & 105 & 10.027 & 10.027 & - & - \\
\hline Miguel e David Ynperiales & 34 & 65.480 & - & 65.480 & - \\
\hline Pedro Ytaliano & 91 & - & 128.891 & - & 128.891 \\
\hline Franco Lercaro & 87 & - & 1.500 .000 & - & 1.500 .000 \\
\hline $\begin{array}{l}\text { Franco Lercaro nuestro, [quenta] } \\
\text { corrente }\end{array}$ & 87 & - & 310.990 & - & 310.990 \\
\hline $\begin{array}{l}\text { Franco Lercaro nuestro, [quenta] } \\
\text { aparte D.J. }\end{array}$ & {$[] 6$.} & - & 407.715 & - & 407.715 \\
\hline Juan Lercaro & 22 & 270.575 & - & 270.575 & - \\
\hline Simón Lercaro, [quenta] corrente & $\ldots$ & - & 2.163 .900 & - & 2.163 .900 \\
\hline $\begin{array}{l}\text { Juan y Domingo Lercaros, [quenta] } \\
\text { aparte R. }\end{array}$ & $7[]$. & - & 125.091 & - & 125.091 \\
\hline $\begin{array}{l}\text { Juan Stevan y Juan Gerónimo } \\
\text { Lercaros, de Pontarli }\end{array}$ & 11 & 603.159 & - & 603.159 & - \\
\hline $\begin{array}{l}\text { El libro de Corte del nuestro } \\
\text { Domingo }\end{array}$ & 53 & - & 1.506 .611 & - & 1.506 .611 \\
\hline El libro de Corte nuevo & 140 & 2.057 .847 & - & 2.057 .847 & - \\
\hline El libro de Corte viejo & 81 & - & 1.011 .268 & - & 1.011 .268 \\
\hline Andrea, Agustín e Nicolao de Mari & 94 & - & 935.847 & - & 935.847 \\
\hline Juan Francisco de Mari & $\ldots$ & - & 37.182 & - & 37.182 \\
\hline Julián de Marín & 11 & 2.163 .900 & - & 2.163 .900 & - \\
\hline Francisco Martínez, de Lerma & $\ldots$ & 73.454 & - & 73.454 & - \\
\hline $\begin{array}{l}\text { Juan de Medina, de Herrera [de } \\
\text { Duero] }\end{array}$ & 28 & 164.029 & - & 164.029 & - \\
\hline $\begin{array}{l}\text { Juan Batista Montenegro y Hijos, } \\
\text { de Nápoles }\end{array}$ & 93 & - & 697.657 & - & 697.657 \\
\hline $\begin{array}{l}\text { Juan Francisco de Negro y conpa } \\
\text { de Pontarli }\end{array}$ & & 351.039 & - & 351.039 & - \\
\hline $\begin{array}{l}\text { Nicolao de Negrón e Andrea } \\
\text { Centuryón }\end{array}$ & 98 & - & 149.336 & - & 149.336 \\
\hline Félix Palavesini & 101 & - & 351.039 & - & 351.039 \\
\hline $\begin{array}{l}\text { Jácome Panes e Pero Batista } \\
\text { Ferrero, de Nápoles }\end{array}$ & $\theta$ & - & 233.813 & - & 233.813 \\
\hline Hétor Picamillo, de Nápoles & 105 & - & 1.747 .500 & - & 1.747 .500 \\
\hline Responsiones & 109 & - & 10.000 & - & 10.000 \\
\hline Antonio de Santa Cruz & $\ldots$ & 245.143 & - & 245.143 & - \\
\hline Agustín Sauli & $\ldots$ & - & 126.597 & - & 126.597 \\
\hline Simón nuestro, [quenta] corrente & 79 & - & 159.024 & - & 159.024 \\
\hline Simón nuestro, [quenta] aparte D. & 101 & - & 157.270 & - & 157.270 \\
\hline $\begin{array}{l}\text { Simón nuestro, [quenta] aparte } \\
\text { G.S. }\end{array}$ & 103 & - & 1.203 .199 & - & 1.203 .199 \\
\hline Suma y sigue. & & 19.042 .803 & 20.955 .026 & 19.015 .092 & 20.927.315 \\
\hline
\end{tabular}



del Campo no identificado, correspondiente a la feria de Octubre de 1564

\begin{tabular}{|c|c|c|c|c|c|}
\hline \multicolumn{2}{|c|}{ Suma anterior ............. } & 19.042 .803 & 20.955 .026 & 19.015 .092 & 20.927 .315 \\
\hline Antonio Spínola, de Génova & 91 & - & 404.764 & - & 404.764 \\
\hline $\begin{array}{l}\text { Benyto Spínola, [quenta] aparte } \\
\text { D.J. }\end{array}$ & 13 & - & 820.762 & - & 820.762 \\
\hline $\begin{array}{l}\text { Francisco Spínola, quenta } \\
\text { corrente }\end{array}$ & $\ldots$ & - & 20.721 & - & 20.721 \\
\hline $\begin{array}{l}\text { Francisco Spínola y Hijos, } \\
\text { [quenta] corrente }\end{array}$ & 104 & - & 274.410 & - & 274.410 \\
\hline $\begin{array}{l}\text { Francisco Spínola y Hijos, } \\
\text { [quenta] aparte N.N. }\end{array}$ & 104 & - & 832.000 & - & 832.000 \\
\hline Lucas Spínola, [quenta] corrente & & - & 20.721 & - & 20.721 \\
\hline $\begin{array}{l}\text { Conde Marcantonio Spínola sobre } \\
\text { de Franco Lercaro }\end{array}$ & $\ldots$ & - & 317.272 & - & 317.272 \\
\hline Stevan Spínola, de Córdova & $\cdots$ & - & 15.854 & - & 15.854 \\
\hline $\begin{array}{l}\text { Stevan Spínola e Juan Bautista de } \\
\text { Marín, de Córdova }\end{array}$ & $\ldots$ & - & 911.294 & - & 911.294 \\
\hline $\begin{array}{l}\text { Stevan Spínola e Juan Batista de } \\
\text { Marín, [quenta] aparte L. }\end{array}$ & & - & 125.190 & - & 125.190 \\
\hline Francisco de Spinosa & 25 & 1.067 .145 & - & 1.067 .145 & - \\
\hline $\begin{array}{l}\text { Cuenta de Tratas fechas en } \\
\text { Pontarli, feria de Apparición }\end{array}$ & 57 & 5.837 .998 & & 5.837 .998 & - \\
\hline $\begin{array}{l}\text { Los Tutores de nuestro padre, } \\
\text { [quenta] aparte B.B. }\end{array}$ & 123 & - & 1.173 .033 & - & 1.173 .033 \\
\hline Miguel Zeno, de Venecia & 124 & - & 76.899 & - & 76.899 \\
\hline \multicolumn{2}{|c|}{ Suma de Balance ............ } & 25.947 .946 & 25.947 .946 & 25.920 .235 & 25.920 .235 \\
\hline Partimentos & $\begin{array}{l}44 y \\
45\end{array}$ & 528.631 & 7.559 .386 & - & 7.030 .755 \\
\hline \multicolumn{2}{|c|}{ Totales ............. } & 26.476 .577 & 33.507 .332 & 25.920 .235 & 32.950 .990 \\
\hline
\end{tabular}

De las rúbricas que reciben el título de "libros de Corte", la que se ha denominado el Libro de Corte del nuestro Domingo parece ser la cuenta de enlace de la contabilidad del cambio que nos ocupa con la propia de su colaborador o tal vez "criado" Domingo, del que existen indicios para sospechar que pertenezca a la familia Lercaro. Las otras dos cuentas de el Libro de Corte viejo y el Libro de Corte nuevo son sin duda las empleadas para enlazar los libros de cuentas de la feria de Medina del Campo -que serían su Libro de Ferias y al que corresponde el fragmento hallado- con los libros, "viejo" y "nuevo", de nuestro cambio, llevados en Valladolid, Burgos o incluso en Medina del Campo, para registrar los negocios distintos de las operaciones realizadas en ferias. 
Por lo que atañe al volumen de las operaciones recogidas en el fragmento de Manual, a continuación se detallan en orden decreciente las dieciséis cuentas que presentan movimiento superior al millón de maravedíes:

\begin{tabular}{|l|r|r|}
\hline \multirow{2}{*}{ Título de la cuenta } & \multicolumn{2}{c|}{ Movimiento } \\
\cline { 2 - 3 } & \multicolumn{1}{|c|}{ Deudor } & Acreedor \\
\hline Tratas fechas en Pontarli, feria de Apparición & 5.837 .998 & \\
\hline Nicolao Gentil, de Mesina [quenta] aparte R.M. & 8.160 & 4.909 .184 \\
\hline Anrricq Bul, canbio & 4.860 .080 & \\
\hline Juan Centuryón & 4.266 .693 & \\
\hline Julián de Marín & 2.163 .900 & \\
\hline Simón Lercaro, [quenta] corrente & & 2.163 .900 \\
\hline El libro de Corte nuevo & 2.057 .847 & \\
\hline Hétor Picamillo, de Nápoles & & 1.747 .500 \\
\hline El libro de Corte del nuestro Domingo & & 1.506 .611 \\
\hline Franco Lercaro & & 1.500 .000 \\
\hline Cibo e Spínola, de Cáliz, [quenta] corrente & 1.314 .079 \\
\hline Simón nuestro, [quenta] aparte & & 1.203 .199 \\
\hline Los Tutores de nuestro padre, [quenta] aparte B.B. & & 1.173 .033 \\
\hline Francisco de Spinosa & 1.067 .145 & \\
\hline Juan, Francisco y Antonio de Fornari, de Nápoles & & 1.065 .207 \\
\hline El libro de Corte viejo & & 1.011 .268 \\
\hline
\end{tabular}

\section{La nómina de personas citadas}

Además de todas las personas que tienen cuenta abierta, cuyo título en muchas ocasiones pone de manifiesto que no se trata de una persona aislada sino de varias de ellas asociadas en forma de compañía más o menos declarada, son numerosas las que se mencionan como corresponsales, dadores, garantes, librados, libradores, remitentes, tenedores, tomadores, etc.

Así, pues, para dar una idea completa de todas las que, de una $u$ otra forma, han intervenido en los cincuenta y dos asientos utilizables -cuarenta y nueve completos y tres inteligibles- se presenta en el Anexo II la nómina de personas mencionadas en ellos, enumeradas en todos los casos en forma individualizada, pero aclarando mediante la correspondiente nota cuándo actuaban de manera asociada, por lo que 
puede ocurrir que una persona figure más de una vez en la lista en el caso de que haya intervenido no sólo individualmente sino también en forma asociada en las operaciones registradas.

En resumen, aparece citado un pequeño grupo de banqueros castellanos de Burgos y Medina del Campo: Pedro de Angulo; y Alonso de Castro; Sevilla: Gerónimo y Juan de Herver; y Gregorio y Herederos de Alonso y Pedro de Spinosa [Espinosa]; y Valladolid y Medina del Campo: Anrricq Bul y comp ${ }^{\mathrm{a}}$ [Enrique Bull] ${ }^{25}$.

También figuran mencionados reiteradamente sus corresponsales genoveses así en Sevilla: Domingo, Juan y -en particularFranco y Simón Lercaro; y Lázaro Usodemar [Usodimare], como en Pontarlier: Juan Stevan y Juan Gerónimo Lercaro; Juan Francisco de Negro y compa ; y Spínola y Centuryoni [Centurione].

Destaca igualmente el número de mercaderes españoles -castellanos sobre todo- con los que resulta relacionado: en Arévalo, Gabriel Bury [Bori] ${ }^{26}$; en Barcelona, Francisco Pujaner [Puiggener]; y Juan Saurí; en Burgos, Martín de Arbieto; Alonso y Cristóbal Cerezo; y Antonio de Santa Cruz; en Herrera de Duero, Ortuño de Ybacax; y Juan de Medina; en Medina del Campo, Lope de Castro y Francisco Martínez de Lerma; y Simón Ruiz; en Sevilla, Juan Alonso de Medina ${ }^{27}$; Catalina Bravo y Diego de Aro [Haro]; Rodrigo de Brizuela; Diego de Bustamante; Alonso de Carrión; Gonzalo Díez; Gonzalo y Gaspar Jorge; Julián de Marín; Francisco de Scobar [Escobar]; Pedro de Tamayo; y Gerónimo de Valladolid ${ }^{28}$; y en Valladolid, Francisco Bravo.

Pero su relación con financieros, negociantes y hombres de negocios italianos es todavía mayor, especialmente con los genoveses y ya en menor grado con los florentinos y venecianos.

De los residentes o estantes en España, se pueden citar: en Barcelona, Pedro Ytaliano [Italián]; en Cádiz, Cibo y Spínola [Espínola]; en Córdoba, Stevan Spínola y Juan Batista de Marín; en Granada, Baltasar

\footnotetext{
25 Este cambio, que más tarde operó también en Toledo, era de ascendencia inglesa. de Salamanca.

26 Cliente de Simón Ruiz, e igualmente de los mercaderes burgaleses García y Miguel

27 Juan Alonso de Medina era marido de María Jorge de Segura, hija de Gonzalo Jorge.

28 Factor de Simón Ruiz en Sevilla, estaba al frente de la llamada "Compañía de Sevilla", formada por Francisco de la Presa, Simón y Vitores Ruiz.
} 
Doria; en Murcia, Alexandre Grasso [Grassi], en Sevilla, Ypólito, Gaetán y Jácome de Bardi; Juan Centuryón [Centurione]; Pablo, Justinián, Gerónimo y Stevan de Franquis [Franchi]; Conrado de Grimaldo [Grimaldi] y Galeazo de Negro; Jácome de Grimaldo; Nicolao de Grimaldo y comp ${ }^{a}$; Francisco Spínola e Hijos; y Lucas Spínola; en Valencia, Agustín Ynperial [Imperial] y comp $^{\text {a }}$ y en Valladolid, Evangelista Canobio; y Carlos y Juan Batista Marteli [Martelli].

Por lo que respecta a los residentes en el extranjero, cabe señalar: en Pontarlier, Juan María Bertori y compa; Stevan, Muzio y Felipe Bontalenti; Pero, Jusepe, Justinián y Francisco Coquella; Agustín Gentil [Gentile]; Batista, Nicolao y Francisco Ynperial [Imperial]; Juan Batista Lita [Litta]; Miguel Pinelo y Balián Fiesco [Fieschi]; y Benyto, Daniel, Juan Batista y Andrea Spínola; en Amberes, Juan Batista Spínola; en Génova, Benyto Centuryón [Centurione]; y Antonio Spínola; en Mesina, Nicolao Gentil; en Milán, Juan Paolo, Guido y Camilo Cusani; en Nápoles, Juan, Francisco y Antonio de Fornari; Juan Batista Montenegro; Jácome Panes y Pero Batista Ferrero; y Hétor Picamillo [Piccamiglio]; y en Venecia, Nicolao de Negrón, Andrea y Ludovico Centuryoni [Centurione]; y Miguel Zeno.

\section{EL CAMBIO}

La coincidencia, por una parte, de que el asiento número 27 de la transcripción hecha en el Anexo I del fragmento del Manual que nos ocupa pusiera de manifiesto que Simón Ruiz, el conocido mercader de Medina del Campo, se hacía cargo "por honor" de una letra que no había sido atendida a su vencimiento por su cliente y amigo Gabriel Bori ${ }^{29} \mathrm{y}$, por otra, la de que existan en el Archivo de Simón Ruiz -hoy conservado en el Archivo Histórico Provincial de Valladolid- sus libros de Ferias correspondientes a la feria de Octubre de 1564 de Medina del Campo, así

29 Según se desprende de la información que facilita en su trabajo María Valentina Cotta do Amaral (1965: 54-6), la familia Bori -Justo, Miguel y Gabriel- formaba parte de un grupo de pequeños mercaderes castellanos de la villa de Arévalo -que Amaral denomina "Revalo"-, conversos de origen morisco, que entre 1526 y 1528 obtuvieron autorización para entrar y salir por los "puertos de tierra" y comerciar en Portugal con la venta de las mercancías que traían consigo y la adquisición de otras en la Casa da India para su posterior venta en Castilla.

Miguel -aproximadamente hasta 1556- y Gabriel -durante más largo tiempofueron clientes de Simón Ruiz; Gabriel lo fue también de García y Miguel de Salamanca, como ya se ha señalado.

Por lo que se refiere a la grafía del apellido Bori, se muestra bastante variable en los diferentes documentos que conocemos, pues unas veces lo transcriben como Pori, Bori, Bory, Boril e incluso Buri o Bury, siendo esta última forma la que emplea nuestro desconocido cambio. 
como algunos otros libros de cuentas generales coetáneos, nos permitía abrigar la sospecha de que se pudiera llegar a identificar el cambio al que pertenecía el Manual del que nos ha llegado el fragmento en cuestión.

Por desgracia, ni en el Manual de Ferias $n^{\circ} 32$ (1564-1566) que se inicia con la feria de Octubre de 1564 ni en el Mayor de Ferias $n^{\circ}$ $58(1563-1566)$ que recoge -entre otras- las operaciones de dicha feria, y tampoco en el Mayor general $n^{\circ} 56$ (1559-1567) que cubre un período algo más amplio, se ha podido localizar el afianzamiento hecho por Simón Ruiz a favor de Gabriel Bori que se deduce del referido asiento 27 del fragmento de Manual, aunque sí aparezcan varias otras operaciones en las que interviene el referido Bori.

Lo que se ha encontrado, empero, es la contabilización con fecha 16 de Octubre de una letra tomada sobre Sevilla para fin de Diciembre sobre Gerónimo de Valladolid, el factor de Simón Ruiz en dicha ciudad, por importe de 751.500 mrs., que bien pudiera haber sido la que sirvió como prenda en la asunción por Simón Ruiz de la deuda de Gabriel Bori, dado que su importe es muy próximo al de $762.555 \mathrm{mrs}$. de la no atendida en su momento por este último.

Como era de suponer, el pago por honor de la letra sobre Gabriel Bori tampoco queda reflejado en las largas cuentas particulares de los dos cambios burgaleses con los que Simón Ruiz venía operando desde antiguo: Gaspar Sánchez y Pero López y Andrés de Cañas, y tampoco figura en la más breve cuenta de Enrique Bul, que aunque sí residía en Medina del Campo, no tiene nada que ver con el cambio que nos ocupa, lo mismo que los otros dos anteriormente citados.

En la escasa correspondencia mantenida entre Simón Ruiz y Gabriel Bori que se conserva en el Archivo de Simón Ruiz no hay igualmente mención alguna a esta operación.

Por otra parte, parece evidente que Pero López y Andrés de Cañas no tienen el padre común que dan a entender los asientos de la transcripción del fragmento de Manual números 19, 20, 26, 46 y 47, en todos los cuales aparece la cuenta de "los Tutores de 'nuestro' padre, aparte B.B.", que está incluida en el folio 123 del correspondiente Mayor de Ferias del cambio que nos ocupa.

Consiguientemente, de la falta de un asiento correlativo del que aparece en el fragmento de Manual cabría sospechar que una posible causa de que en los libros de cuentas de Simón Ruiz no se haya registrado tal operación fuera la de que el impago de la letra sobre Bori durase tan 
corto espacio de tiempo que no encontraran justificado proceder a su contabilización en los libros de dicho mercader-banquero.

Sin embargo, aunque carezca realmente de evidencia razonable para ello, pues me baso únicamente en la alusión al padre común en la cuenta que aparece en los asientos citados, tengo para mí que el desconocido cambio que nos ocupa bien pudiera ser el que actuaba en Medina del Campo en 1564 bajo la razón social de "Juan de Medina y Luis Alonso, cambios"30, integrada por Juan de Medina y su posible cuñado Luis Alonso, que serían hijo y yerno -hijo político-, respectivamente, del padre tutelado.

Como señala Henri Lapeyre (1955: 264-5), los Medina eran una familia de cambios o bancos de Medina del Campo de los que se tiene larga noticia desde 1531, en que ya figuraban como tales Bernabé y Antonio de Medina, que son continuados en 1535 por Antonio y Luis de Medina, los que a su vez fueron sucedidos en 1540 por Juan de Medina, al que en 1563 se une Luis Alonso, posiblemente su cuñado, y pasan a ser reemplazados en 1570 por Luis Alonso de Medina y Alonso Corral (Ruiz Martínez 1970: 39), de los cuales el primero podría ser hijo de Luis Alonso.

\section{CONCLUSIONES}

El hallazgo casual de un fragmento del libro Manual -dos pliegos referidos a la feria de Octubre de 1564- de un cambio o banco de Medina del Campo, cuya identidad no se deduce directamente del texto de los asientos, ha puesto de manifiesto la existencia de nuevas y originales fórmulas en la redacción de los asientos de Diario de la partida doble que al parecer se empleaban por cambios y bancos en la Castilla de mediados del siglo XVI, distintas de la hasta ahora conocida por los libros de cuentas conservados de mercaderes castellanos y que a su vez había sido, en líneas generales, la divulgada por Bartolomé Salvador de Solórzano en su tratado de 1590.

La utilizada para los asientos simples en el fragmento de Manual, aunque ligeramente diferente de la que nos era conocida, no se aleja en exceso de dicho formato.

30 Simón Ruiz no solía operar con Juan de Medina y Luis Alonso, cambios, pero incidentalmente en 1565 realizó con ellos el día 12 de Abril una operación de 117.300 mrs.. 
Pero junto con ella se nos muestra lo que podría ser la primicia de los incipientes tanteos en la búsqueda de un nuevo tipo de asiento: el compuesto o complejo, más eficaz en ciertos casos que los simples, por refundir en uno solo varios de éstos, como es el caso que se presenta en el referido Manual cuando se trata de registrar una "letra compartida" por varias personas -ya sea en calidad de dadores o, por el contrario, de tomadores a cambio-, pues permite reflejar la operación con mayor fidelidad, a la par que se consigue un apreciable ahorro de escritura y, por ende, de papel y de tiempo.

Por desgracia no se ha llegado a dar el paso definitivo en el empleo de este tipo de asientos y han quedado exclusivamente reducidos a la contabilización de las letras compartidas. Sin embargo, en esta búsqueda de soluciones nuevas se ha conculcado en principio la esencia de la partida doble -tal vez sin advertirlo porque no se tuviera conciencia de su existencia-, aunque pese a ello resulte muy sencillo recuperar virtualmente la ortodoxia del método.

En las cuentas al igual que en el texto del cuerpo de los asientos registrados en el fragmento de Manual, figura una amplia nómina de bancos y mercaderes nacionales y de corresponsales genoveses en Sevilla y en la feria de Besanzón -que en 1564 se celebraba en la localidad de Pontarlier según se desprende del texto de los asientos-, así como de hombres de negocios genoveses -y algún que otro florentino o veneciano-, residentes tanto en España como en el extranjero, lo que parece evidenciar que su propietario era un cambio bien relacionado con la actividad financiera de los genoveses en España.

$\mathrm{Ha}$ de señalarse incidentalmente que los pertinentes asientos contenidos en este fragmento de Manual aclaran el auténtico significado -mayor aprecio de la moneda metálica que de la escritural- y la manera de recoger en cuentas la fórmula del pago por cambios y bancos en "dinero de banco" de las letras giradas sobre ferias castellanas "con tanto al millar", modalidad contractual tan denostada por los moralistas del siglo XVI, que no llegaron a entender su fundamento.

Por último, en cuanto atañe a la identidad del cambio que actuaba en Medina del Campo y al que está referido el libro Manual del que casualmente hemos podido conocer el fragmento que nos ocupa, pese a darse la feliz coincidencia de que en uno de sus asientos aparece citado Simón Ruiz -el conocido mercader-banquero de Medina del Campo- como afianzador de otro mercader castellano cliente y amigo suyo -Gabriel Bori-, y de que a su vez se conservan los libros de Ferias de los Ruiz 
comprensivos de la feria de Octubre de Medina del Campo de 1564, no se ha podido determinar su nombre o razón social.

Sin embargo, personalmente pienso que pudiera tratarse del cambio que actuaba en Medina del Campo bajo la razón social de Juan de Medina y Luis Alonso, cambios, integrada por Juan de Medina -descendiente de una antigua familia de banqueros medinenses- y su posible cuñado Luis Alonso.

\title{
REFERENCIAS
}

\author{
Archivo de Simón Ruiz \\ Manual de Ferias $\mathrm{n}^{\circ} 31$ (18.03.1563-03.12.1564) \\ Manual de Ferias $n^{\circ} 32(12.11 .1564-12.03 .1566)$ \\ Mayor de Ferias $n^{\circ} 55$ (1559-1567) \\ Mayor de Ferias $n^{\circ} 58(1563-1564)$ \\ Índice de Ferias $n^{\circ} 80$ (1559-1567) \\ Índice de Ferias $\mathrm{n}^{\circ} 84$ (1563-1564) \\ Mayor general $n^{\circ} 56(1560-1567)$ \\ Índice general $n^{\circ} 82(1560-1573)$
}

\section{BIBLIOGRAFÍA}

Actas del Primer Coloquio Internacional de Historia Económica, 21-23 de marzo de 1977 (1978) Alfonso OTAZU (ed.) Madrid: Moneda y Crédito.

Actas del Primer Congreso sobre Archivos Económicos de Entidades Privadas, 3-4 junio 1982 (1983). Madrid: Archivo Histórico del Banco de España.

Actas del Segundo Congreso sobre Archivos Económicos de Entidades Privadas, 26-27 de junio 1986 (1986). Madrid: Archivo Histórico del Banco de España.

AgUILERA-BARChet, Bruno (1989) Historia de la letra de cambio en España (Seis siglos de práctica trayecticia). Madrid: Tecnos [reimpresión de la edición de 1988].

ALBORNOZ, Bartolomé Frías de (1573) Arte de los Contractos. Valencia: Pedro de Huete. 
AMARAL, Maria Valentina Cotta do (1965) Privilégios de mercadores estrangeiros no reinado de D. Joāo III. Lisboa: Instituto de Alta Cultura.

ARCHIVO HISTÓRICO PROVINCIAL DE VALLADOLID (2008) Inventario del Archivo de Simón Ruiz. Valladolid: Junta de Castilla y León.

ARGOTE DE MOLINA, Gonçalo (1588) Nobleza del Andaluzia. Sevilla: Fernando Díaz.

BANCO DE ESPAÑA (1987) Una historia económica. Madrid: Banco de España.

BASAS FERNÁNDEZ, Manuel (1964) "Banqueros burgaleses del siglo XVI", Boletín de la Institución Fernán González, 163 ( $2^{\circ}$ semestre), pp. 314-332.

- (1968) "Burgos, plaza de cambios en el siglo XVI", Hispania, 110, Septiembre-Diciembre, pp. 564-593.

BENASSI, Umberto (1915) "Per la storia delle Fiere dei Cambi", Bolletino Storico Piacentino", X, Enero-Febrero, pp. 5-15 y 62-71.

BENNASAR, Bartolomé (1970) "Marchands flamands et italiens à Valladolid au XVI ${ }^{\mathrm{e}}$ siècle", Fremde Kaufleute auf der iberischen Halbinsel. Köln: Böhlau-Verlag, pp. 48-55.

- (1983) Valladolid en el Siglo de Oro. Una ciudad de Castilla y su entorno agrario en el siglo XVI. Valladolid: Fundación Municipal de Cultura.

BERGIER, Jean-François (1963) Genève et l'économie européenne de la Renaissance. Paris: SEVPEN.

BRAUDEL, Fernand (1976) El Mediterráneo y el mundo mediterráneo en la época de Felipe II. Madrid: Fondo de Cultura Económica [ $2^{\mathrm{a}}$ ed.].

CABESTANY FoRT, Juan-F. (1964) "Nómina de la "Matrícula de Mercaders" de Barcelona (1479-1696)", Documentos y Estudios, XIII, Julio, pp. 167-183.

Cantos BeníteZ, Pedro de (1763) Escrutinio de Maravedises, y Monedas de Oro antiguas, su valor, reduccion y cambio a las Monedas corrientes. Deducido de Escrituras, Leyes y Pragmaticas antiguas, y modernas de España. Madrid: Antonio Marín.

CARANDE THOVAR, Ramón (1965) Carlos $V$ y sus banqueros. La vida económica en Castilla (1516-1556), 3 tomos. Madrid: Sociedad de Estudios y Publicaciones, Tomo I [ $2^{\mathrm{a}}$ ed.].

CHACÓN JIMÉNEZ, Francisco (1979) Murcia en la centuria del quinientos. Universidad de Murcia: Academia Alfonso X el Sabio.

Colmeiro y Penido, Manuel (1965) Historia de la Economía Política en España, 2 vols. Madrid: Taurus [reedición de la única edición de 1863, con nota preliminar y bibliografía por Gonzalo Anes]. 
COROMINAS, Joan en colaboración con José A. Pascual (1980-81) Diccionario crítico etimológico castellano e hispánico, 6 vols. Madrid: Editorial Gredos.

CotTA do AmARAL, Maria Valentina. Véase AMARAL, María Valentina Cotta do

COVARRUBIAS OROzCo, Sebastián de (1977) Tesoro de la Lengua Castellana o Española. Madrid: Ediciones Turner [reproducción de la edición de Madrid de 1611].

DA SILVA, José-Gentil. Véase Romano, Ruggiero y José-Gentil DA SILVA

Dalle MOLLe, Luciano. Véase Molle, Luciano Dalle

De RoOVer, Raymond. Véase ROOVER, Raymond de

DOMíNGUEZ VICENTE, Joseph Manuel (1732) Discursos Juridicos, sobre las aceptaciones, pagas, intereses, y demas requisitos, y qualidades de las letras de cambio. Dividido en tres Libros. Madrid: Herederos de Juan García Infanzón.

EDLER, Florence (1934) Glossary of Mediaeval Terms of Business. Cambridge Mass.: The Mediaeval Academy of America.

EHRENBERG, Richard (1922) Das Zeitalter der Fugger. Geldkapital und Creditverkehr im 16. Jahrhundert, 2 vols. Jena: Gustav Fischer.

- (1955) Le siècle des Fugger. París: SEVPEN [traducción francesa abreviada].

ESPEJO, Cristóbal y Julián PAZ. Véase PAZ, Julián y Cristóbal ESPEJO.

FANFANI, Amintore (1968) Storia Economica. Torino: Unione TipograficeEditrice Torinese [ $3^{\mathrm{a}}$ ed.].

FITA, Fidel (1968) "Historiadores é historias de Medina del Campo", Boletín de la Real Academia. de la Historia, t. 45, cuaderno 6, Diciembre, pp. 510-530.

- (1905) "Tres historiadores de Medina del Campo. Ilustraciones biográficas y bibliográficas", Boletín de la Real Academia de la Historia, t. 46, cuaderno 3, Marzo, pp. 238-258.

FragA, Pedro Puy (coord.) (1991) Estudios en Homenaje al Profesor Carlos G. Otero Díaz. Universidade de Santiago de Compostela.

Fremde Kaufleute auf der iberischen Halbinsel (1970) Hermann KELLENBENZ (coord.) Köln: Böhlau-Verlag.

FRÍAS DE ALBORNOZ, Bartolomé. Véase ALBORNOZ, Bartolomé Frías de 
GASCON, Richard (1971) Grand commerce et vie urbaine au XVl siècle. Lyon et ses marchands (environs de 1520-environs de 1580), 2 vols. Paris et La Haye: Mouton.

GILI GAYA, Samuel (1960) Tesoro lexicográfico (1492-1726). Madrid: CSIC.

GIOFFRÉ, Domenico (1960) Gênes et les foires de change de Lyon à Besançon. Paris: SEVPEN.

GonZÁlez FerRANDO, José Ma (1983) "Los libros de cuentas de la familia Ruiz, mercaderes-banqueros de Medina del Campo (1551-1606)", Actas del Primer Congreso sobre Archivos Económicos de Entidades Privadas, 3-4 junio 1982, pp. 23-45.

- (1991) "Bartolomé Salvador de Solórzano, adelantado de la 'contabilidad aplicada' en España", Revista Española de Financiación y Contabilidad, XX, 68, Julio-Septiembre, pp. 713-755.

- (1993a) Negociación de Cambios y Asientos. Un opúsculo de autor anónimo sobre asientos, cambios y contabilidad por partida doble, de finales del primer tercio del siglo XVII, Prólogo de Esteban Hernández Esteve. Madrid: Instituto de Contabilidad y Auditoría de Cuentas.

- (1993b) "Los numerales en los libros de cuentas y documentos españoles de los siglos XII al XVIII", Técnica Contable, 45, 531, pp. 233-238.

- (2010) Los libros de cuentas (1545-1574) de la familia Salamanca, mercaderes e hidalgos burgaleses del siglo XVI. Burgos: Diputación Provincial de Burgos.

GORIS, Jean-Albert (1967) Étude sur les Colonies Marchandes Méridionales (Portugais, Espagnols, Italiens) à Anvers de 1488 à 1567. Contribution à l'histoire des débuts du capitalisme. Louvain: Librairie Universitaire [reproducción fotográfica de la edición de 1925].

HEERS, Jacques (1979) Société et économie à Gênes (XIVe-XVe siècles). London: Variorum Reprints.

HERNÁNDEZ ESTEVE, Esteban (1986) "Aportaciones al estudio de la banca castellana en el siglo XVI", Actas del Segundo Congreso sobre Archivos Económicos de Entidades Privadas, 26-27 de junio 1986, pp. 15-42.

- (1989) "Apuntes para una historia de la Contabilidad Bancaria en España", Revista Española de Financiación y Contabilidad, XVIII, 58, Enero-Marzo, pp. 21-96.

- (1991) "La banca en el alba de los tiempos modernos. Modelos bancarios en Castilla y Aragón en la España de los siglos XV y XVI", Estudios en Homenaje al Profesor Carlos G. Otero Díaz, pp. 45-115; Universidade de Santiago de Compostela. 
HEVIA Y BOLAÑOS, Juan de $(1617,1619,1619)$ Labyrinto de Comercio Terrestre y Naval donde breve y compendiosamente trata de la Mercancia y Contratacion de tierra y mar. Lima: Francisco del Canto [ $1^{\text {a }}$ ed.];

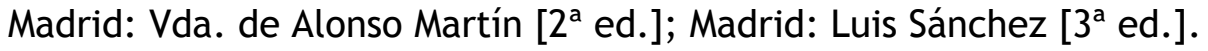

KeLLENBENZ, Hermann (1959) "Karl V. und die Messen in Lyon", Gesammelte aufsätze zur Kulturgeschichte Spaniens. Münster: Ascendorffsche Verlag, tomo 14, pp. 194-202.

- (1970) "Die fremde Kaufleute auf der iberischen Halbinsel vom 15. Jahrhundert bis zum Ende des 16. Jahrhunderts", Fremde Kaufleute auf der iberischen Halbinsel. Köln: Böhlau-Verlag, pp. 265-376.

LAPEYRE, Henri (1953) Simón Ruiz et les Asientos de Philippe II. Paris: SEVPEN.

- (1955) Une Famille de Marchands: les Ruiz. Contribution à l'étude du commerce entre la France et l'Espagne au temps de Philippe II. Paris: SEVPEN.

- (1956) "La banque, les changes et le crédit au XVI siècle", Revue d'histoire moderne et contemporaine, III, Octobre-Novembre, pp. 284297.

- (1961) "Banque et crédit en Italie du XVI ${ }^{\mathrm{e}}$ au XVIII ${ }^{\mathrm{e}}$ siècle", Revue d'histoire moderne et contemporaine, VIII, Juillet-Septembre, pp. 211226.

- (1970) "Les marchands étrangers dans le royaume de Valence aux XV et $\mathrm{XVI}$ siècles", Fremde Kaufleute auf der iberischen Halbinsel. Köln: Böhlau-Verlag, pp. 100-117.

- (1981) El comercio exterior de Castilla a través de las aduanas de Felipe II. Universidad de Valladolid.

- (1982) La Taula de Cambis (En la vida económica de Valencia a mediados del reinado de Felipe II). Valencia: Del Cenia al Segura.

LÓPEZ DE COCA Y CASTAÑER, José Enrique y María Teresa LóPEZ BELTRÁN (1980) "Mercaderes genoveses en Málaga (1487-1516). Los hermanos Centurión e Ytalián", Historia. Instituciones. Documentos, Año 7², pp. 95-153.

LÓPEZ OSSORIO, Juan (1614-1616) Ystoria titulada principio, grandeza y caida de la novle villa de Medina del Campo, fundaçion y nonvre que a tenido hasta el tiempo presente, por Juan Lopez Ossorio, vezino della, manuscrito. Transcrito en Ildefonso RODRíGUEZ Y FERNÁNDEZ, Historia de Medina del Campo. Madrid: Imprenta de San Francisco de Sales, pp. 5342. 
LORENZO SANZ, Eufemio (1979) Comercio de España con América en la época de Felipe II, 2 vols. Diputación Provincial de Valladolid: Servicio de Publicaciones.

- (coord.) (1986) Historia de Medina del Campo y su tierra, 3 vols. Valladolid: Ayuntamiento de Medina del Campo et al. (vol. II).

MADDALENA, Aldo (1967) "Affaires et gens d'affaires lombards sur les foires de Bisenzone: L'exemple des Lucini (1579-1619)", Annales (ESC), 22, Septembre-Octobre, pp. 939-990.

MARTín LAMOUROUX, Fernando (1988) "El libro Mayor del banquero de Corte Ochoa Pérez de Salinas (1498-1500)", Revista Española de Financiación y Contabilidad, XVII, 56, Mayo-Agosto, pp. 297-334.

MELIS, Federigo (1976) Mercaderes italianos en España, Siglos XIV-XVI. (Investigaciones sobre su correspondencia y su contabilidad). Prólogo de Felipe Ruiz Martín. Universidad de Sevilla.

MerCado, Tomás de (1571 [1977]). Suma de Tratos y Contratos. Sevilla: Hernando Díaz. Reedición facsimilar a cargo de Nicolás Sánchez Albornoz ( $2^{\mathrm{a}}$ ed). Madrid: Instituto de Estudios Fiscales.

MOLLE, Luciano Dalle (1954) Il contrato di Cambio nei Moralisti dal secolo XII alla metà del secolo XVII. Roma: Edizione di Storia e Litteratura.

MORAleja PinIlla, Gerardo (1971) Historia de Medina del Campo. Medina del Campo: Manuel Mateo Fernández.

OtAZU, Alfonso (ed.) (1978) Dinero y Crédito (Siglos XVI al XIX). Primer Coloquio Internacional de Historia Económica, 21-23 de marzo de 1977. Madrid: Moneda y Crédito.

OTTE, Enrique (1978) "Sevilla, plaza bancaria europea en el siglo XVI". Alfonso OTAZU (ed.) Dinero y Crédito (Siglos XVI al XIX). Primer Coloquio Internacional de Historia Económica, 21-23 de marzo de 1977. Madrid: Moneda y Crédito, pp. 89-112.

PAZ, Julián y Cristóbal ESPEJO (1908-1912) Las antiguas ferias de Medina del Campo. Valladolid: Imprenta la Nueva Pincia y Tipografía del Colegio de Santiago.

PhoOnsen, Johannes (1715) Les Loix et les Coutumes du Change des Principales Places de l'Europe. Livre contenant, non seulement ce qu'on fait ordinairement, mais ce qu'un habile Marchand doit observer, dans les difficultez qui se presentent sur toutes sortes de Lettres de Change: \& traduit du Hollandois de Mons. J. Phoonsen, par Jean Pierre Ricard. Amsterdam: Estienne Roger.

PIKE, Ruth (1966) Enterprise and Adventure. The Genoese in Seville and the Opening of the New World. Ithaca, N.Y.: Cornell University Press. 
- (1978) Aristócratas y Comerciantes. La sociedad sevillana en el siglo XVI. Esplugues de Llobregat, Barcelona: Ariel.

PULIDO BUENO, Ildefonso (2004) La familia genovesa Centurión (mercaderes, diplomáticos y hombres de armas), al servicio de España, 1380-1680. Huelva: El Autor.

Relacion de la antigüedad y sitio de Medina del campo y sus ferias, y de la contratación de ellas, y del estado que tienen hasta hoy 18 de octubre de 1606 (1850) Colección de Documentos Inéditos para la Historia de España, por Miguel Salvá y Pedro Sainz de Baranda. Madrid: Viuda de Calero, tomo XVII, pp. 541-572.

RePRESA, Armando y Felipe RUIz MARTín (1980) Libro Mayor del 'Banquero de Corte' de los Reyes Católicos Ochoa Pérez de Samaniego. Madrid: Banco de Bilbao.

RODRíGUEZ y FERNÁNDEZ, Ildefonso (1903-1904) Historia de la muy Noble, muy Leal y Coronada villa de Medina del Campo, conforme à varios documentos y notas à ella pertinentes. Madrid: Imprenta de San Francisco de Sales.

RodRíGUEZ GonZÁLEZ, Ricardo (1995) Mercaderes castellanos del Siglo de Oro. Universidad de Valladolid.

Romano, Ruggiero y José Gentil Da SILVA (1962) "Histoire des Changes: les foires de 'Bisenzone' 1600 à 1650", Annales (ESC), 17, Julliet-Août, 4, pp. 715-721.

ROOVER, Raymond De (1946-47) "Le contrat de change depuis la fin du XIII siècle jusqu'au début du XVII" 25, 1-2, pp. 111-122.

- (1953a) "Anvers comme marché monétaire au XVI siècle", Revue Belge de Philologie et d'Histoire, 31, 4, pp. 1003-1047.

- (1953b) L'Évolution de la Lettre de Change, XIVe-XVIII siècles. Paris: SEVPEN.

RUIZ MARTíN, Felipe (1965) Lettres marchandes échangées entre Florence et Medina del Campo. Paris: SEVPEN.

- (1970a) "La Banca en España hasta 1782", El Banco de España, una Historia Económica. Madrid: Banco de España, pp. 1-196.

- (1970b) "Los hombres de negocios genoveses en España durante el siglo XVI", Fremde Kaufleute auf der iberischen Halbinsel. Köln: BöhlauVerlag, pp. 84-99.

- (1975) "Joan y Pau Saurí: negociantes catalanes que intervienen en las empresas imperiales de Felipe II", Homenaje al Dr. D. Juan Reglà 
Campistol, 2 tomos. Universidad de Valencia: Facultad de Filosofía y Letras, tomo I, pp. 457-477.

- (1990) Pequeño capitalismo, gran capitalismo. Simón Ruiz y sus negocios en Florencia. Barcelona: Crítica [versión original en lengua española del estudio introductorio a Felipe RUIZ MARTíN (1965) Lettres marchandes échangées entre Florence et Medina del Campo. Paris: SEVPEN].

SALÓN, Miguel Bartolomé (1591-1598) Commentarium in disputationem de lustitia, quam habet $D$. Thomas, secunda Sectione secundae Partis suae Summae Theologicae ... Et in omnibus universorum hominum contactibus, \& commercijs copiose explicatur, 2 T. Valentiae: Gabriel Ribes, Tomus Primus; Valentiae: Aluarum Francum, Tomus Secundus.

SALVADOR DE SOlóRzano, Bartolomé de (1590 [1990]) Libro de Caxa y Manual de cuentas de Mercaderes, y otras personas, con la declaracion dellos. Madrid: Pedro Madrigal; Madrid: ICAC [reproducción facsimilar con Prólogo de Esteban Hernández Esteve].

SARAVIA DE LA CALLE, Fernando (1544 [1999]) Instrucion de Mercaderes. Medina del Campo: Pedro de Castro [ $1^{\mathrm{a}}$ ed.]. Madrid: Joyas Bibliográficas, 1949 [reedición].

SOLNON, Jean-Jacques (1983) Quand la Franche-Compté était espagnole. Paris: Fayard.

TENENTI, Alberto (1978) "Las rentas de los genoveses en España a comienzos del siglo XVII". Alfonso OTAZU (ed.) Dinero y Crédito (Siglos XVI al XIX). Primer Coloquio Internacional de Historia Económica, 21-23 de marzo de 1977. Madrid: Moneda y Crédito, pp. 207-219.

UlLOA, Modesto (1977) La Hacienda Real de Castilla en el reinado de Felipe II. Madrid: Fundación Universitaria Española.

URQUIJO URQUIJO, María Jesús (1994) Archivo Histórico Provincial y Universitario de Valladolid: Guía del investigador. Universidad de Valladolid.

VÁZQUEZ DE PRADA, Valentín (1960) Lettres marchandes d'Anvers, 4 tomos. Paris: SEVPEN, tomo I.

VIGO GUTIÉRREZ, Abelardo del (1997) Cambistas, mercaderes y banqueros en el Siglo de Oro Español. Madrid: Biblioteca de Autores Cristianos (BAC).

VILLALón, Cristóbal (1546 [1945]) Provechoso tratado de cambios, y contrataciones de mercaderes, y reprobacion de usura. Valladolid: Francisco Fernández de Córdova [ $3^{\mathrm{a}}$ ed]. Valladolid: Imprenta Castellana [reproducción facsimilar]. 


\section{GLOSARIO}

Alcance. Cantidad de la que alguien resultaba deudor en una rendición de cuentas. Saldo que se ha de pagar. Resto. Sobrante.

Alcanzar. Resultar alguien deudor en una rendición de cuentas. Sobrar.

Al millar. Fórmula empleada para cuantificar el rendimiento de una inversión en censos, juros y toda clase de activos financieros, mediante la indicación del capital necesario - $k$-, expresado en miles de maravedíes, para producir una renta anual de 1.000 mrs. -un millar-, lo que abreviadamente se representaba por "k U al millar"; así, $15 \mathrm{U}$ al millar -15.000 al millar- equivaldría a nuestro $6,667 \%$ o, expresado fraccionariamente, $62 / 3 \%$. Con tanto al millar. Millar.

Alzado. Persona que ha quebrado maliciosamente. Ausentado. Falido.

Alzarse. Quebrar intencionadamente, ocultando o enajenando los bienes, para no pagar a los acreedores. Ausentarse. Falir.

Apuntar partidas. Hacer alguna señal, marca o contraseña en el "calderón numeral" de las partidas del libro Mayor o libro de Caxa para indicar que habían sido comprobadas y encontradas conformes. Referir y Apuntar.

Apunte. Asiento contable.

Armar una cuenta. Abrir una cuenta de Mayor.

Arraigadura. Acción y efecto de arraigar.

Arraigar. Prestar garantía. Afianzar la responsabilidad a resultas de un juicio.

Asentar. Anotar o registrar una operación o una partida en los libros de cuentas. Pasar partidas.

Asiento [contable]. Anotación de una operación o de una partida en un registro o libro de cuentas. Apunte. Asiento complejo. Asiento simple. Partida. Partido. Pasar partidas.

Asiento complejo. Apunte contable del Manual en el que figuran varias cuentas deudoras y una acreedora o, recíprocamente, varias acreedoras y una deudora. Asiento compuesto. Asiento simple. Partimentos.

Asiento compuesto. Asiento complejo.

Asiento simple. Apunte contable del Manual en el que sólo interviene una cuenta de cargo y otra de abono. Asiento complejo. Asiento compuesto.

Atrancar ferias. Saltar ferias. Cambiar para una feria más alejada en el tiempo que la primera. Primera feria. Trascabalgar ferias.

Ausentado. El que ha incurrido en impagos por falta de liquidez o de patrimonio. Quebrado. Alzado. Falido. 
Ausentarse. Dejar impagadas deudas por falta de liquidez o de patrimonio. Quebrar. Alzarse. Falir.

Banco. Banquero. Cambiador. Cambista. Cambio.

Beneficiario del cambio. Persona que, por cuenta del dador a cambio, había de recibir del pagador del cambio el valor de la letra de cambio. Cobrador del cambio.

Buena dita. Crédito mercantil. Solvencia. Dita.

Buena por. Abono de una partida. Hacer bueno. Vale por. Vuena por.

Calderón, Calderón numeral. Signo - $U$ - con que se denotaban abreviadamente los millares. Millar.

Cambio, Canbio, Canvio. 1. Cambiador. Cambista. Banquero. Banco. Canvio. 2. Trueque o permuta de una moneda por otra. Expresión del valor que por una unidad o número dado de unidades monetarias de una plaza se entrega o recibe en otra, en moneda de esta última; con mayor precisión se denomina también curso, precio o tipo del cambio. Conto. Cuento. 3. Letra de cambio.

Cambio atrancado. Letra librada sobre feria posterior a la primera. Atrancar ferias. Primera feria. Trascabalgar ferias.

Cambio ficticio. Cambio seco en el que se prescindía del envío de la letra inicial para su protesto, creando desde el primer momento la de recambio con el precio del cambio de éste adecuadamente prefijado, como forma de encubrir un préstamo a cinco o seis meses de plazo. Cambio seco.

Cambio por letras. Cambio real.

Cambio de más suma. Letra de más suma.

Cambio mercantil. Cambio real.

Cambio nundinal. Cambio real que se hacía entre dos ferias de país distinto o entre una plaza y una feria de otro país, y viceversa. Cambio real.

Cambio de plaza a plaza. Cambio real.

Cambio real. Trueque o permuta de una moneda presente por otra ausente, con superposición de una operación de crédito a corto plazo a otra de transferencia de fondos entre dos plazas o lugares extranjeros, realizada librando letras de cambio de vencimiento generalmente no superior a los noventa días; se llamaba también cambio por letras, mercantil, de plaza a plaza y trayecticio, así como nundinal cuando intervenía alguna feria. Recambio.

Cambio seco. Cambio por letras efectuado sin el propósito de pagarlo a su vencimiento, con objeto de que se protestara la letra inicial para que se librase una letra de recambio sobre la plaza originaria, obteniendo 
así, de hecho, un préstamo por un plazo del orden de seis meses. Cambio ficticio.

Cambio trayecticio. Cambio real.

Caxero. Tenedor de libros. Contable. Manualero.

Cédula de cambio. Letra de cambio.

Cerrar los libros. Saldar las cuentas del Mayor para cerrarlas y dar por concluidas las negociaciones de la feria, abriéndolas a continuación con los saldos restantes, en el mismo Mayor o en su caso en otro, para registrar las operaciones de la siguiente feria.

Cobrador del cambio. Persona que, por cuenta del dador a cambio, recibía del pagador del cambio el valor de la letra de cambio. Beneficiario del cambio.

Con tanto al millar. Tanto por mil -\%o-, que abreviadamente se expresaba por "al Ur" o, más brevemente, "al U", y que en la expresión "con $i$ al millar" daba a entender que incluía su valor nominal multiplicado por $(1,00 i)$. Al millar. Contado. Fuera de banco. Millar. Precio del contado. Premio del dinero de banco.

Conferir. Cotejar y comparar la cuenta llevada por un cambio o banco a un tercero con la cuenta recíproca abierta por éste a dicho cambio o banco, para ver si estaban conformes. Conciliar.

Contado. 1. Al contado. Dinero en metálico; normalmente en reales. De Contado. Fuera de banco. 2. Típica operación castellana de préstamo a corto plazo, consistente en la entrega de una cantidad de dinero en metálico -reales generalmente-, la cual se había de devolver en efectivo, como máximo tres meses más tarde -o en una feria próxima-, en la misma o distinta plaza del Reino de Castilla, pero incrementada en el interés o precio del contado -también denominado simplemente contado-, que se expresaba en tanto por mil y que para un período de tres meses, en condiciones normales de mercado, solía oscilar entre el 5 y el $25 \%$ o al millar -en la notación del siglo XVI, entre el 5 y el 25 al Ur-; es decir, del orden de un 2 a un $10 \%$ de interés anual nominal. Con tanto al millar. Precio del contado.

Contador. 1. Mesa de madera, habitualmente cubierta con un paño de color verde, que bancos, cambios y mercaderes empleaban en las ferias u oficinas para contar el dinero. 2. Especie de armario o escritorio para guardar los libros de cuentas, los justificantes y la correspondencia. 3. Sala, habitación u oficina en la que se llevaba la "cuenta y razón" de los cambios, bancos y mercaderes.

Contar. Pagar al contado por un cambio o banco el saldo a favor de un cliente. Reducir dinero de banco. 
Contar consigo [letra]. Contar consigo mismo, hacer una remesa con letras de cambio en su propio nombre. Valerse sobre.

Continuar los cambios. Prolongación de los cambios a su vencimiento librando sucesivas letras de cambio cuyo valor se iba incrementando por acumulación del daño producido en cada uno de los subsiguientes recambios. Correr los cambios.

Conto. Curso oficial del cambio de una feria. Cambio. Cuento.

Contravalor de la letra de cambio. Importe de la letra de cambio expresado en moneda de la plaza de cambio en la que se libra, resultado de aplicar al valor de la letra el tipo de cambio señalado en la misma. Valor de la letra de cambio.

Corredor [de cambios]. El que gestionaba la solicitación y libranza de letras de cambio para otras plazas. Corretaje.

Correr los cambios. Negociar de manera continuada los cambios, prolongándolos mediante sucesivos recambios, tornándolos y volviéndolos. Cambios corridos. Continuar los cambios. Prolongar los cambios. Recambio. Traer a cambio.

Correspondiente. Corresponsal.

Corretaje. Comisión que percibían los corredores de cambios por su actuación.

Creedor. Acreedor.

Criado. Empleado que vivía y comía en casa de su patrono; se aplicaba por igual a los empleados en el negocio que a la servidumbre familiar.

Cuenta castellana. Numeración romana peculiar, cuasi posicional, propia de algunos reinos hispanos y muy extendida entre los siglos XIV al XVII en los documentos contables y financieros castellanos, con empleo generalmente de letras cursivas minúsculas y utilización de dos signos especiales denominados millar - $\mathrm{U}$ - y quento $-\mathrm{q}^{\circ}$ - para expresar los millares y los millones, respectivamente, y en la que se usaba de manera muy limitada la regla de la sustracción, pues sólo se empleaba para la formación de 9 -ix-, $40-x l$ o xL-, y $90-x C^{-}$, pero no para la de 4 -iiij-, o 400 -cccc- ni para la de 900 -dcccc o Dcccc-. Con objeto de facilitar la lectura de los números en que aparecen trabadas varias $i, x$ o $c$, se colocaba una pequeña ${ }^{\circ}$ volada sobre la letra final de $4-i i i j^{\circ}$; de 8 -viij ${ }^{\circ}$; de $80-l x x x^{\circ}$ o $L x x x^{\circ}$; de $400-$ cccc $^{\circ}$, y de $800-d c c c^{\circ}$ o $D c c c^{\circ}$, de manera que con sólo verla ya se podía reconocer el número de que se trataba, sin tener que recontar los puntos de enlace. Para que 900 no se confundiera con 800 , en lugar de una o se ponía una e sobre la última c: $d c c c c^{e}$ o $D c c c c{ }^{e}$. La ausencia de cifra, o cero, se representaba con un punto o una raya; y la fracción medio, con el símbolo $\underline{o}$ con la 
letra $\underline{s}$-semi-. Cuenta guarisma. Cuenta llana. Letras castellanas. Millar. Números castellanos. Quento.

Cuenta guarisma. Numeración arábiga resultante de la evolución de la cuenta castellana al ir sustituyendo las letras numerales por cifras o "guarismos", que en el comienzo de su utilización en documentos contables y financieros conservaba todavía los signos de millar y cuento propios de la cuenta castellana, aunque hacía intervenir ya el cero. Poco a poco se fue prescindiendo del cuento, que se sustituyó por un punto, pero el uso del calderón perduró largo tiempo, sobre todo en las cuentas públicas, hasta que se acabó reemplazando también por el punto. Cuenta castellana. Millar. Quento.

Cuenta llana. Denominación usual de la cuenta castellana en el Reino de Aragón.

Cuenta y razón. Llevanza de los libros de cuentas. Teneduría de libros. Contabilidad.

Cuento. Millón. Quento.

Cuento. Precio oficial del cambio de una feria. Cambio. Conto.

Cumplimiento [letra]. Pago de una letra de cambio.

Cumplir: Vencer. Pagar. Liquidar.

Dador a cambio. Persona que facilitaba al tomador a cambio el contravalor de la letra de cambio. Tomador a cambio.

Dar a cambio. Facilitar el contravalor de una letra de cambio al tomador a cambio, bien como anticipo de dinero o por compra de la misma para pagar una deuda o disponer de fondos en una plaza extranjera. Dinero remitido. Sacar a cambio.

Declarar. Explicar, desvelar lo que está oculto o ignorado.

De contado. Al contado. Contado. Fuera de banco.

Del credere. Estar del creer. Estar por las ditas.

Depósito. Operación de préstamo a corto plazo practicada en Castilla en forma de cambio local de feria a feria sobre la misma plaza, utilizada corrientemente, por una parte, como instrumento de colocación de fondos por mercaderes, bancos, cambios e incluso particulares y asimismo, por otra, como medio de obtención de fondos por los propios mercaderes.

Deve por, Deven por. 1. Fórmula que se utilizaba normalmente para enlazar en los asientos del Diario o Manual la cuenta de cargo con la de abono, y por lo tanto equivalente al de nuestra vieja partícula " $a$ ". 2. En el fragmento del Manual del cambio, fórmula o expresión que se emplea para identificar la cuenta de cargo. Vale por. Vuena por. 
Dinero de banco. Dinero de cuenta. Saldo mantenido en la cuenta de un cambio o banco, compensable en todo momento mediante transacciones bancarias, y que sólo podía hacerse efectivo al vencimiento del plazo de disposición; su recuperación en cualquier otro momento daba lugar a su reducción en el correspondiente precio del contado o, en su caso, del premio del dinero de banco. Precio del contado. Premio del dinero de banco. Reducir dinero de banco.

Dinero de contado. Dinero en efectivo -usualmente en reales- o fuera de banco. Contado.

Dinero remitido. Dar a cambio. Sacar a cambio.

Dinero tomado. Tomar dinero. Tomar a cambio.

Distantia loci. Distancia que media entre el lugar en que se da a cambio el dinero y la plaza en que se paga, y cuya existencia era necesaria según los teólogos para que tal cambio fuera lícito. Cambio real.

Dita. Prenda o seguro que se da de que se pagará una deuda. Garantía. Buena dita. Estar por las ditas.

Escritura, Escrituras. Teneduría de libros. Contabilidad. Libros de cuentas. Registros contables.

Escudo de marco. Moneda de cuenta empleada en las ferias de Besanzón, diseñada con una equivalencia de 99 escudos de marco por 100 escudos de oro genoveses de las cinco estampas (España, Florencia, Génova, Nápoles y Venecia). Moneda de cuenta.

Estar del creer. Del credere. Estar por las ditas. Provisión. Responsión.

Estar por las ditas. Dar caución del cobro de las deudas derivadas de operaciones realizadas por el propio garante mediante la percepción de una prima de riesgo adecuada. Del credere. Dita. Estar del creer. Provisión. Responsión.

Estrecheza. Falta de dinero en el mercado de cambios. Largueza.

Falido. Fallido. En bancarrota o sin crédito. Incobrable. Alzado. Ausentado. Falir. Quebrar o perder el crédito. Alzarse. Ausentarse.

Fenequito. Finiquito.

Feria. Amplio mercado extraordinario celebrado en paraje público y fechas determinadas, a cuyo final se abría normalmente un plazo -denominado de "pagamentos"- para liquidar las obligaciones que vencían en dicha feria. Atrancar ferias. Pagamentos. Primera feria. Trascabalgar ferias.

Finiquito. Remate de una cuenta o certificación de su liquidación. Quitanza.

Fuera de banco. Expresión utilizada en las letras de cambio libradas sobre plazas o ferias de Castilla para indicar que su valor podía hacerse 
efectivo de contado, en lugar de quedar abonado en la cuenta del banco o cambio correspondiente -como era lo normal-, pero en tal caso previa la deducción del premio del dinero de banco estipulado en la propia letra con la expresión de "con tanto al millar".

Fuera de cambio. Fuera de banco.

Guindaleta. Pie derecho del que los cambistas debían tener colgada la balanza para pesar las monedas de oro y plata.

Hacer buena una partida. Abonar en cuenta el importe de una partida. Hacer bueno.

Hacer bueno. Abonar en cuenta. Hacer buena una partida. Vale por. Vuena por.

Hombre de negocios. Asentista de dinero. Financiero, negociante en cambios. Mercader-banquero.

Hordinario. Ordinario.

Largueza. Abundancia de dinero en el mercado de cambios. Estrecheza.

Lastar. Suplir o prestar lo que otro ha de pagar, con derecho a reintegrarse.

Letra de más suma. Letra de la que, por haber sido sacada o tomada a cambio por varias personas que generalmente compartían su importe en distinta cuantía, se dice que está librada por "más suma" de la cantidad aportada o recibida, respectivamente, por cada una de ellas. Cambio de más suma.

Letras castellanas. Letras numerales $i, v, l, c$, y $d$, así como los símbolos $q^{\circ}$ y U, propios todos ellos de la cuenta castellana. Cuenta castellana.

Libro de Caja. Libro de Caxa.

Libro de Caxa. 1. Libro Mayor. 2. Por extensión, denominación dada a la partida doble por los mercaderes, bancos y cambios castellanos en los siglos XV y XVI. Libro de Corte.

Libro de Corte. 1. Libros de cuentas -llevados por partida doble- empleados por los cambios o bancos para contabilizar tanto las operaciones propias como las bancarias en que intervenían, distintas de las correspondientes a las de las ferias. Libro de Ferias. 2. Por extensión, nombre dado en Castilla a la partida doble por los mercaderes, bancos y cambios desde mediados del siglo XVI. Libro de Caxa (2).

Libro de Ferias. Libros de cuentas -Diario y Mayor llevados en partida doble- de los cambios o bancos castellanos, que se empleaban para registrar las diferentes operaciones bancarias en que intermediaban en las sucesivas ferias. Libro de Corte. 
Libro nuevo. Mayor abierto para recoger las cuentas nuevas que se fueran abriendo tras haber terminado el anterior o "viejo" una vez utilizados todos sus folios, aunque todavía pudieran quedar en él cuentas sin saldar por disponer de suficiente espacio en blanco en el correspondiente folio. Libro viejo.

Libro viejo. Mayor terminado por haberse utilizado todos sus folios, pero que todavía puede contener cuentas abiertas cuyo saldo no se haya traspasado al Mayor "nuevo" -abierto al efecto- por tener aún el folio de la correspondiente cuenta espacio en blanco para asentar más partidas. Libro nuevo.

Manual. Libro Diario.

Manualero. Tenedor de libros que llevaba solamente el Manual o Diario. Caxero.

Maravedí. Unidad monetaria castellana de cuenta. Moneda de cuenta.

Mayor de Caja. Libro de Caxa. Libro Mayor.

Mercader. Comerciante en gran escala, exportador e importador.

Mercader-banquero. Mercader que además negociaba en cambios. Hombre de negocios.

Millar. Calderón numeral empleado para leer con mayor facilidad las cantidades expresadas en cuenta castellana -o en cuenta guarisma- a cuyo efecto se colocaba antes de la cifra de las centenas, de forma que, sin aumentar en cosa alguna su valor, servía para indicar que las cifras que lo antecedían correspondían a la clase de los millares. En los manuscritos adoptaba la forma de una "u" mayúscula estilizada - $U$ - y en los impresos se solía representar por medio de la inversión del tipo de imprenta "fl" -en el que estaba ligada la $f$ a la l-, que de tal forma imitaba al calderón manuscrito "U". Al millar. Calderón. Con tanto al millar. Quento.

Moneda ausente. Dinero del que no se dispone materialmente, pero que se supone se podrá disponer de él al cabo de un cierto tiempo en la misma o distinta plaza.

Moneda de cuenta. Unidad monetaria no representada materialmente que se utilizaba como unidad de cuenta, con independencia de las monedas reales que se emplearan para cobros y pagos. Escudo de marco. Maravedí.

Moneda presente. Dinero amonedado del que se dispone en mano.

Números castellanos. Cuenta castellana.

Oficio. Ocupación habitual. 
Oficio servil. El considerado mecánico o bajo, en oposición a las artes liberales o nobles.

Oficio vil. Oficio servil.

Ordinario. Correo dedicado a llevar con cierta periodicidad cartas, órdenes, objetos de reducido volumen y alto valor, etc., de una población a otra.

Pagador del cambio. Persona que se encargaba de pagar al beneficiario o cobrador del cambio, por cuenta del tomador del cambio, el valor de la letra de cambio. Beneficiario del cambio. Pago por honor.

Pagamento, Pagamentos. Período de unos veinte días, establecido a la finalización de cada una de las ferias, destinado al proceso de liquidación de los saldos de las operaciones con vencimiento en dichas reuniones.

Pago por honor [letra]. Pago de la letra por un tercero, en defecto del pagador de la misma, para evitar el desprestigio personal de este último.

Partida. Cada cantidad que se anota en una cuenta. Partido.

Partido. Asiento. Partida.

Partimentos. Pseudocuenta utilizada en el Manual del cambio para representar en cierto modo al viejo término de "Varios" de los asientos complejos. Asiento complejo. Pertenecen a.

Pasar partidas. Traspasar a la pertinente cuenta del libro Mayor cada una de las partidas integrantes de los asientos del libro Diario. Asentar.

Pena de llevar la cuenta [ferias]. Tiempo y esfuerzo empleado por los bancos o cambios en la llevanza de la cuenta de sus clientes durante las ferias, por el que solían recibir de ellos una compensación que era normal que incluyera una gratificación para "caxeros" y "manualeros".

Pertenecen a. Fórmula que se emplea en el Manual del cambio para detallar las partidas de cargo o de abono que en definitiva resume la pseudocuenta de Partimentos.

Plaza de cambio. Población en la que tenían lugar importantes negociaciones de cambios.

Precio del contado. Interés o recargo dependiente de la situación del mercado, que se agregaba al importe del contado concedido, para su cobro conjunto al vencimiento de dicha operación y habida cuenta de la duración de la misma; se expresaba en tanto por mil, y para un plazo de tres meses solía oscilar entre el 5 y el $25 \%$ o al millar. Con tanto al millar. Contado. Premio del dinero de banco.

Premio del dinero de banco. Prima del dinero de contado -o fuera de banco- sobre el dinero de banco, que se señalaba en las letras de cambio libradas en dinero de banco sobre los lugares de cambio castellanos en un tanto por mil cuyo valor modal era el de seis al 
millar, abreviadamente, "6 al Ur". Contado. Con tanto al millar. Dinero de banco. Dinero de contado. Fuera de banco.

Primera feria. Próxima feria, pero no la inmediata siguiente a la de la libranza de una letra, sino la que se celebrase después de haber llegado el cambio a su destino. Atrancar ferias. Feria.

Prolongar los cambios. Correr los cambios.

Provisión. Garantía de cobro de las deudas comerciales por la cual el comisionista o corresponsal vendedor percibía una prima, comisión suplementaria -doble comisión- o "responsión", que solía ser como mínimo del $1 / 2 \%$. Estar por las ditas.

Prueba. Justificación, manifestación de la verdad de alguna cosa que se hace patente.

Quento. Millón. Símbolo - $q^{\circ}$ - empleado para leer las cantidades expresadas en cuenta castellana -o cuenta guarisma- con mayor facilidad, a cuyo efecto se colocaba antes de la cifra de los millares, de forma que, sin aumentar en cosa alguna su valor, servía para indicar que las cifras que lo antecedían correspondían a la clase de los millones. Cuento. Millar.

Quitanza. Finiquito. Recibo o carta de pago que se daba al deudor cuando pagaba.

Reducir dinero de banco. Convertir el dinero de banco en dinero de contado rebajando del importe del primero el precio del contado que correspondiera por la anticipación del vencimiento del saldo, tipo que normalmente era de 5 al millar. Contar. Precio del contado. Premio del dinero de banco.

Referir y Apuntar. Referir consistía en cotejar las partidas de los asientos del Manual con las correspondientes pasadas al Mayor para comprobar si estaba bien hecho su traslado, y apuntarlas se decía de cruzar el calderón numeral de la pertinente partida del Mayor con una rayita de abajo para arriba -o un punto en su interior o, en su caso, una combinación de ambas- para que se entendiera que estaban referidas o comprobadas. Apuntar partidas. Referir partidas.

Referir partidas. Cotejar o relacionar las partidas de los asientos del Manual con las correlativas del Mayor o libro de Caxa para comprobar su exactitud. Referir y Apuntar.

Remesa. Adquisición de una letra de cambio para situar fondos o pagar una deuda en otra plaza. Dar a cambio.

Rescontrar. Compensar en cuentas partidas de distinto signo.

Rescuentro. Compensación en cuentas de una partida con otra de distinto signo. 
Respondiente. Fiador. Garante.

Responsión. 1. Responsabilidad, obligación de compensar o reparar un impago, un daño, etc. 2. Fondos con que responder. 3. Provisión, comisión o corretaje sobre los cambios.

Resto. Saldo de una cuenta. Alcance.

Sacar a cambio. Tomar a cambio.

Sacar a pagar. Sacar a cambio.

Sobrante. Cantidad de la que alguien resultaba acreedor en una rendición de cuentas. Saldo que se ha de cobrar. Resto. Alcance.

Sobrar. Resultar alguien acreedor en una rendición de cuentas. Alcanzar.

Sobre de [letra]. Con la garantía de la persona designada en la letra de cambio.

Sotaescrita [letra]. Garantía del buen fin de una letra subscripta en ella.

Tanto al millar. Al millar. Con tanto al millar.

Tomador del cambio. Persona que recibía del dador a cambio el contravalor de la letra de cambio. Dador a cambio.

Tomar a cambio. Recibir el contravalor de una letra de cambio, bien sea como forma de obtener crédito o de cobrar un saldo sobre una plaza extranjera, y librar la letra correspondiente. Dinero tomado.

Tomar a depósito. Depósito.

Traer a cambio. Negociar prolongadamente los cambios de una a otra feria. Correr los cambios.

Tratante. Apelativo genérico con el que se designaba por igual a mercaderes, comerciantes, hombres de negocios, cambios y bancos.

Trascabalgar ferias. Saltar ferias. Atrancar ferias.

Trata. Letra de cambio girada a cargo de un corresponsal deudor.

Vale por. Vuena por.

Valerse sobre [letra]. Reembolsarse un saldo librando una letra de cambio sobre otra plaza. Contar consigo.

Valor de la letra de cambio. Importe de la letra expresado en moneda de la plaza de cambio en que se ha de pagar -valor nominal-, incluido en su caso el premio del dinero de banco -valor efectivo- si la susodicha plaza fuera castellana. Contravalor de la letra de cambio.

Venda. Venta. 

del Campo no identificado, correspondiente a la feria de Octubre de 1564

Vuena por: 1. Buena por. Deve por. 2. En el Manual del cambio, fórmula utilizada para señalar la cuenta o cuentas que se abonan. Deve por. Hacer buena una partida. Hacer bueno. Vale por. 


\section{ABREVIATURAS}

Las abreviaturas que figuran en el fragmento de Manual se recogen, debidamente agrupadas, en el siguiente cuadro:

\begin{tabular}{|c|c|}
\hline $\begin{array}{l}\text { Andrea } \\
\text { tolomé } \\
\text { autista } \\
\text { Batista } \\
\text { omingo } \\
\text { ancisco } \\
\text { rónimo } \\
\text { Juan } \\
\text { Idovico } \\
\text { Vicolao } \\
\text { Tristán } \\
\text {-istóval }\end{array}$ & 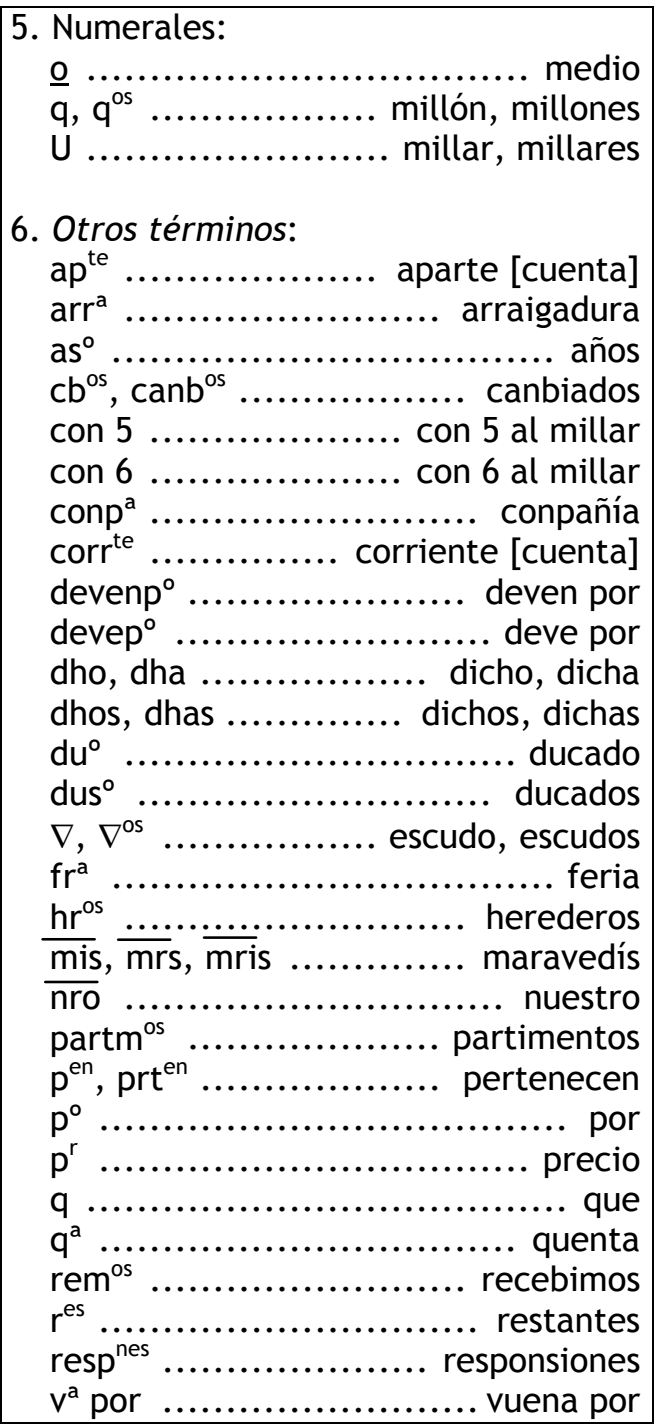 \\
\hline
\end{tabular}

ANEXOS 


\section{ANEXO I}

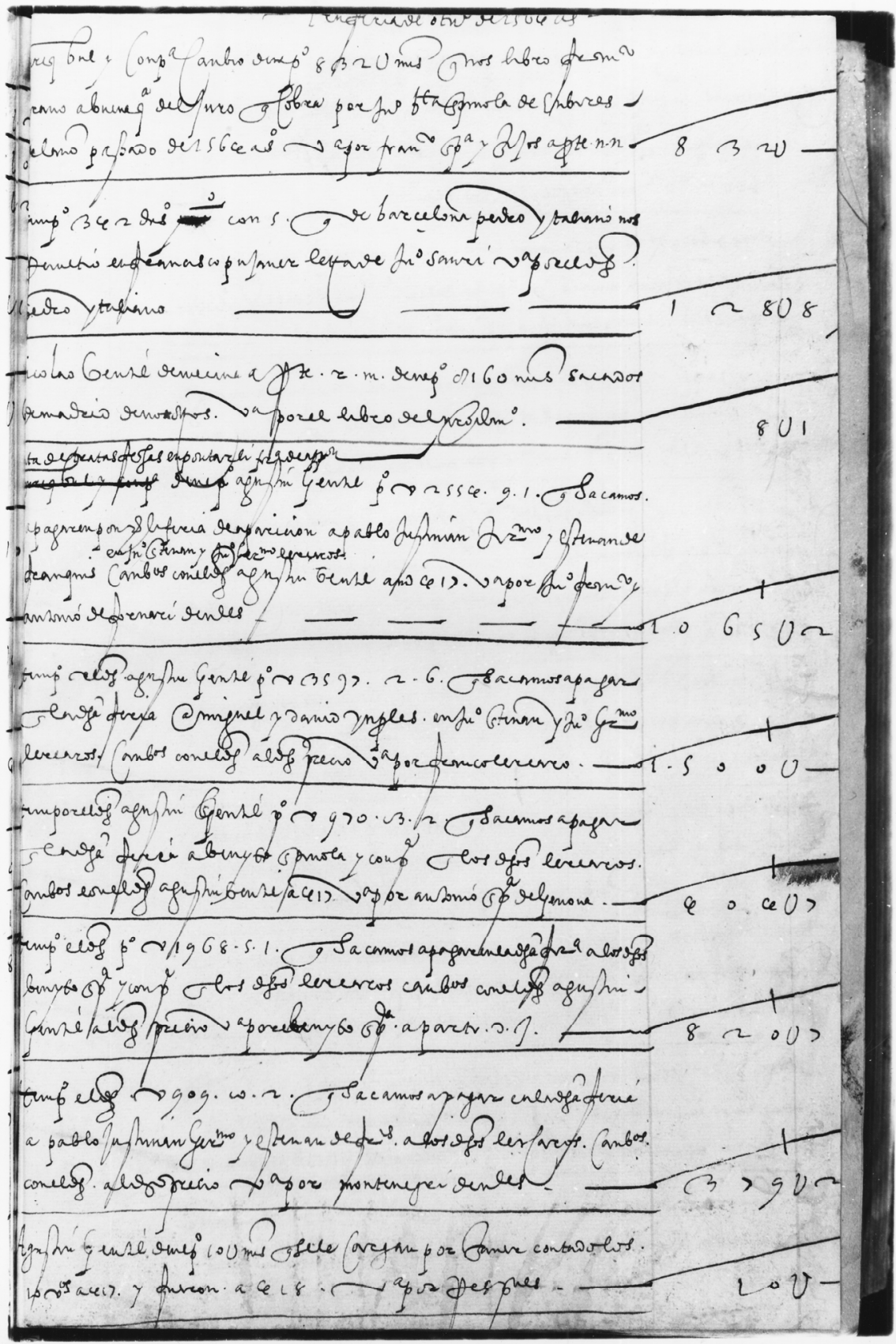


en feria de otubre de 1564 años

\begin{tabular}{|c|c|c|}
\hline [104] & 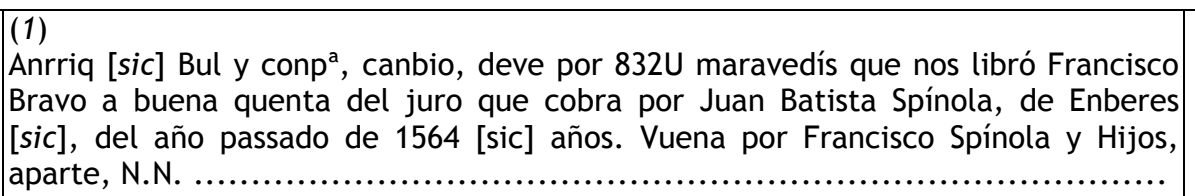 & 832U----- \\
\hline [91] & $\begin{array}{l}(2) \\
\text { Item por } 342 \text { ducados }\langle-1 / 2->\text { con } 5 \text { [al millar], que de Barcelona Pedro Ytaliano nos } \\
\text { remetió en Francisco Pujaner, letra de Juan Saurí. Vuena por el dicho Pedro } \\
\text { Ytaliano } \ldots \ldots \ldots \ldots \ldots \ldots \ldots \ldots \ldots \ldots \ldots \ldots \ldots \ldots \ldots \ldots \ldots \ldots \ldots \ldots \ldots \ldots \ldots \ldots \ldots \ldots \ldots \ldots \ldots \ldots \ldots \ldots \ldots \ldots \ldots \ldots \ldots \ldots \ldots \ldots \ldots \ldots \ldots \ldots \ldots \ldots \ldots \ldots \ldots \ldots \ldots \ldots \ldots \ldots \ldots\end{array}$ & $128 \mathrm{U} 8[91]$ \\
\hline $\begin{array}{l}97 \\
53\end{array}$ & $\begin{array}{l}(3) \\
\text { Nicolao Gentil, de Mecina }[\text { sic }] \text {, aparte, R.M., deve por }[8 \mathrm{U}] 160 \mathrm{mrs} . \text { sacados de } \\
\text { Madrid de nosotros. Vuena por el libro del nuestro Domingo ......................... }\end{array}$ & $8 U 1[60]$ \\
\hline 57 & 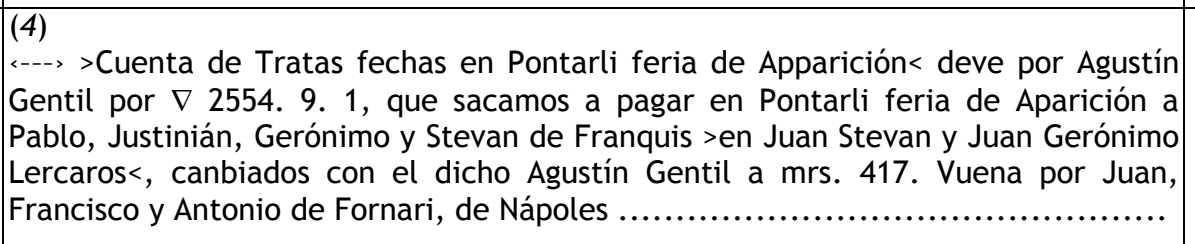 & 1065U2[07] \\
\hline $\begin{array}{l}57 \\
87\end{array}$ & $\begin{array}{l}\text { (5) } \\
\text { Item por el dicho Agustín Gentil por } \nabla \text { 3597. 2. 6, que sacamos a pagar en la dicha } \\
\text { feria a Miguel y David Ynperiales en Juan Stevan y Juan Gerónimo Lercaros, } \\
\text { canbiados con el dicho al dicho precio. Vuena por Franco Lercaro .................... }\end{array}$ & 1500U----- \\
\hline 91 & $\begin{array}{l}\text { (6) } \\
\text { Item por el dicho Agustín Gentil por } \nabla \text { 970. 13. 2, que sacamos a pagar en la dicha } \\
\text { feria a Benyto Spínola y conp }{ }^{\mathrm{a}} \text { en los dichos Lercaros, canbiados con el dicho } \\
\text { Agustín Gentil a } 417 . \text { Vuena por Antonio Spínola, de Génova ......................... }\end{array}$ & 404U7[64] \\
\hline 13 & $\begin{array}{l}\text { (7) } \\
\text { Item por el dicho por } \nabla \text { 1968. 5. 1, que sacamos a pagar en la dicha feria a los } \\
\text { dichos Benyto Spínola y conp }{ }^{a} \text { en los dichos Lercaros, canbiados con el dicho } \\
\text { Agustín Gentil al dicho precio. Vuena por Benyto Spínola, aparte, D.J. .............. }\end{array}$ & 820U7[62] \\
\hline $\begin{array}{l}57 \\
93\end{array}$ & $\begin{array}{l}(8) \\
\text { Item por el dicho } \nabla \text { 909. 10. 2, que sacamos a pagar en la dicha feria a Pablo, } \\
\text { Justinián, Gerónimo y Stevan de Franquis a los dichos Lercaros, canbiados con el } \\
\text { dicho al dicho precio. Vuena por Montenegri, de Nápoles ............................. }\end{array}$ & $379 U 2[65]$ \\
\hline $\begin{array}{r}{[6]} \\
{[109]}\end{array}$ & $\begin{array}{l}(9) \\
\text { Agustín Gentil deve por } 10 \mathrm{U} \text { mrs. que se le cargan por haver contado los } 10 \text { [U] } \\
\text { escudos a } 417 . \text { y fueron a } 418 \text {. Vuena por Responsiones ............................ }\end{array}$ & 10U---- \\
\hline
\end{tabular}



del Campo no identificado, correspondiente a la feria de Octubre de 1564

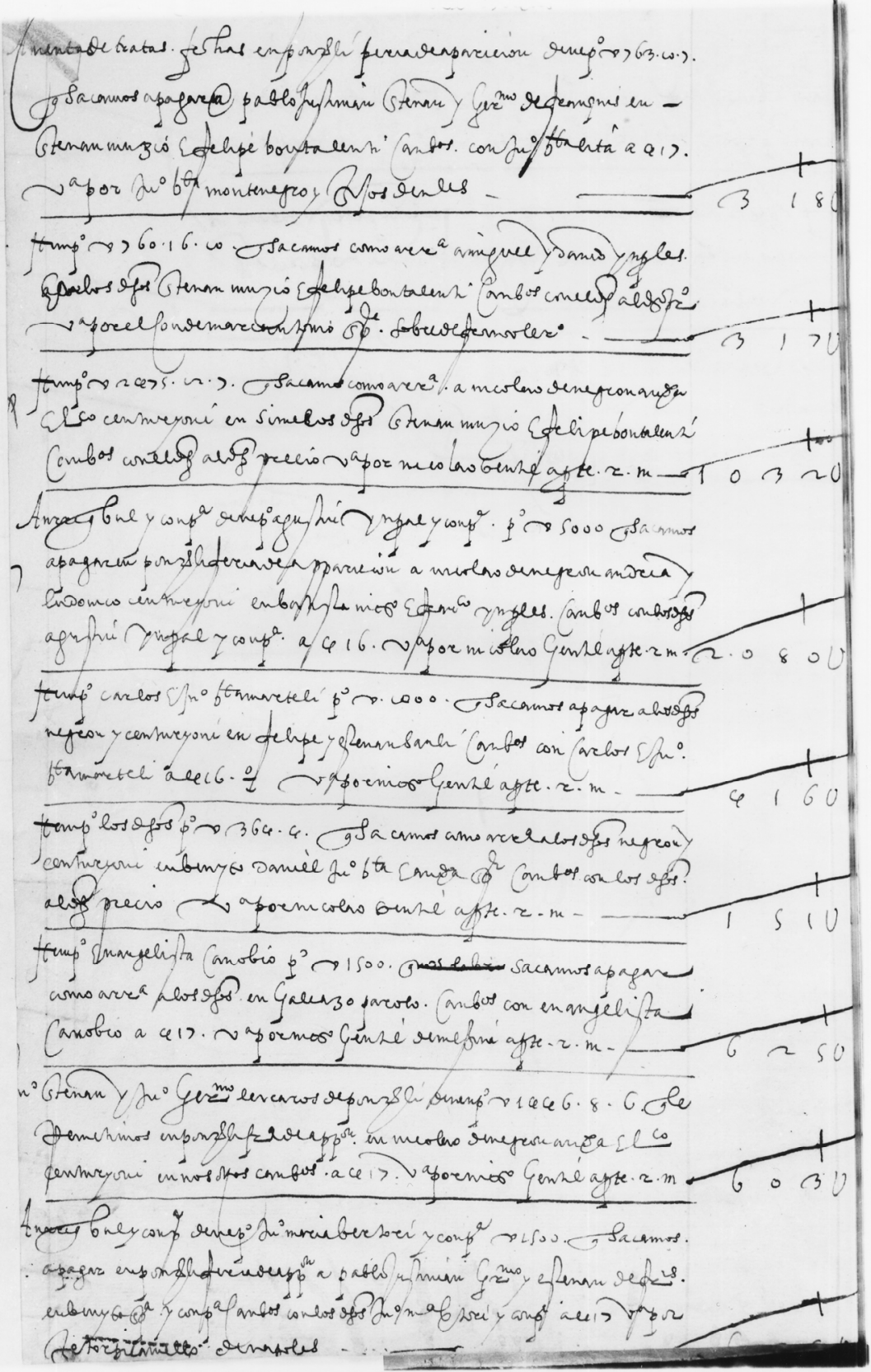




\begin{tabular}{|c|c|c|}
\hline $\begin{array}{l}{[57]} \\
{[93]}\end{array}$ & 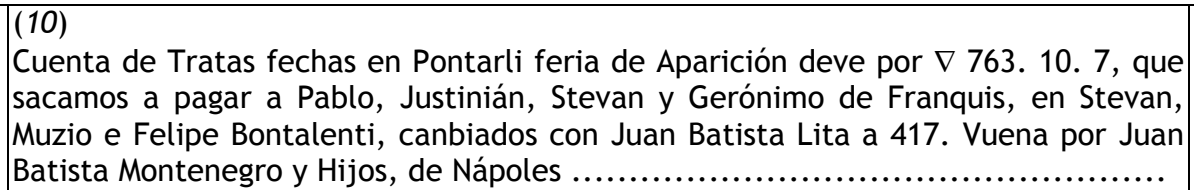 & $318 U 392$ \\
\hline 57 & $\begin{array}{l}\text { (11) } \\
\text { Item por } \nabla \text { 760. 16. 10, que sacamos como arraigadura a Miguel y David Ynperiales, } \\
\text { en los dichos Stevan, Muzio e Felipe Bontalenti, canbiados con el dicho al dicho } \\
\text { precio. Vuena por el Conde Marcantonio Spínola sobre de Franco Lercaro ........... }\end{array}$ & $317 U 271$ \\
\hline $\begin{array}{l}{[57]} \\
{[97]}\end{array}$ & 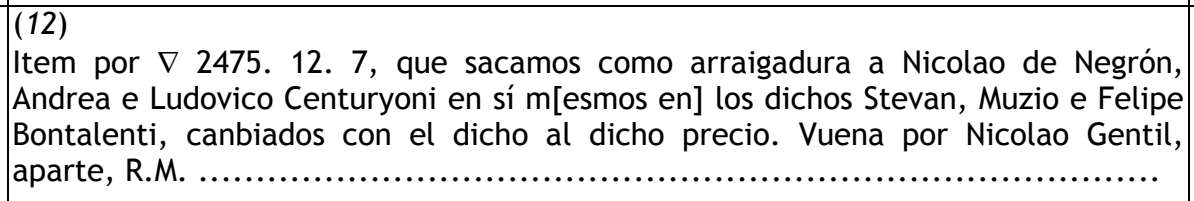 & 1032 U337 \\
\hline$[9] 7$ & $\begin{array}{l}(13) \\
\text { Anrriq Bul y conp }{ }^{a} \text { deve por Agustín Ynperial y conp }{ }^{a} \text { por } \nabla 5000 \text {, que sacamos a } \\
\text { pagar en Pontarli feria de Apparición, a Nicolao de Negrón, Andrea y Ludovico } \\
\text { Centuryoni, en Batista, Nicolao e Francisco Ynperiales, canbiados con los dichos } \\
\text { Agustín Ynperial y conp a }{ }^{\mathrm{a}} \text { a } 46 \text {. Vuena por Nicolao Gentil, aparte, R.M. .............. }\end{array}$ & 2080U---- \\
\hline $\begin{array}{r}3 \\
{[97]}\end{array}$ & $\begin{array}{l}(14) \\
\text { Item por Carlos e Juan Batista Marteli por } \nabla 1000 \text {, que sacamos a pagar a los } \\
\text { dichos Negrón y Centuryoni, en Felipe y Stevan Sauli, canbiados con Carlos e Juan } \\
\text { Batista Marteli a } 4161 / 2 \text {. Vuena por Nicolao Gentil, aparte, R.M. ................. }\end{array}$ & $416 \cup 500$ \\
\hline $\begin{array}{r}3 \\
{[97]}\end{array}$ & $\begin{array}{l}(15) \\
\text { Item por los dichos por } \nabla \text { 364. 4, que sacamos como arraigadura a los dichos } \\
\text { Negrón y Centuryoni, en Benyto, Daniel, Juan Batista e Andrea Spínola, canbiados } \\
\text { con los dichos al dicho precio. Vuena por Nicolao Gentil, aparte, R.M. ............. }\end{array}$ & 151U6[89] \\
\hline 3 & $\begin{array}{l}(16) \\
\text { Item por Evangelista Canobio por } \nabla \text { 1500, que } \leftrightarrow--->\text { sacamos a pagar como } \\
\text { arraigadura a los dichos en Galeazo Parolo, canbiados con Evangelista Canobio a } \\
\text { 417. Vuena por Nicolao Gentil, de Mesina, aparte, R.M. .......................... }\end{array}$ & $625 U 500$ \\
\hline $\begin{array}{l}{[11]} \\
{[97]}\end{array}$ & 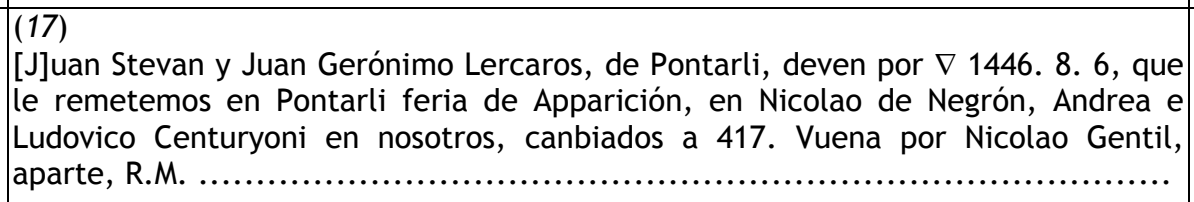 & $603 \cup 159$ \\
\hline [105] & $\begin{array}{l}(18) \\
\text { Anrriq Bul y conp }{ }^{a} \text { deve por Juan María Bertori y conp }{ }^{a} \nabla 1500 \text {, que sacamos a } \\
\text { pagar en Pontarli feria de Apparrición, a Pablo, Justinián, Gerónimo y Stevan de } \\
\text { Franquis, en Benyto Spínola y conp }{ }^{a} \text {, canbiados con los dichos Juan María Bertori y } \\
\text { conp }^{\mathrm{a}} \text { a } 417 \text {. Vuena por Hétor Picamillo, de Nápoles ..................................... }\end{array}$ & [625U500] \\
\hline
\end{tabular}



del Campo no identificado, correspondiente a la feria de Octubre de 1564

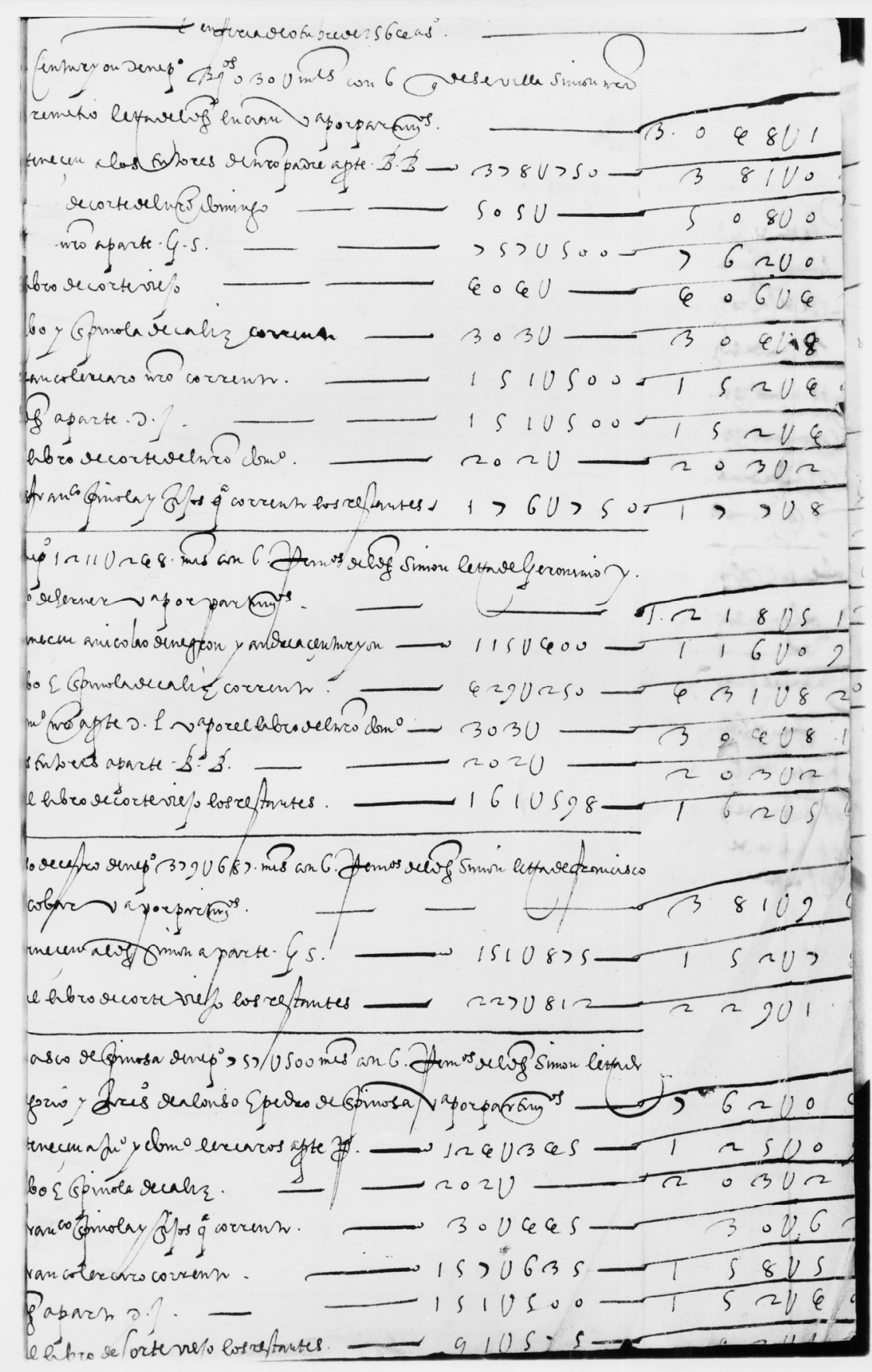


en feria de otubre de 1564 años

\begin{tabular}{|c|c|c|}
\hline $\begin{array}{c}1[. .] \\
44 \\
1[23] \\
5[3] \\
103 \\
8[1] \\
9[9] \\
87 \\
{[\ldots 6]} \\
5[3] \\
10[4]\end{array}$ & 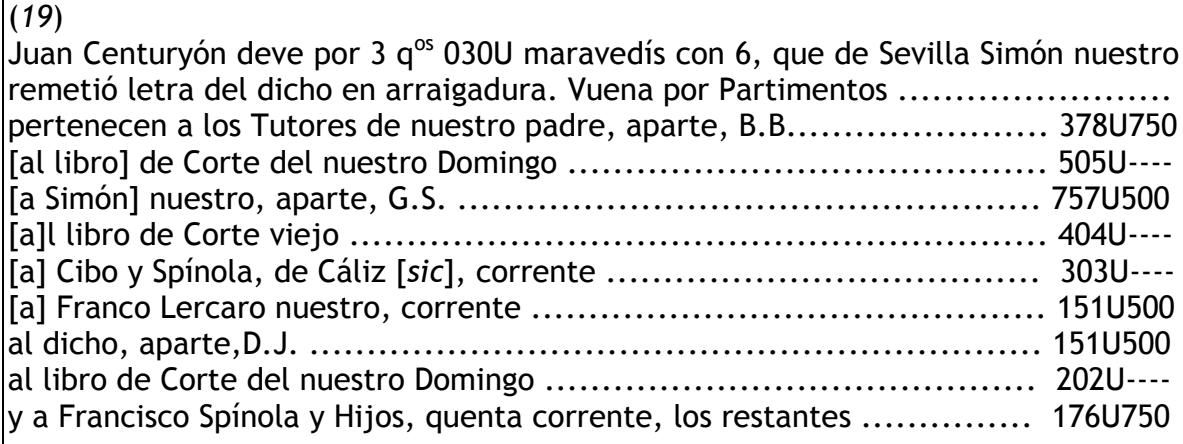 & $\begin{array}{r}3048 \mathrm{U} 1[79] \\
381 \mathrm{U} 0[22] \\
508 \mathrm{U}[30] \\
762 \mathrm{U}[45] \\
406 \mathrm{U}[24] \\
304 \mathrm{U}[18] \\
152 \mathrm{U}[09] \\
152 \mathrm{U}[09] \\
203 \mathrm{U}[12] \\
177 \mathrm{U}[10]\end{array}$ \\
\hline $\begin{array}{c}1[. .] \\
44 \\
9[8] \\
9[9] \\
5[3] \\
123 \\
81\end{array}$ & 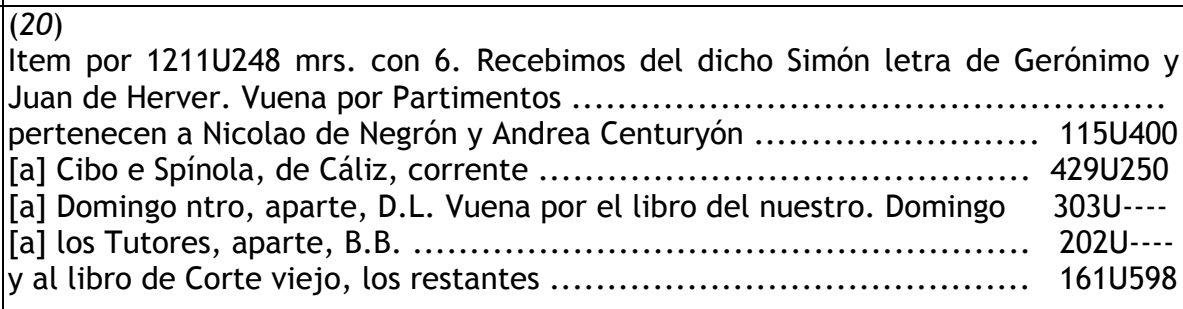 & $\begin{array}{r}1218 U 51[4] \\
116 \cup 09[2] \\
431 \cup 82[5] \\
304 U 81[8] \\
203 \cup 21[2] \\
162 U 56[7]\end{array}$ \\
\hline $\begin{array}{c}21 \\
4[4] \\
10[3] \\
81\end{array}$ & 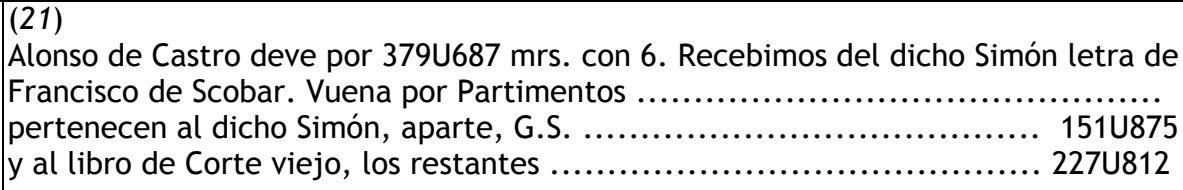 & $\begin{array}{l}381 \cup 96[5] \\
152 \cup 78[6] \\
229 U 1[79]\end{array}$ \\
\hline $\begin{array}{c}25 \\
44 \\
7[.] \\
{[99]} \\
10[4] \\
87 \\
{[.] 6} \\
{[81]}\end{array}$ & 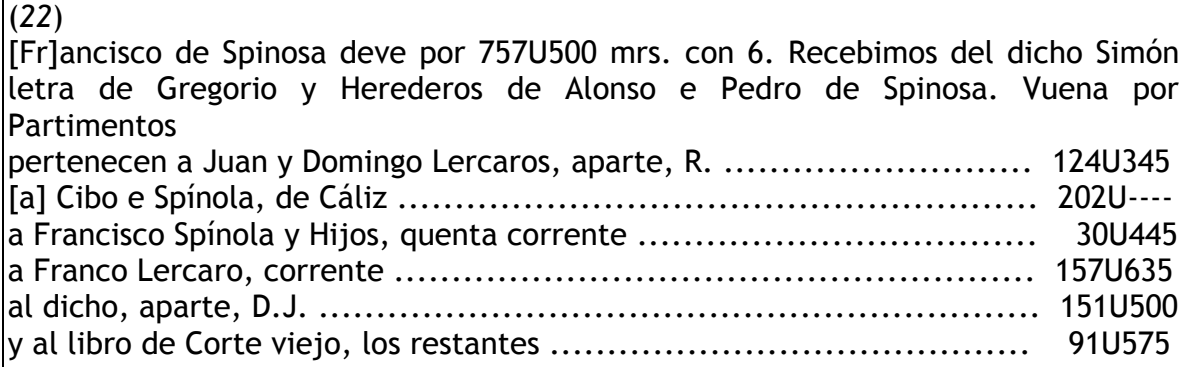 & $\begin{array}{r}762 U 04[5] \\
125 U 09[1] \\
203 U 2[12] \\
30 U 6[28] \\
158 U 5[81] \\
152 U 40[9] \\
92 U 1[24]\end{array}$ \\
\hline
\end{tabular}




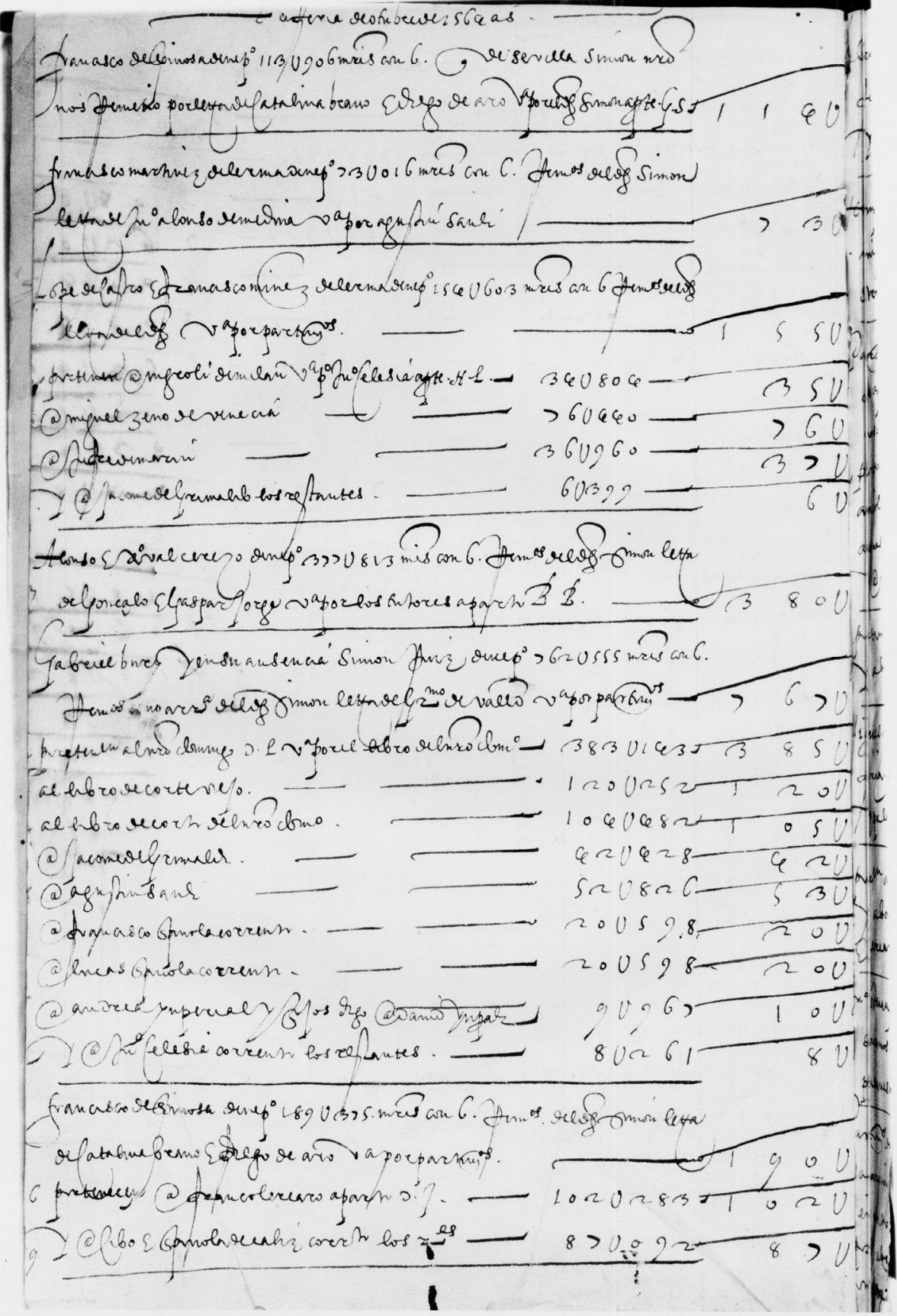




\begin{tabular}{|c|c|c|}
\hline $\begin{array}{r}{[25]} \\
{[103]}\end{array}$ & 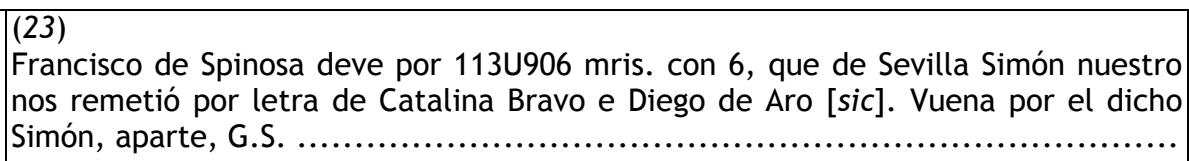 & 114U589 \\
\hline $\begin{array}{l}{[\ldots]} \\
{[\ldots]}\end{array}$ & $\begin{array}{l}24) \\
\text { Francisco Martínez de Lerma, deve por } 73 \cup 016 \text { mris. con } 6 . \text { Recebimos del dicho } \\
\text { Simón letra de Juan Alonso de Medina. Vuena por Agustín Sauli ...................... }\end{array}$ & $73 \cup 454$ \\
\hline $\begin{array}{r}{[\ldots]} \\
{[44]} \\
{[\ldots]} \\
{[124]} \\
{[\ldots]} \\
{[\ldots]}\end{array}$ & 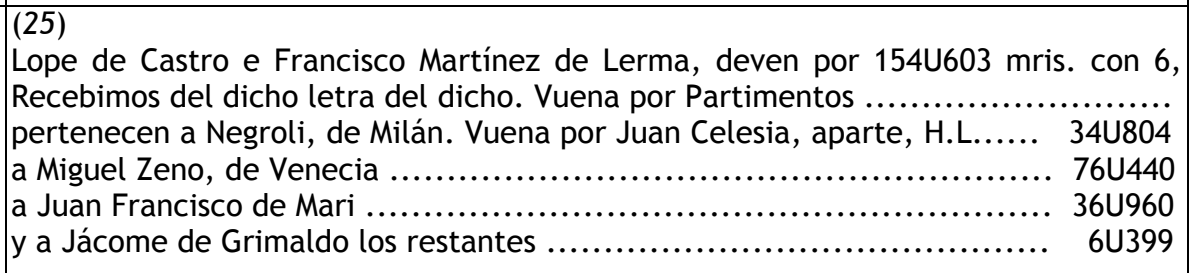 & $\begin{array}{r}155 \mathrm{U} 531 \\
35 \mathrm{U} 013 \\
76 \mathrm{U} 899 \\
37 \mathrm{U} 182 \\
6 \mathrm{U} 437\end{array}$ \\
\hline $\begin{array}{r}{[\ldots]} \\
{[123]}\end{array}$ & $\begin{array}{l}\text { (26) } \\
\text { Alonso e Christóval Cerezo deve por } 377 \text { U813 mrs. con 6. Recebimos del dicho } \\
\text { Simón letra de Gonçalo e Gaspar Jorge. Vuena por los Tutores, aparte, B.B. ........ }\end{array}$ & $380 \cup 080$ \\
\hline $\begin{array}{c}{[\ldots]} \\
{[44]} \\
{[53]} \\
{[81]} \\
{[53]} \\
{[\ldots]} \\
{[\ldots]} \\
{[\ldots]} \\
{[\ldots]} \\
{[105]} \\
{[\ldots]}\end{array}$ & 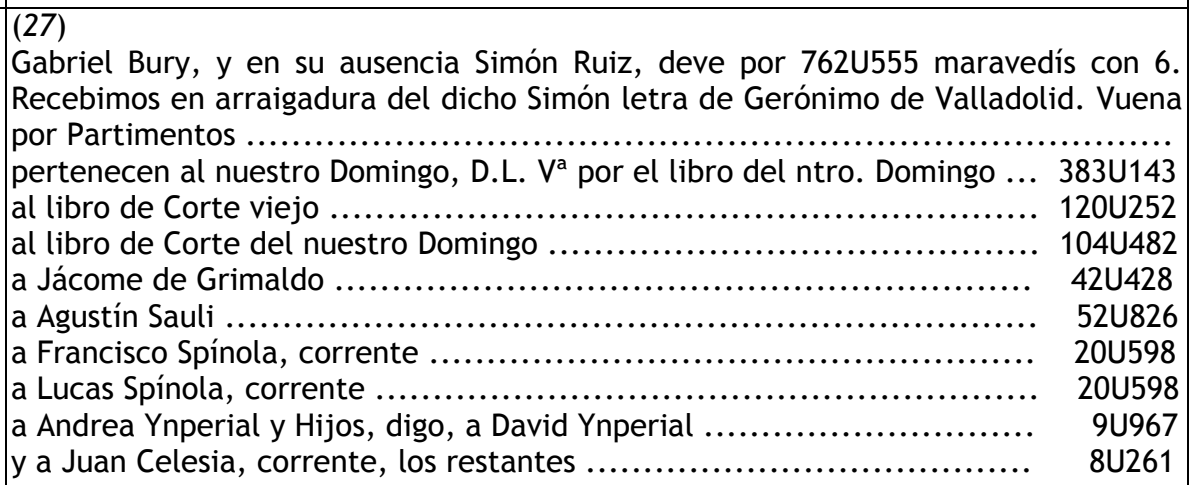 & $\begin{array}{c}767 U 130 \\
385 U 442 \\
120 U 974 \\
105 U 109 \\
42 U 683 \\
53 U 143 \\
20 U 721 \\
20 U 721 \\
10 U[02] 7 \\
8 U 310\end{array}$ \\
\hline $\begin{array}{l}{[25]} \\
{[44]} \\
{[.] 6} \\
{[9] 9}\end{array}$ & 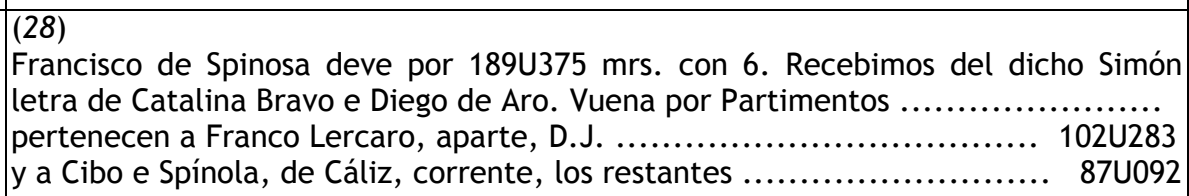 & $\begin{array}{r}190 U 5[1] 1 \\
102 U 8[97] \\
87 \cup 6[14]\end{array}$ \\
\hline
\end{tabular}



del Campo no identificado, correspondiente a la feria de Octubre de 1564

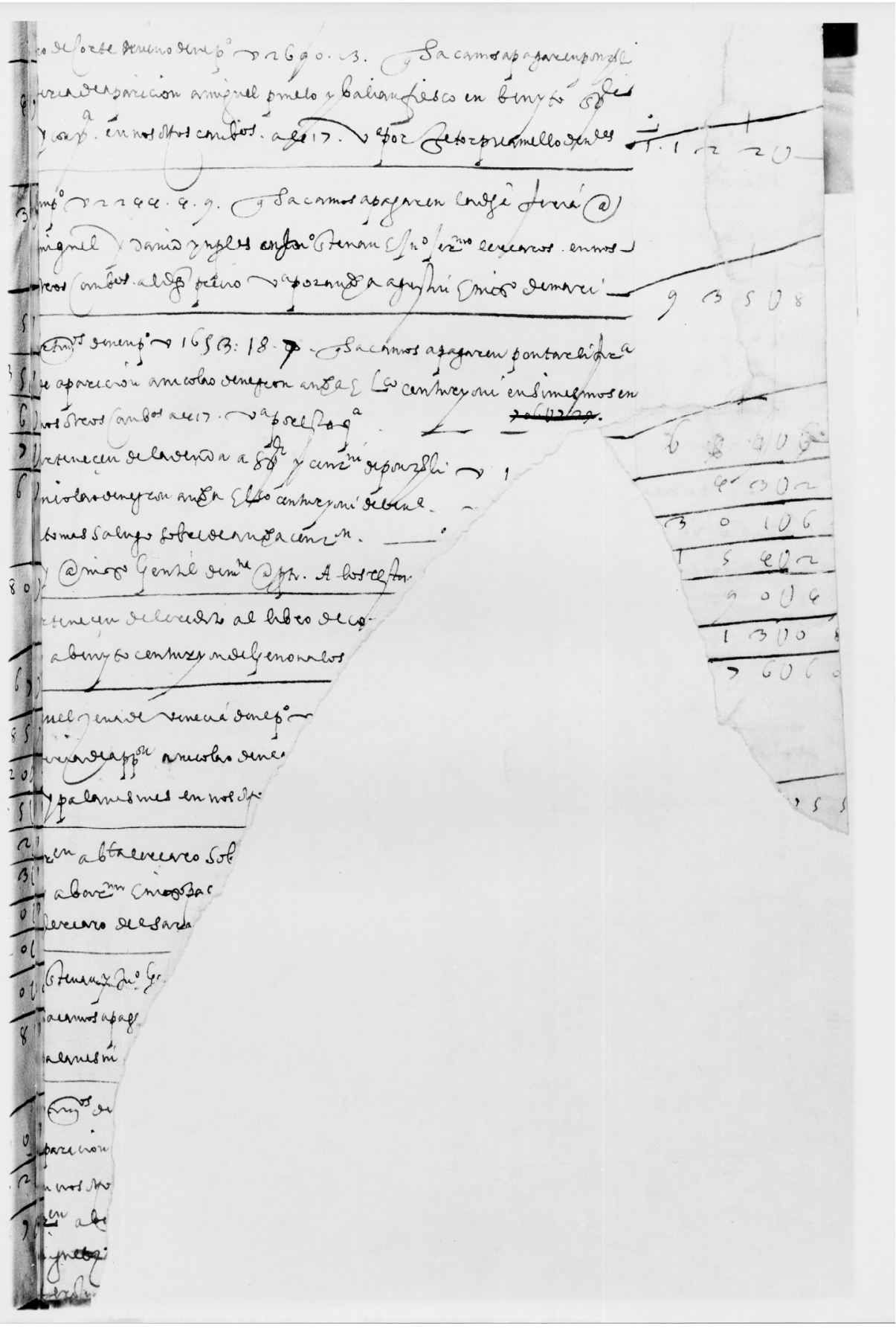


en feria de otubre de 1564 años

\begin{tabular}{|c|c|c|}
\hline 140 & $\begin{array}{l}(29) \\
\text { [El li]bro de Corte nuevo deve por } \nabla \text { 2690. 13, que sacamos a pagar en Pontarli } \\
\text { feria de Aparición a Miguel Pinelo y Balián Fiesco en Benyto Spínola y conp }{ }^{\mathrm{a}} \text { en } \\
\text { nosotros, canbiados a } 417 \text {. Vuena por Hétor Picamillo, de Nápoles .................... }\end{array}$ & 1.122U---- \\
\hline $\begin{array}{l}140 \\
94\end{array}$ & $\begin{array}{l}(30) \\
\text { Item por } \nabla \text { 2244. 4. 9, que sacamos a pagar en la dicha feria a Miguel y David } \\
\text { Ynperiales en Juan Stevan e Juan Jerónimo [sic] Lercaros en nosotros, canbiados al } \\
\text { dicho precio. Vuena por Andrea, Agustín e Nicolao de Mari.......................... }\end{array}$ & 935U8[47] \\
\hline $\begin{array}{r}{[44]} \\
68 \\
92 \\
98 \\
134 \\
138\end{array}$ & 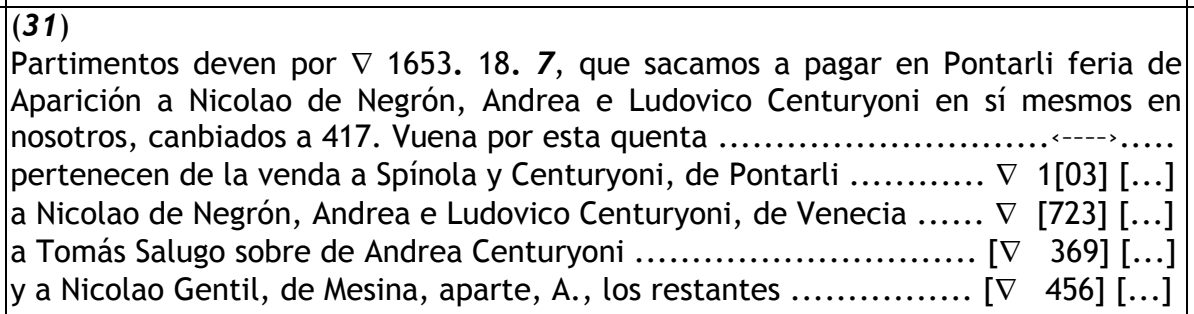 & $\begin{array}{c}689 U 6[88] \\
43 \cup 2[\ldots] \\
301 \cup 6[\ldots] \\
154 U 2[\ldots] \\
{[1] 90 U 4[\ldots]}\end{array}$ \\
\hline $\begin{array}{l}140 \\
114\end{array}$ & $\begin{array}{l}(32) \\
\text { Pertenecen del crédito al libro de Co[rte nuevo....................................... } \\
\text { y a Benyto Centuryón, de Génova, los }[\text { restantes } \ldots \ldots \ldots \ldots \ldots \ldots \ldots \ldots \ldots \ldots \ldots \ldots \ldots \ldots \ldots \ldots \ldots \ldots \ldots\end{array}$ & $\begin{array}{l}13 \cup 08[.] \\
76 \cup 60[.]\end{array}$ \\
\hline 124 & 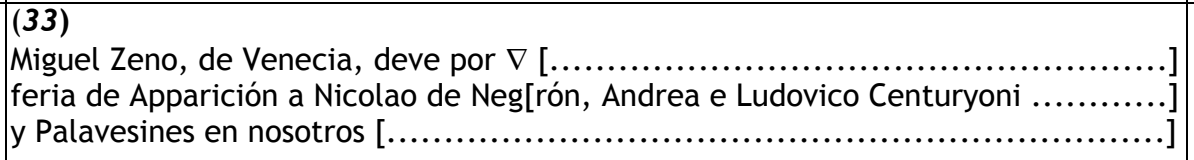 & [...] $] 55[]$. \\
\hline $\begin{array}{r}99 \\
139\end{array}$ & 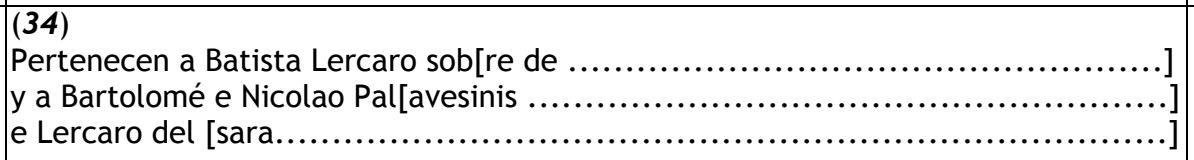 & \\
\hline 11 & 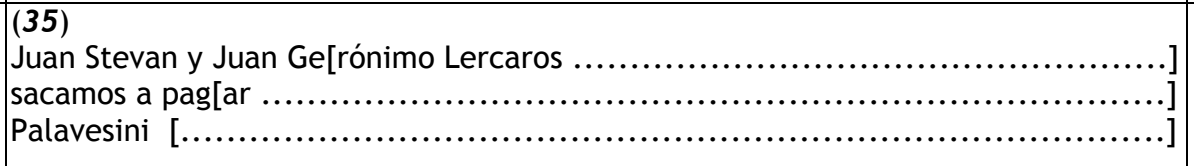 & \\
\hline $\begin{array}{c}44 \\
\\
12[.] \\
{[. .]} \\
{[124]} \\
{[124]}\end{array}$ & 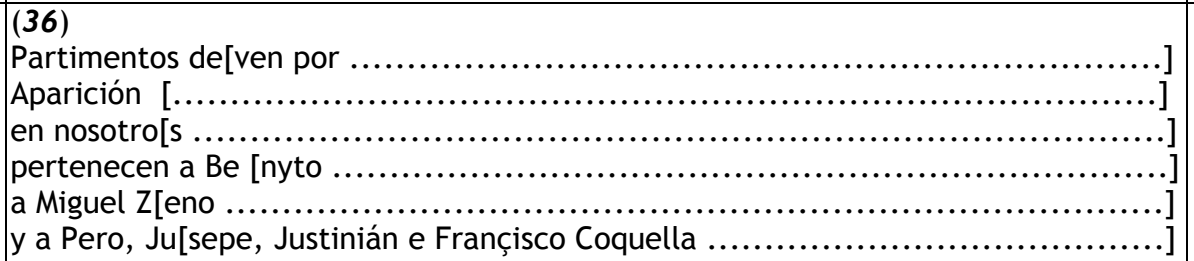 & \\
\hline
\end{tabular}



del Campo no identificado, correspondiente a la feria de Octubre de 1564

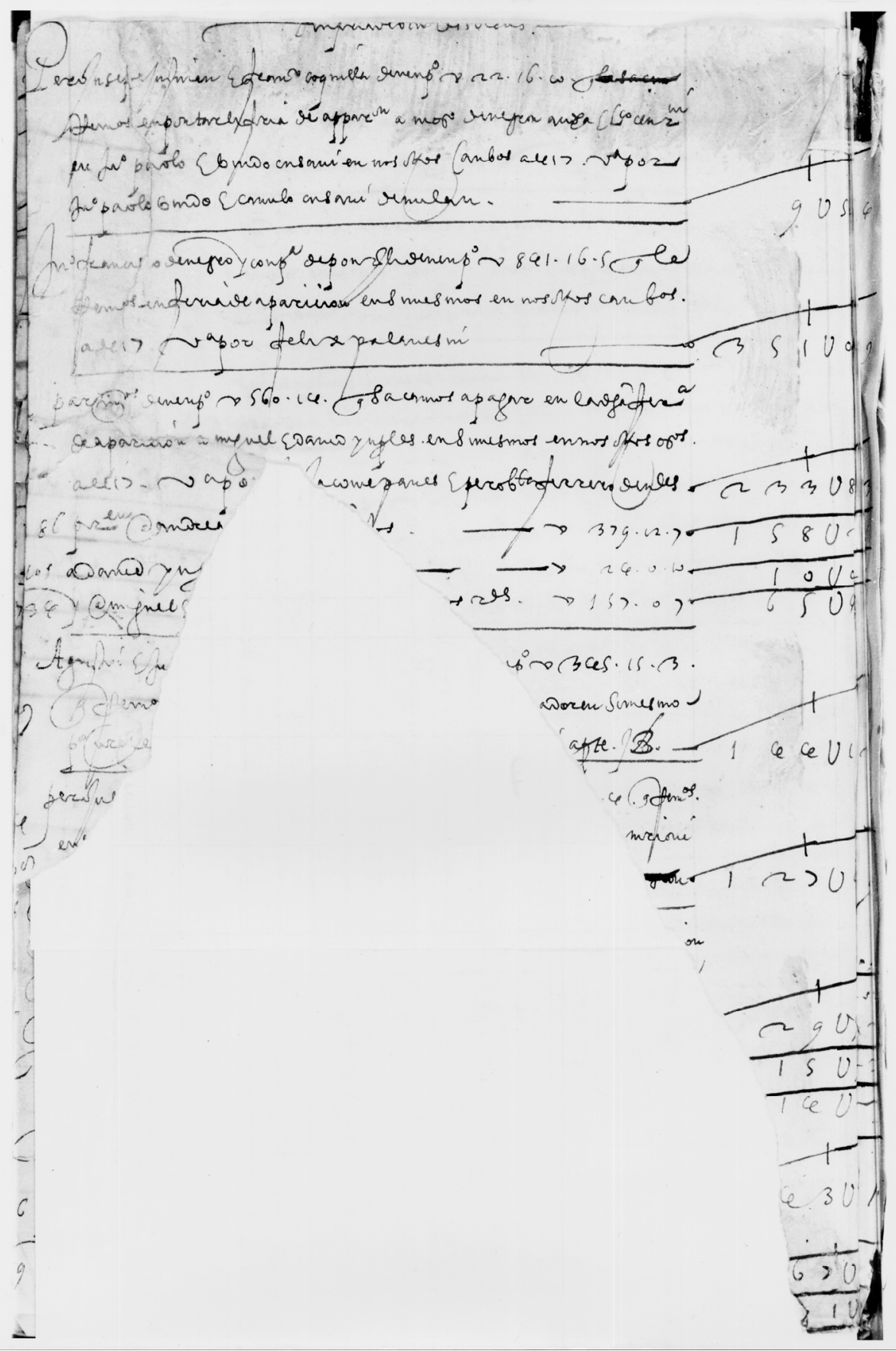




\begin{tabular}{|c|c|c|}
\hline$[\ldots]$ & 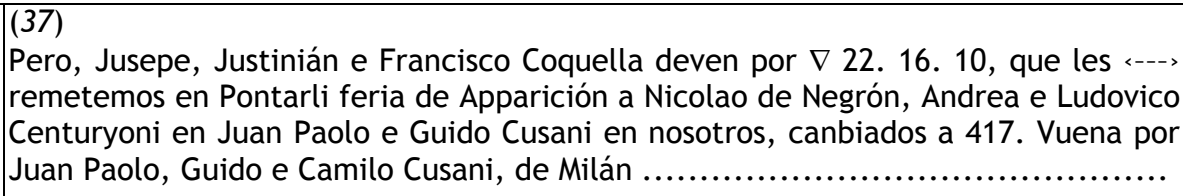 & $9 U 524$ \\
\hline $\begin{array}{l}{[\ldots]} \\
101\end{array}$ & 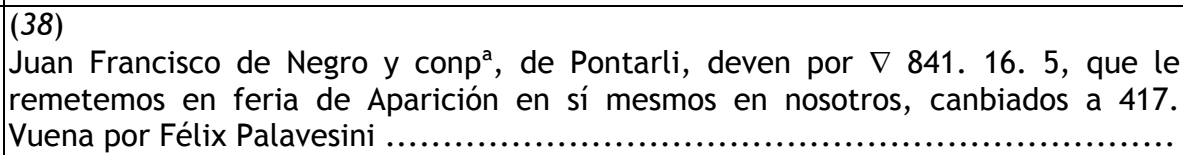 & 351U039 \\
\hline $\begin{array}{c}{[44]} \\
{[\ldots]} \\
86 \\
105 \\
34\end{array}$ & 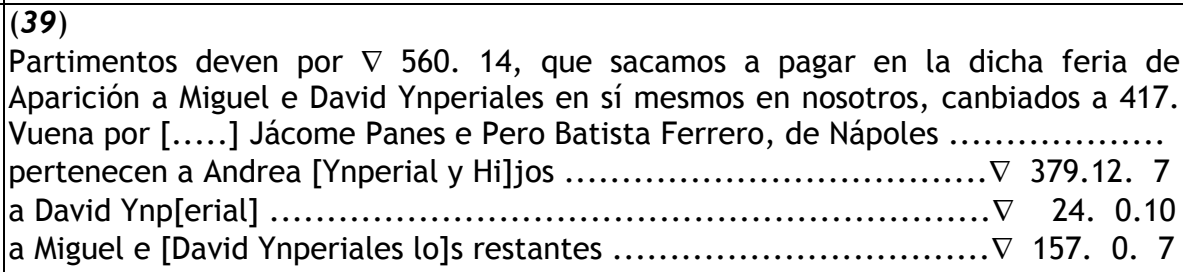 & $\begin{array}{r}233 \cup 813 \\
158 U 306 \\
10 U 027 \\
65 \cup 480\end{array}$ \\
\hline $\begin{array}{l}{[. .] 7} \\
{[\ldots]}\end{array}$ & 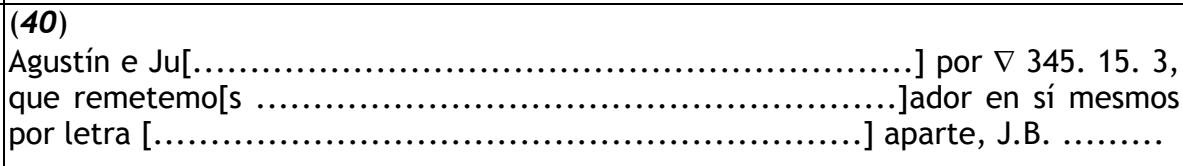 & 144U183 \\
\hline \multirow[t]{5}{*}{$\begin{array}{l}{[12] 4} \\
107\end{array}$} & 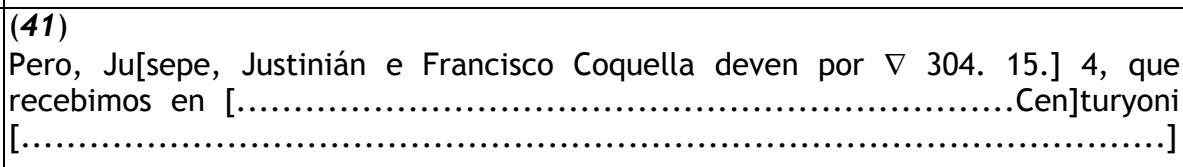 & 127U089 \\
\hline & 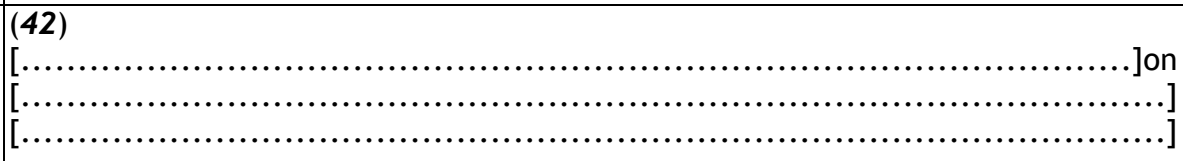 & $\begin{array}{l}29 U 923 \\
15 U 923 \\
14 U 000\end{array}$ \\
\hline & 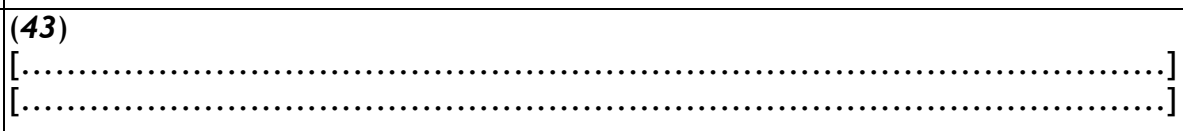 & 43บ931 \\
\hline & 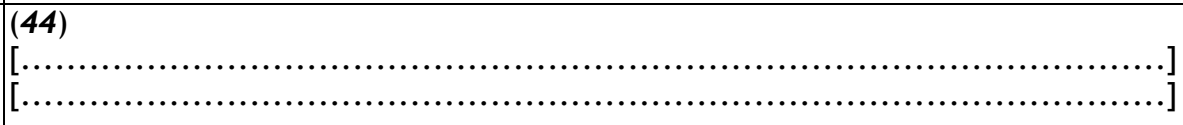 & 67U755 \\
\hline & 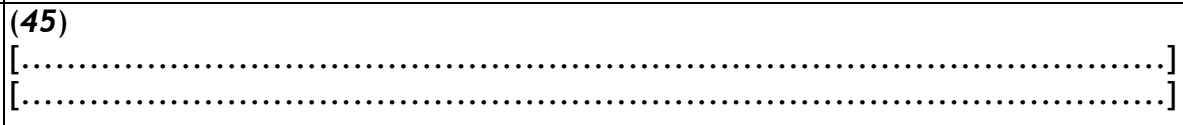 & $31 \cup 3[.]$. \\
\hline
\end{tabular}



del Campo no identificado, correspondiente a la feria de Octubre de 1564

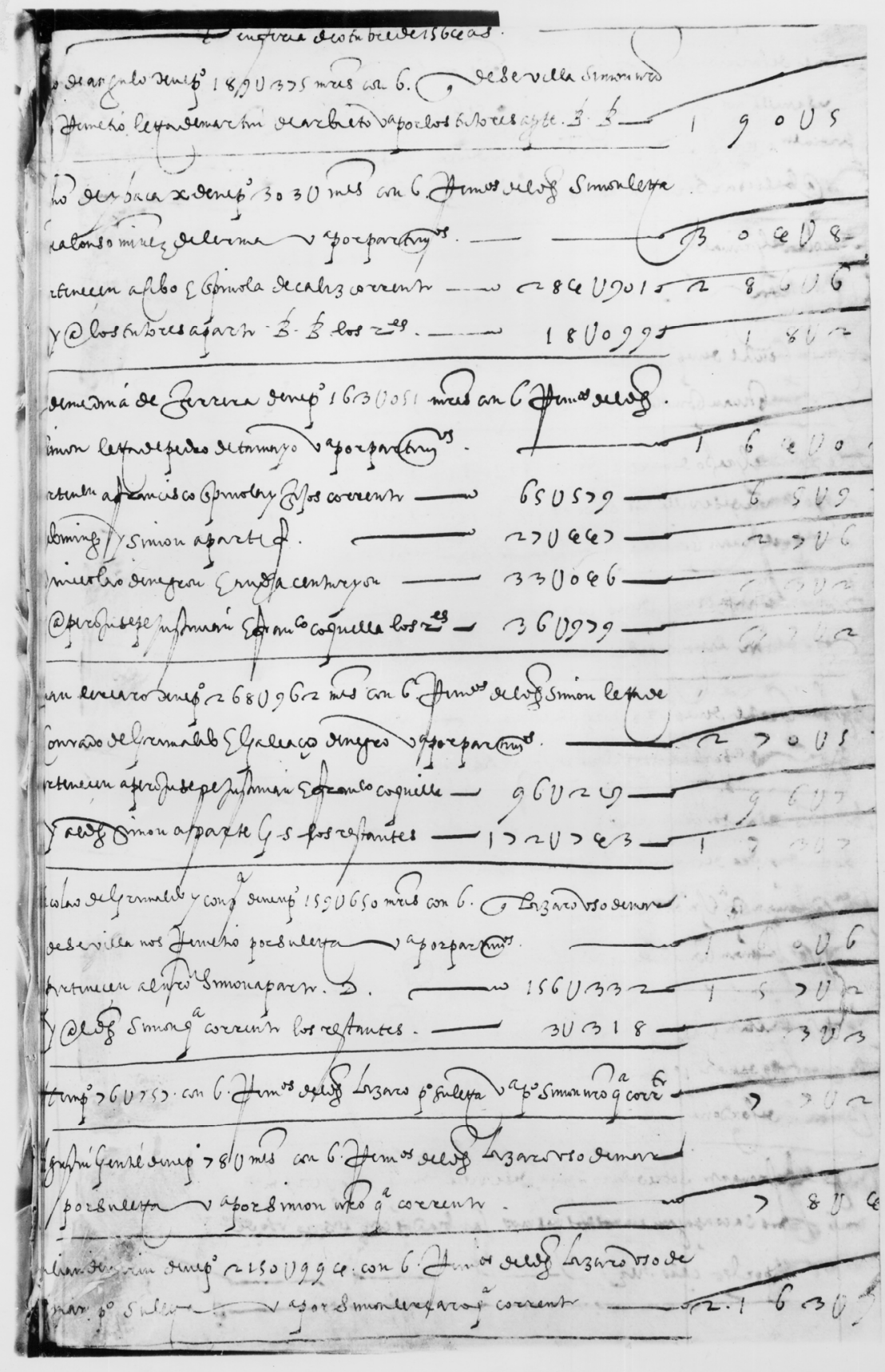


En feria de otubre de 1564 años

\begin{tabular}{|c|c|c|}
\hline $\mid \begin{array}{c}{[\ldots]} \\
{[12] 3}\end{array}$ & $\begin{array}{l}(46) \\
\text { Pedro de Angulo deve por } 189 \cup 375 \text { mris. con } 6 \text {, que de Sevilla Simón nuestro nos } \\
\text { remetió letra de Martín de Arbieto. Vuena por los Tutores, aparte, B.B. ............ }\end{array}$ & 190U5[11] \\
\hline $\begin{array}{r}28 \\
45 \\
99 \\
12[3]\end{array}$ & 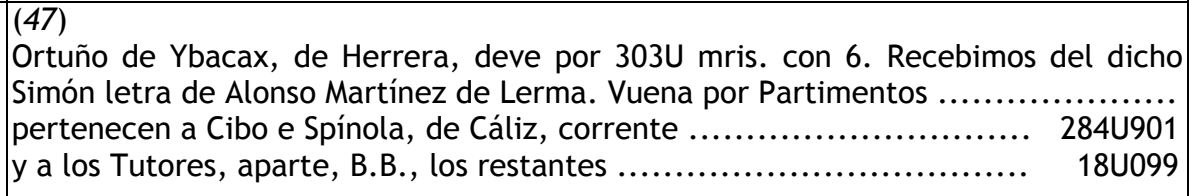 & $\begin{array}{r}304 \mathrm{U} 8[18] \\
286 \mathrm{U} 6[10] \\
18 \mathrm{U} 2[08]\end{array}$ \\
\hline $\begin{array}{r}28 \\
45 \\
104 \\
127 \\
98 \\
124\end{array}$ & 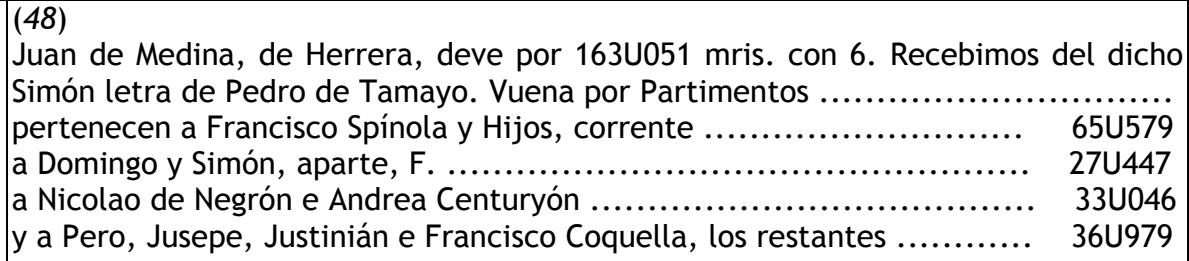 & $\begin{array}{r}164 \mathrm{U} 0[29] \\
65 \mathrm{U} 9[72] \\
27 \mathrm{U} 6[12] \\
33 \mathrm{U} 2[44] \\
37 \mathrm{U} 2[01]\end{array}$ \\
\hline $\begin{array}{r}22 \\
45 \\
124 \\
103\end{array}$ & \begin{tabular}{|l}
$(49)$ \\
Juan Lercaro deve por 268 U962 mrs. con 6. Recebimos del dicho Simón letra de \\
Conrado de Grimaldo e Galeaço de Negro. Vuena por Partimentos .................. \\
pertenecen a Pero, Jusepe, Justinián e Francisco Coquella ............... \\
Y al dicho Simón, aparte, G.S., los restantes ............................. 172U743
\end{tabular} & $\begin{array}{r}270 U 5[75] \\
96 \cup 7[96] \\
173 \cup 7[79]\end{array}$ \\
\hline $\begin{array}{c}19 \\
45 \\
101 \\
{[7] 9}\end{array}$ & 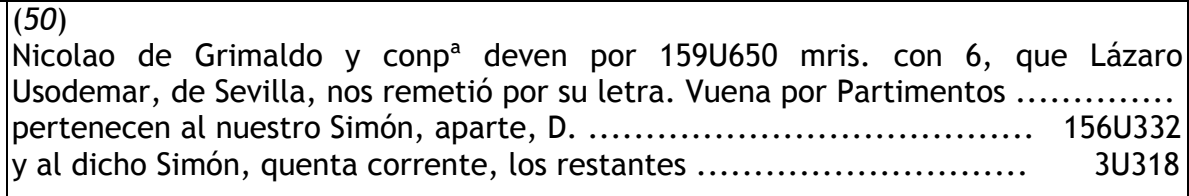 & $\begin{array}{r}160 \mathrm{U} 6[08] \\
157 \mathrm{U} 2[70] \\
3 \mathrm{U} 3[38]\end{array}$ \\
\hline $\begin{array}{l}19 \\
79\end{array}$ & $\begin{array}{l}\text { (51) } \\
\text { Item por } 76 U 757 \text { [maravedís] con } 6 . \text { Recebimos del dicho Lázaro Usodemar por su } \\
\text { letra. Vuena por Simón nuestro, quenta corrente ................................. }\end{array}$ & 77U2[18] \\
\hline $\begin{array}{r}6 \\
79\end{array}$ & $\begin{array}{l}\text { (52) } \\
\text { Agustín Gentil deve por } 78 \mathrm{U} \text { mrs. con } 6 . \text { Recebimos del dicho Lázaro Usodemar por } \\
\text { su letra. Vuena por Simón nuestro, quenta corrente ............................ }\end{array}$ & $78 \cup 4[68]$ \\
\hline $\begin{array}{c}11 \\
{[\ldots]}\end{array}$ & $\begin{array}{l}\text { (53) } \\
\text { Julián de Marín deve por 2.150U994 [maravedís] con 6. Recebimos del dicho Lázaro } \\
\text { Usodemar por su letra. Vuena por Simón Lercaro, quenta corrente .............. }\end{array}$ & $2.163 \cup 9[00]$ \\
\hline
\end{tabular}



del Campo no identificado, correspondiente a la feria de Octubre de 1564

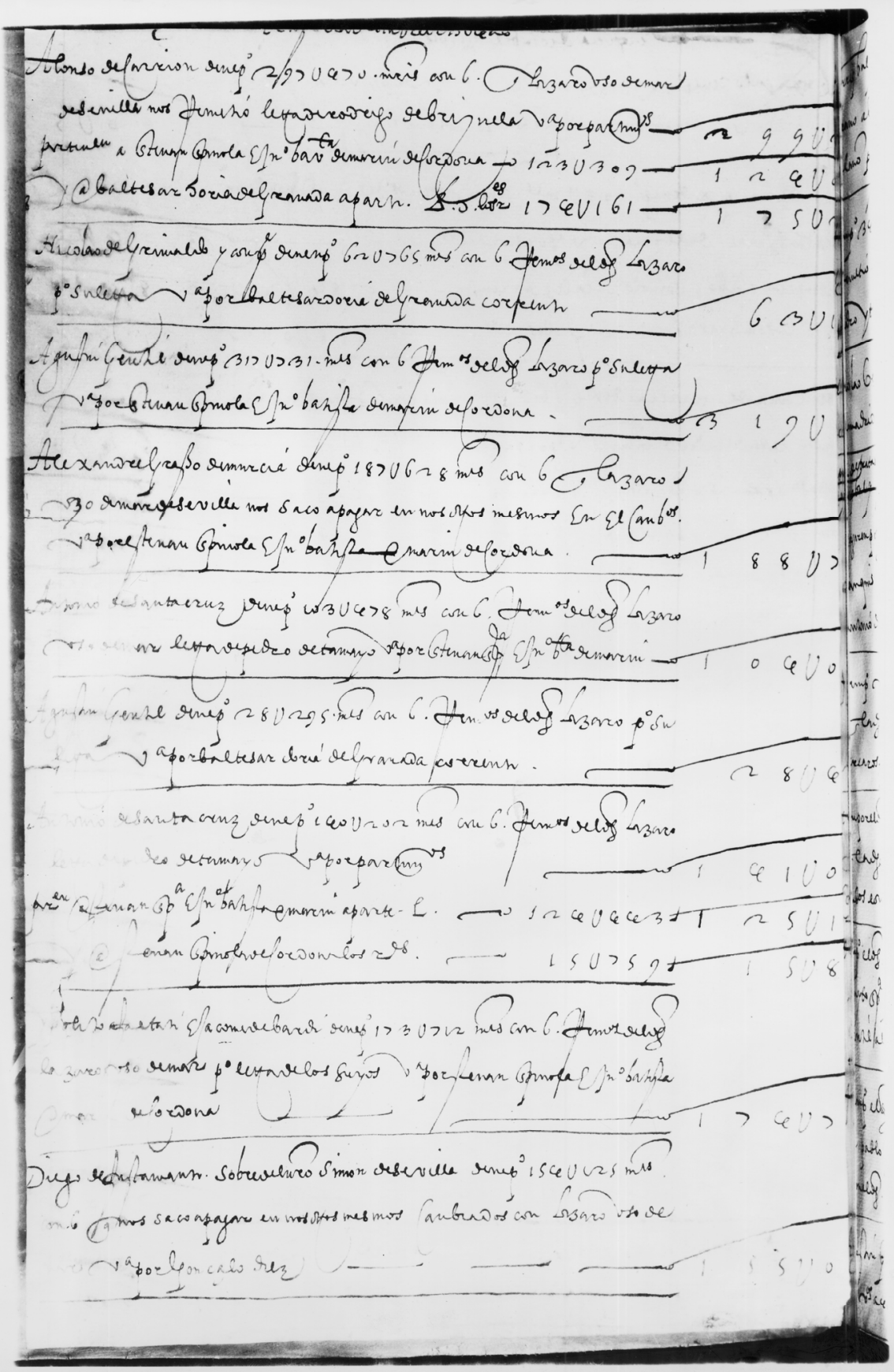

Pecvnia, 10 (2010), pp. 133-201 


\begin{tabular}{|c|c|c|}
\hline $\begin{array}{l}{[\ldots]} \\
{[45]} \\
{[\ldots]} \\
{[\ldots]}\end{array}$ & $\begin{array}{l}\text { (54) } \\
\text { Alonso de Carrión deve por } 297 \cup 470 \text { mris. con 6, que Lázaro Usodemar, de Sevilla, } \\
\text { nos remetió letra de Rodrigo de Brizuela. Vuena por Partimentos ................... } \\
\text { pertenecen a Stevan Spínola e Juan Bautista de Marín, de Córdova ...... } 123 \text { U309 } \\
\text { y a Baltasar Doria, de Granada, aparte, B.D., los restantes .............. 174U161 }\end{array}$ & $\begin{array}{l}299 U 255 \\
124 U 049 \\
175 U 206\end{array}$ \\
\hline $\begin{array}{c}{[19]} \\
{[\ldots]}\end{array}$ & $\begin{array}{l}\text { (55) } \\
\text { Nicolao de Grimaldo y conp }{ }^{a} \text { deven por } 62 U 765 \text { mrs. con } 6 . \text { Recebimos del dicho } \\
\text { Lázaro por su letra. Vuena por Baltasar Doria, de Granada, corrente ................. }\end{array}$ & 63U142 \\
\hline \begin{tabular}{|l}
{$[6]$} \\
{$[\ldots]$}
\end{tabular} & $\begin{array}{l}\text { (56) } \\
\text { Agustín Gentil deve por } 317 \text { 731 mrs. con 6. Recebimos del dicho Lázaro por su } \\
\text { letra. Vuena por Stevan Spínola e Juan Batista de Marín, de Córdova ................ }\end{array}$ & $319 \cup 638$ \\
\hline$\left[\begin{array}{l}{[\ldots]} \\
{[\ldots]}\end{array}\right.$ & $\begin{array}{l}\text { Al) } \\
\text { Alexandre Grasso, de Murcia, deve por } 187 \cup 628 \text { mrs. con } 6, \text { que Lázaro Usodemar, } \\
\text { de Sevilla, nos sacó a pagar en nosotros mesmos en él canbiados. Vuena por Stevan } \\
\text { Spínola e Juan Batista de Marín, de Córdova ...................................... }\end{array}$ & $188 U 754$ \\
\hline $\begin{array}{l}{[\ldots]} \\
{[\ldots]}\end{array}$ & 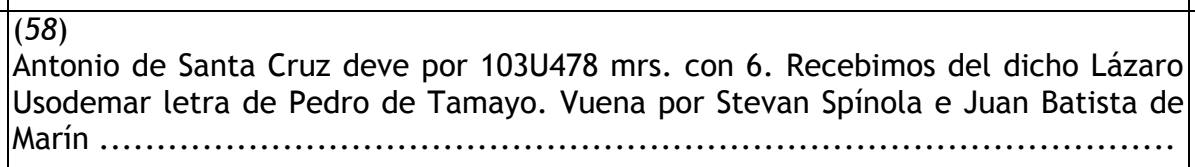 & 104U099 \\
\hline \begin{tabular}{|l}
{$[6]$} \\
{$[\ldots]$}
\end{tabular} & $\begin{array}{l}\text { (59) } \\
\text { Agustín Gentil deve por } 28 \mathrm{U} 295 \mathrm{mrs} \text {. con } 6 . \text { Recebimos del dicho Lázaro por su } \\
\text { letra. Vuena por Baltasar Doria, de Granada, corrente ............................... }\end{array}$ & $28 U 465$ \\
\hline $\begin{array}{l}{[\ldots]} \\
{[45]} \\
{[\ldots]} \\
{[\ldots]}\end{array}$ & 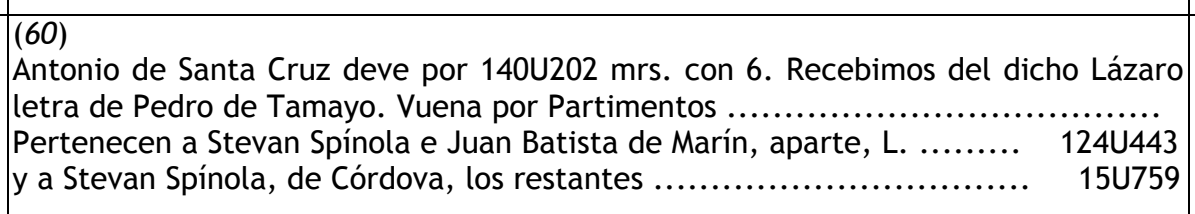 & $\begin{array}{r}141 \mathrm{U} 044 \\
125 \mathrm{U} 190 \\
15 \mathrm{U} 854\end{array}$ \\
\hline$\left[\begin{array}{l}{[\ldots]} \\
{[\ldots]}\end{array}\right.$ & 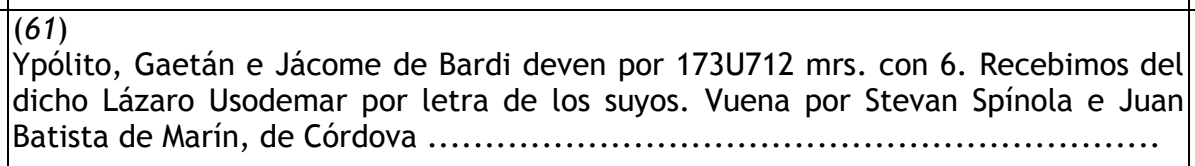 & 174U754 \\
\hline$\left[\begin{array}{l}{[\ldots]} \\
{[\ldots]}\end{array}\right.$ & 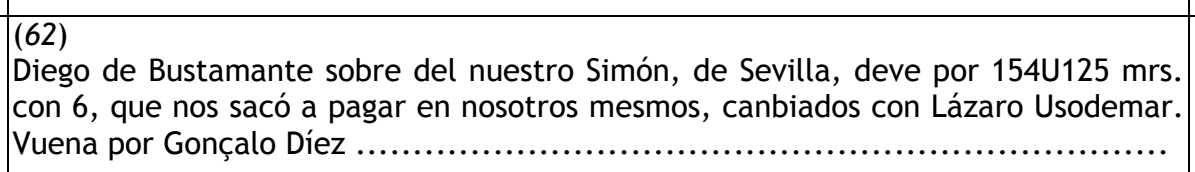 & $155 \cup 050$ \\
\hline
\end{tabular}




\section{ANEXO II}

\section{NÓMINA DE PERSONAS}

El distinto tipo de letra que se ha empleado en la siguiente nómina de personas tiene por objeto permitir conocer a primera vista si tienen cuenta abierta en la contabilidad del cambio que nos ocupa, así como si su presencia en las distintas operaciones es individual o asociada:

- cursivas negritas, cuando se trata de personas que gozan de cuenta particular en el Mayor;

- cursivas solamente, si la persona en cuestión está asociada o relacionada con otra u otras y en tal forma aparece en la rúbrica del Mayor, en cuyo caso mediante Nota se expresa el título completo de la cuenta; y

- redondas simplemente, para aquellas personas citadas que no tengan cuenta abierta en el Mayor, y de la misma forma se detalla en Nota, en su caso, el nombre completo de la firma en cuestión.

\begin{tabular}{|c|c|}
\hline $\begin{array}{l}\text { Pedro de Angulo } \\
\text { Martín de Arbieto } \\
\text { Diego de Aro [Haro] }{ }^{1} \\
\\
\text { Gaetán de Bardi }{ }^{2} \\
\text { Ypólito de Bardi }^{2} \\
\text { Jácome de Bardi }^{2} \\
\text { Juan María Bertori }\end{array}$ & $\begin{array}{l}\text { Felipe Bontalenti }{ }^{4} \\
\text { Muzio Bontalenti }^{4} \\
\text { Stevan Bontalenti } \\
\text { Catalina Bravo }^{4} \\
\text { Francisco Bravo } \\
\text { Rodrigo de Brizuela } \\
\text { Anrriq Bul [Enrique Bull] } \\
\text { Gabriel Bury [Bori] }^{6} \\
\text { Diego de Bustamante, de Sevilla }^{7}\end{array}$ \\
\hline
\end{tabular}

Catalina Bravo e Diego de Aro.

Ypólito, Gaetán e Jácome de Bardi.

Juan María Bertori y conpa ${ }^{\mathrm{a}}$.

Stevan, Muzio e Felipe Bontalenti.

Anrriq Bul y conp ${ }^{a}$, canbio.

Gabriel Bury y en su ausencia Simón Ruiz.

Diego de Bustamante sobre del nuestro Simón. 


\begin{tabular}{|c|c|}
\hline 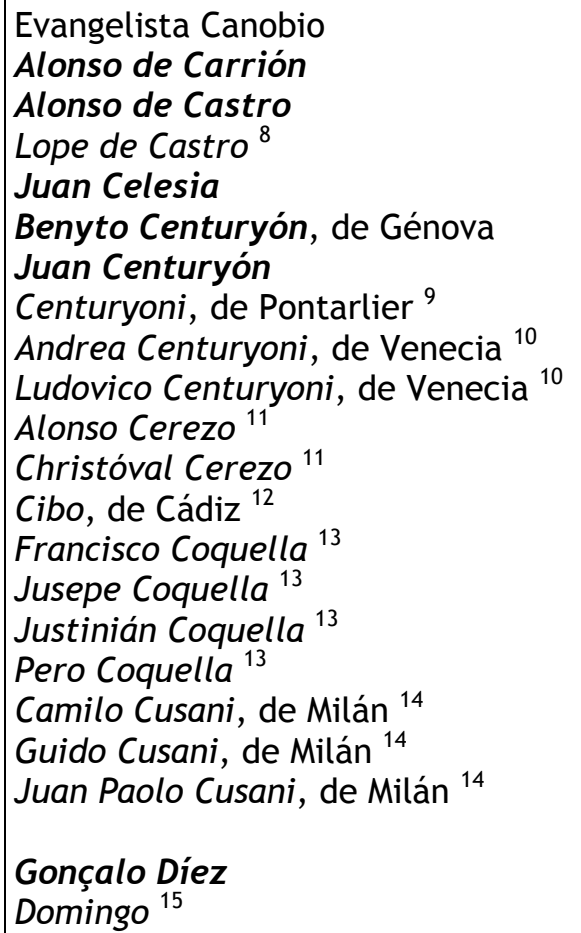 & $\begin{array}{l}\text { Domingo nuestro } \\
\text { Baltasar Doria, de Granada } \\
\text { Pero Batista Ferrero, de Nápoles }{ }^{16} \\
\text { Balián Fiesco }{ }^{17} \\
\text { Antonio de Fornari, de Nápoles }{ }^{18} \\
\text { Francisco de Fornari, de Nápoles }{ }^{18} \\
\text { Juan de Fornari, de Nápoles }{ }^{18} \\
\text { Gerónimo de Franquis }{ }^{19} \\
\text { Justinián de Franquis }{ }^{19} \\
\text { Pablo de Franquis }{ }^{19} \\
\text { Stevan de Franquis }{ }^{19} \\
\text { Agustín Gentil } \\
\text { Nicolao Gentil, de Mesina } \\
\text { Alexandre Grasso, de Murcia } \\
\text { Conrrado de Grimaldo }{ }^{20} \\
\text { Jácome de Grimaldo } \\
\text { Nicolao de Grimaldo }{ }^{21} \\
\text { Gerónimo de Herver }{ }^{22} \\
\text { Juan de Herver }{ }^{22}\end{array}$ \\
\hline
\end{tabular}

8 Lope de Castro e Francisco Martínez de Lerma.

9 Spínola e Centuryoni.

10 Nicolao de Negrón, Andrea e Ludovico Centuryoni.

11 Alonso e Christóval Cerezo.

12 Cibo e Spínola.

13 Pero, Jusepe, Justinián e Francisco Coquella.

14 Juan Paolo, Guido e Camilo Cusani.

15 Domingo y Simón.

16 Jácome Panes e Pero Batista Ferrero.

17 Miguel Pinelo y Balián Fiesco.

18 Juan, Francisco y Antonio de Fornari.

19 Pablo, Justinián, Gerónimo y Stevan de Franquis.

20 Conrrado de Grimaldo e Galeaço de Negro.

21 Nicolao de Grimaldo e conp ${ }^{a}$.

22 Gerónimo y Juan de Herver. 
Ortuño de Ybacax, de Herrera de Duero Agustín Ynperial ${ }^{23}$ Andrea Ynperial ${ }^{24}$ Batista Ynperial ${ }^{25}$ David Ynperial David Ynperial ${ }^{26}$ Francisco Ynperial ${ }^{25}$ Miguel Ynperial ${ }^{26}$ Nicolao Ynperial 25 Pedro Ytaliano

Gaspar Jorge 27 Gonzalo Jorge ${ }^{27}$

Batista Lercaro ${ }^{28}$

Domingo Lercaro ${ }^{29}$

Franco Lercaro

Franco Lercaro nuestro

Juan Lercaro

Juan Lercaro ${ }^{29}$

Juan Gerónimo Lercaro, de Pontarlier ${ }^{30}$ Juan Stevan Lercaro, de Pontarlier ${ }^{30}$
Simón Lercaro

Juan Batista Lita

Agustín de Mari ${ }^{31}$

Andrea de Mari ${ }^{31}$

Juan Francisco de Mari

Nicolao de Mari ${ }^{31}$

Juan Bautista de Marín, de Córdoba ${ }^{32}$

Julián de Marín

Carlos Marteli ${ }^{33}$

Juan Batista Marteli ${ }^{33}$

Alonso Martínez de Lerma

Francisco Martínez de Lerma

Francisco Martínez de Lerma ${ }^{34}$

Juan de Medina, de Herrera de Duero

Juan Alonso de Medina

Juan Batista Montenegro, de Nápoles ${ }^{35}$

Galeaço de Negro ${ }^{36}$

Juan Francisco de Negro, de Pontarlier ${ }^{37}$

Nicolao de Negrón ${ }^{38}$

Nicolao de Negrón, de Venecia ${ }^{39}$

23 Agustín Ynperial y conpa.

24 Andrea Ynperial e Hijos.

25 Batista, Nicolao e Francisco Ynperiales.

26 Miguel e David Ynperiales.

27 Gonzalo e Gaspar Jorge.

28 Batista Lercaro sobre de ...

29 Juan y Domingo Lercaros

30 Juan Stevan y Juan Gerónimo Lercaros.

31 Andrea, Agustín e Nicolao de Mari.

32 Stevan Spínola e Juan Batista de Marín.

33 Carlos e Juan Batista Marteli.

34 Lope de Castro e Francisco Martínez de Lerma.

35 Juan Batista Montenegro y Hijos.

36 Conrrado de Grimaldo e Galeaço de Negro.

37 Juan Francisco de Negro y conp ${ }^{a}$.

38 Nicolao de Negrón y Andrea Centuryón.

39 Nicolao de Negrón, Andrea e Ludovico Centuryoni. 
Bartolomé Palavesini ${ }^{40}$

Félix Palavesini

Nicolao Palavesini 40

Jácome Panes, de Nápoles ${ }^{41}$

Galeazo Parolo

Hétor Picamillo, de Nápoles

Miguel Pinelo ${ }^{42}$

Francisco Pujaner

Tomás Salugo 43

Antonio de Santa Cruz

Agustín Sauli

Felipe Sauli ${ }^{44}$

Stevan Sauli ${ }^{44}$

Juan Saurí

Francisco de Scobar

Simón ${ }^{45}$

Simón nuestro

Spínola, de Cádiz ${ }^{46}$

Spínola, de Pontarlier ${ }^{47}$

Andrea Spínola ${ }^{48}$

Antonio Spínola, de Génova
Benito Spínola ${ }^{48}$

Benyto Spínola

Daniel Spínola ${ }^{48}$

Francisco Spínola

Francisco Spínola ${ }^{49}$

Juan Batista Spínola ${ }^{48}$

Juan Batista Spínola, de Amberes

Lucas Spínola

Conde Marcantonio Spínola ${ }^{50}$

Stevan Spínola, de Córdoba

Stevan Spínola, de Córdoba ${ }^{51}$

Herederos de Alonso de Spinosa 52

Francisco de Spinosa

Gregorio de Spinosa ${ }^{52}$

Herederos de Pedro de Spinosa ${ }^{52}$

Pedro de Tamayo

Lázaro Usodemar, de Sevilla

Gerónimo de Valladolid, de Sevilla

Miguel Zeno, de Venecia

40 Bartolomé e Nicolao Palavesinis.

41 Jácome Panes e Pero Batista Ferrero.

42 Miguel Pinelo y Balián Fiesco.

43 Tomás Salugo sobre de Andrea Centuryón.

44 Felipe y Stevan Sauli.

45 Domingo y Simón.

46 Cibo e Spínola.

47 Spínola e Centuryoni.

48 Benito, Daniel, Juan Batista e Andrea Spínola.

49 Francisco Spínola y Hijos.

50 Conde Marcantonio Spínola sobre de Franco Lercaro.

51 Stevan Spínola e Juan Batista de Marín.

52 Gregorio y Herederos de Alonso y Pedro de Spinosa. 